University of Louisville

ThinkIR: The University of Louisville's Institutional Repository

\title{
This is a black-white conversation : navigating race, class, and gender at an urban school.
}

Jelisa S. Clark

University of Louisville

Follow this and additional works at: https://ir.library.louisville.edu/etd

Part of the Educational Sociology Commons

\section{Recommended Citation}

Clark, Jelisa S., "This is a black-white conversation : navigating race, class, and gender at an urban school." (2017). Electronic Theses and Dissertations. Paper 2625.

https://doi.org/10.18297/etd/2625

This Doctoral Dissertation is brought to you for free and open access by ThinkIR: The University of Louisville's Institutional Repository. It has been accepted for inclusion in Electronic Theses and Dissertations by an authorized administrator of ThinkIR: The University of Louisville's Institutional Repository. This title appears here courtesy of the author, who has retained all other copyrights. For more information, please contact thinkir@louisville.edu. 
THIS IS A BLACK-WHITE CONVERSATION: NAVIGATING RACE, CLASS, AND GENDER AT AN URBAN SCHOOL

\author{
By \\ Jelisa S. Clark \\ B.B.A., University of Kentucky, 2010 \\ M.A., University of Louisville, 2013

\begin{abstract}
A Dissertation
Submitted to the Faculty of the

College of Arts and Sciences of the University of Louisville in Partial Fulfillment of the Requirements

for the Degree of
\end{abstract} \\ Doctor of Philosophy \\ in Applied Sociology \\ Department of Sociology \\ University of Louisville \\ Louisville, Kentucky
}

May 2017 
Copyright 2017 by Jelisa Clark

All Rights Reserved 

THIS IS A BLACK-WHITE CONVERSATION: NAVIGATING RACE, CLASS, AND GENDER AT AN URBAN BOARDING SCHOOL

$$
\text { By Jelisa Clark }
$$

B.B.A., University of Kentucky 2010

M.A. University of Louisville, 2013

A Dissertation Approved on

April 26, 2017

by the following Dissertation Committee

Derrick Brooms

Cynthia Negrey

Patricia Gagne

Latrica Best

Ahmad Washington 


\section{DEDICATION}

To the ancestors

Whose names I do not know

Whose pain I can only imagine

Your strength sustains me

Propels me

Uplifts me

This is for you

This is for us. 


\section{ACKNOWLEGMENTS}

First, and foremost, I would like to thank my parents, Carol and Jesse Clark for being my biggest supporters, advocates, and teachers in a multitude of life lessons. And to the other members of my family, Deanna McMillian, Micheal Travis Jr., Mikaya Travis, Micheal Travis III, Tammara Travis, Ananiah Burrus, Samaria Travis, Jeriah McMillian, DeAngelia McMillian, Mikel Travis, Eleanor Roberts, and Lucretia Fels thank you for patience, support, and encouragement.

I have had amazing teachers throughout my life. I would like to give thanks to Allana Thompkins and Maura Scott for allowing me to see myself represented in academic spaces and for seeing my potential. I would also like to give special thanks Derrick Brooms, without whom this dissertation would not be possible. Thank you for the multitude of opportunities to grow and develop into a critical scholar. And thank you for reminding me to wear my running shoes! To the remaining members of my committee, Cynthia Negrey, Patricia Gagne, Latrica Best, and Ahmad Washington, it has been an honor and privilege to work with you.

I would not have made it through this arduous journey without amazing peers, colleagues, and friends. To my sister scholars, Veronica Newton, Billie Castle, and Khirsten Echols, you are the epitome of black girl magic, your fortitude and tenacity inspire me. Thank you for reminding me we are not in this alone in journey. I would also like to extend many thanks to Kent Pugh, Darion Blalock, Kara Castleberry, Cierra Bell, Harriet Oduro, Ashley Giron, Patricia Amirault and Carly Jackson.

Finally, I would like to thank you to the state of Kentucky, the Southern Regional Education Board, the Department of Sociology, and the School of Interdisciplinary and Graduate Studies for providing opportunities for professional development and financial support. 


\section{ABSTRACT \\ THIS IS A BLACK WHITE-CONVERSATION: NAVIGATING RACE, CLASS, AND GENDER AT AN URBAN SCHOOL \\ Jelisa Clark}

April 26, 2017

My dissertation, This is a Black-White Conversation: Navigating Race, Class, and

Gender at an Urban School, examines how racial ideologies operate in schools and informs programs and policies in an urban school in the Southeast, which I will refer to as Oakwood School (OS). OS, founded in the mid-2000s, positions itself as an educational alternative to traditional public schools. However, because of the social context and popular and policy messages about Black males, it is important to investigate how schools such as OS operate, the school culture they develop, and how they draw on (or resist) the Black male crisis discourse. In this research I pose the following questions: (1) To what extent is OS premised on the Black male crisis discourse; (2) How do the students, faculty, and staff navigate the boundaries of race, class, and gender; and (3) How do racial ideologies (i.e., colorblind racism and Black male crisis discourse) influence the experiences of faculty and students?

In answering these questions, I employed ethnographic methods consisting of observations, formal and informal interviews, and document analysis. Between September 2015 and May 2016, I conducted over 250 hours of participant observation and interviews with faculty, students, parents, and volunteers. Findings suggest that 
colorblind ideology operates on various facets and on multiple levels in the school. By focusing on developing character and ignoring the racial realities of student's lives, faculty seem to being drawing on stereotypes of Black males as hypersexual men who reproduce with no intention of caring for their children. Furthermore, it overemphasizes the cultural factors in the educational outcomes for Black males. While Oakwood School is premised as an educational alternative, it continues to maintain and reproduce White supremacy similar to traditional educational institutions. While the context of this research is a very specific K-12 setting, these findings have broader implications for social policies intended to address racial inequality. My research suggests that without examining the intersection of race and gender we have the potential to enact policies and programs that do not fully address the underlying causes for inequality and continue to marginalize the populations we are seeking to serve. 


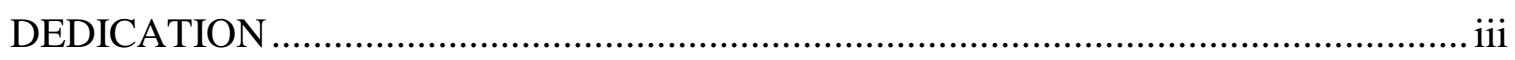

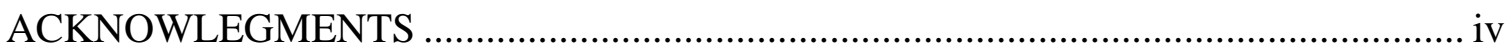

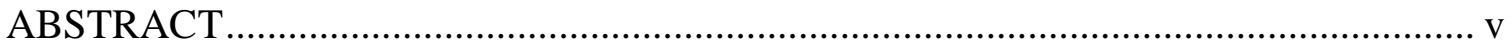

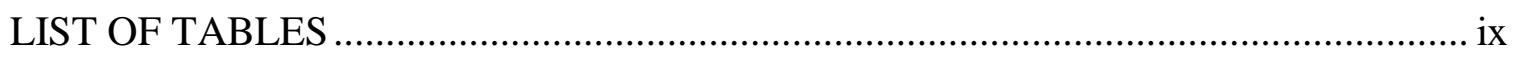

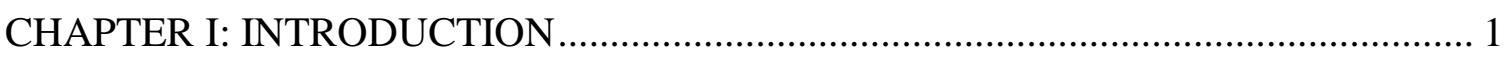

CHAPTER II: REVIEW OF THE LITERATURE .................................................... 4

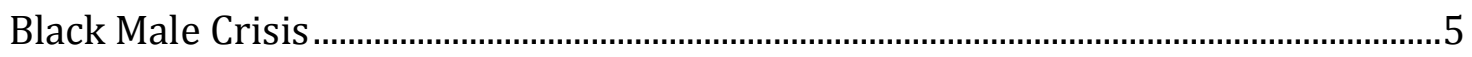

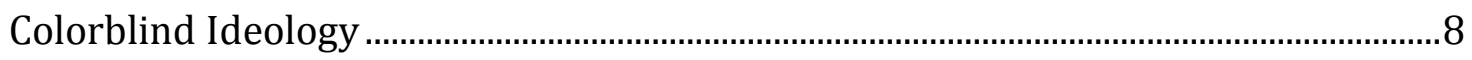

Understanding Black Male (Under)achievement ........................................................... 10

Cultural/familial .......................................................................................................... 12

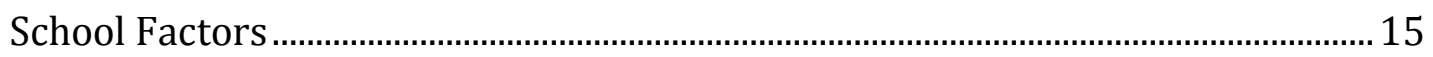

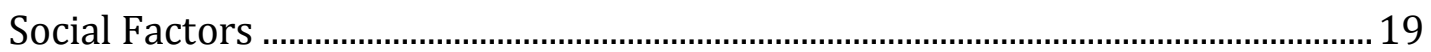

Single-Sex Schools ................................................................................................... 21

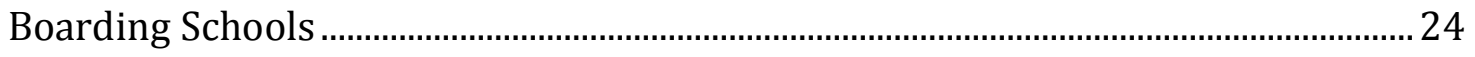

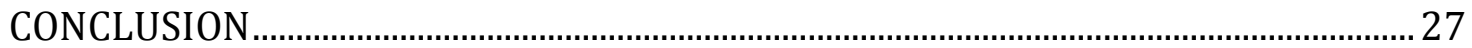

CHAPTER III: THEORETICAL FRAMEWORK ……………………...................... 28

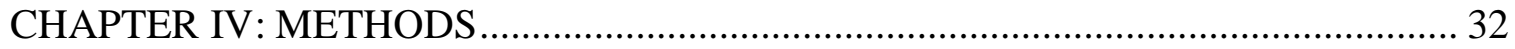

RESEARCH SETTING …………………………………………………………….... 32

The Day-to Day at OS........................................................................................................ 35

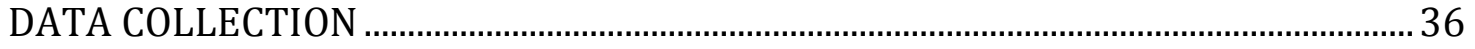

Participant Observation and Document Analysis......................................................... 37

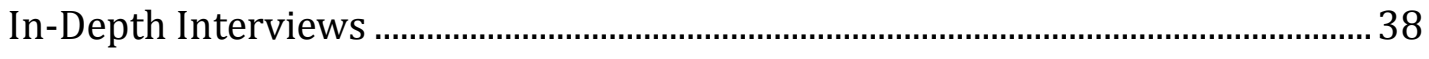

DATA ANALYSIS........................................................................................................ 41

LIMITATIONS ....................................................................................................... 42

ETHICIAL CONSIDERATIONS .................................................................................. 42

RESEARCHER POSITIONALITY..................................................................................... 43

CHAPTER V: THE SOCIAL GEOGRAPHY OF RACE: RESIDENTIAL SEGREGATION AND THE WHITE GAZE............................................................ 45

Residential Segregation and Urban Ghettos ………………………….......................... 47 
Oakwood School: A Means for White contact (Blackness Within a White Space) .52

Understanding Student Needs ............................................................................... 58

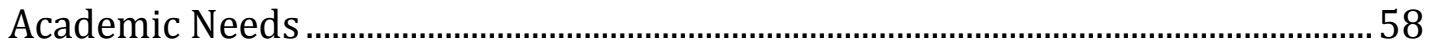

Students' Home Lives: Social and Cultural Needs ....................................................... 64

Paternalism and Parental Exclusion............................................................................. 69

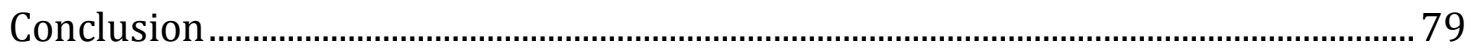

CHAPTER VI: SCHOOLING BY WHITENESS, SCHOOLING FOR WHITENESS: WHITE RACIAL FRAMING AND COLORBLIND IDEOLOGY AT OS ..................... 81

White Saviors and the "Saving" of Black Boys ……………………………………….... 82

White Identity and the Avoidance of Race ………………………………………......... 89

Poster, Foods, and Festival: A Superficial Acknowledgement of Race........................ 94

Colorblind Discourse and the Minimization of Race...................................................... 102

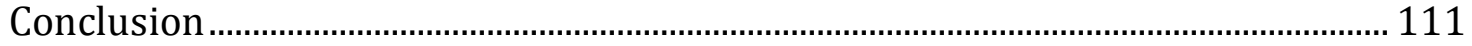

CHAPTER VII: THIS IS WHAT MEN DO: RESPECT, RESPONSIBILITY, AND OTHER MEASURES OF CHARACTER AT OAKWOOD SCHOOL ……………..... 113

Teaching and Institutionalizing Character .................................................................... 114

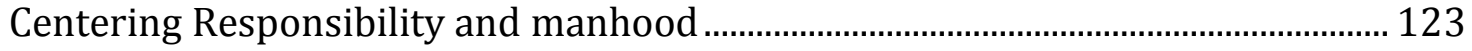

Trust, Distrust, and True Selves .................................................................................. 132

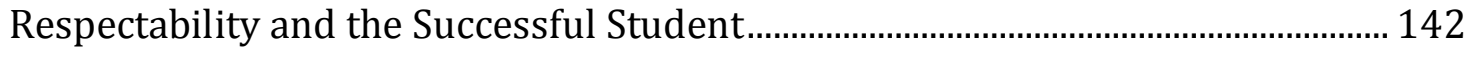

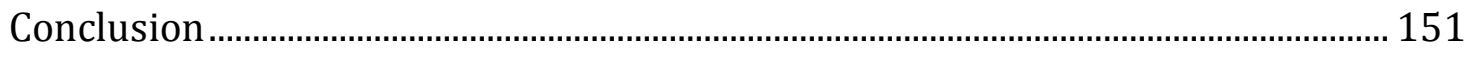

CHAPTER VIII: DISCUSSION AND CONCLUSION …………………………….... 153

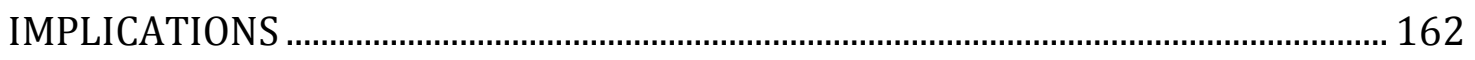

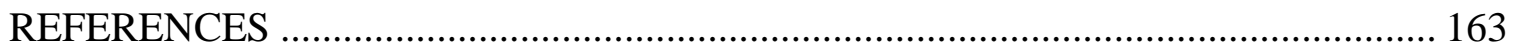

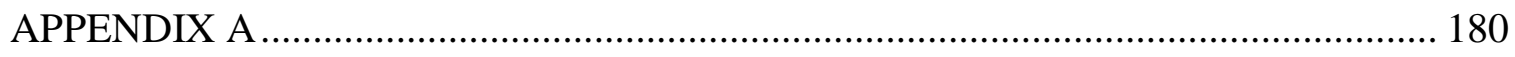

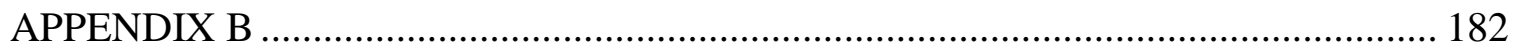

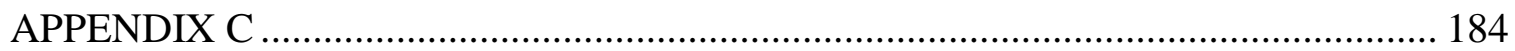

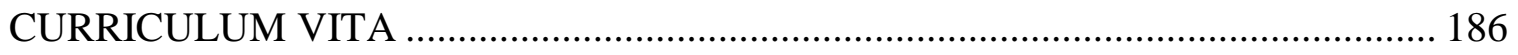




\section{LIST OF TABLES}

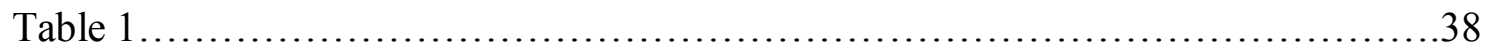

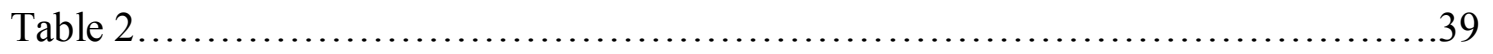

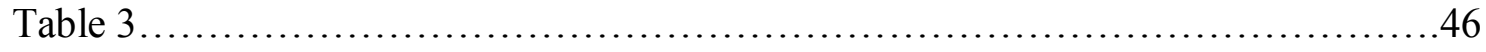

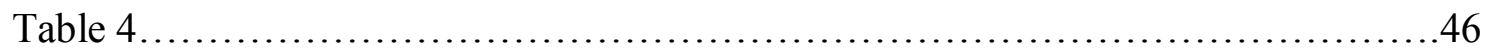




\section{CHAPTER I: INTRODUCTION}

Thus in many ways, we have developed a love-hate affair with Black Males. We love them if they are seen as non-threatening, profitable, and entertaining, yet they are reviled if they are viewed as hostile, intelligent, non-conforming, independent, or strong-willed (Howard 2014: 30)

For Black males, adulation and scorn are often two sides of the same coin, and as we have seen in the cases of O.J. Simpson, Michael Vick, and Michael Jackson, even those who seem to be loved and adored can easily and quickly fall from grace and find themselves hated and despised (Noguera 2008).

Both popular and scholarly discourse imagines the Black male as an endangered species (Brown and Donner 2011). From the Moynihan Report in 1965 to My Brother's Keeper in 2014, policymakers and scholars have promoted a notion of Black male exceptionalism, or the idea that Black men require special attention because of the unique problems they face (Butler 2013). Their experiences in school are no exception. They are overrepresented in special education, underrepresented in advanced placement, and disproportionately suspended and expelled (Scott, Allen, and Lewis 2014; Skiba and Peterson 2003). Nationally, 59\% of Black males graduate, compared to $80 \%$ of White males (Schott Foundation 2015). But these statistics do not tell the full story; many Black males successfully navigate educational institutions despite having the odds stacked against them. There is a plethora of literature on the challenges that Black males face, but we know less about which factors contribute to their successes. Often times policies directed at Black males are reactionary and not based on an understanding of what works bet (Harper 2006). Furthermore, these understanding are imbued with a 
racist ideology that positions Black males as dangerous. So the question becomes, to what extent are policies directed toward Black males predicated on this love-hate relationship? Are schools serving Black males doing so out of love or out of fear? And how does this affect the manner in which Black males navigate schools?

Black males have been set apart as a population in need of interventions and there are a variety of policies and programs tailored to them (Davis 2003; Martin, Fergus, Noguera 2010), including single-sex education and boarding schools. Single-sex education is premised on the notion that schools would be better positioned to address the needs of boys in a single-sex environment. There has been a significant growth in the number of public single sex schools. In 1999 there were only four public schools offering single sex education and by 2006 there were 223 (Martin, Fergus, and Noguera 2010); however, this increase has not been supported by consistent outcomes from research on single sex schooling (Bracey 2007; Salamone 2006). Boarding schools have experienced a similar growth; more than 30 urban boarding programs have been developed across the country since 2006 (King 2013). Boarding schools are increasingly presented as an option for poor children whose healthy development and learning are not well supported by their school, community, or family circumstances (Mayer, Thomas, and Logue 2003). Despite the growing interest in urban boarding schools, we know very little about their effectiveness, as the literature on urban boarding schools for low-income students remains sparse.

Schools play a crucial role in student outcomes. According to Martin et al. (2010), the ways that schools operate and who is operating them can help us understand whether and how students learn "how to do" school and are successful (p. 4). Because urban 
boarding schools position themselves as an alternative to traditional school settings, it is important to investigate how they work. Additionally, because boarding schools are being targeted at marginalized populations it is important to analyze race, class, and gender in these settings.

Oakwood School (OS), an urban boarding school in the Southeast, was founded by John and Judy Everrett in 2005, with the goal of serving low-income males who could benefit from a safe and structured learning environment. This dissertation will investigate the practices and policies at OS, paying asking the following questions: (1) To what extent is OS premised on the Black male crisis discourse; (2) How do the students, faculty, and staff navigate the boundaries of race, class, and gender; and (3) How do racial ideologies (i.e., colorblind racism and Black male crisis discourse) influences the experience of faculty and students? Results of this project are poised to provide valuable information about the operation and effectiveness of this particular school and provide information about schools for boys of color more generally. 


\section{CHAPTER II: REVIEW OF THE LITERATURE}

You took my son away from me. Do you know how hard it was for me to get him to stay in school and graduate? You know how many Black men graduate? Not many. Lesley McSpadden

Race permeates all aspects of American society and schools are no exception. In fact, schools are a central institution involved in the drawing and redrawing of racial lines (Lewis 2003). Subtle beliefs about racial superiority and inferiority serve to evaluate certain traditions, art, languages, literature, and ways of being and knowing of some groups as superior while disparaging the contributions of others (Zamudio et al. 2011). These beliefs shape policies, programs, relationships, and interactions. According to Lewis (2003) while schools don't teach racial identity and classification in the same manner as they teach reading and math they are a setting in which individuals learn the rules of racial classification. Specifically, individuals learn to believe that a person's race can offer clues about them (Zamudio et al. 2011).

For instance, Rist (1970) found that teachers in an urban school made subjective judgments about students' potential for success based on physical appearance, interactional behavior, the use of language, and social factors such as income, parents level of education, and family size. Students who displayed behaviors in line with (White) middle class attributes we expected to be successful. Similarly, Emihovich 
(1983) found that two male students, one White and one Black, behaved similarly but received very different messages. The White student was perceived as an exceptional child who misbehaved because he was not interested in the course material. The Black student, on the other hand, was perceived as being of average ability whose problems stemmed from an inability to remain focused and adhered to classroom norms. The manner in which the Black student was perceived was shaped by a larger narrative about Black male teenage violence and thus the student, "condemned not for what he did, but for what he represented: the potential Black troublemaker who could do untold damage to a school and its occupants" (p. 271; also see Ferguson 2001; Rios 2014; Noguera 2008; Howard 2014).

The Black male crisis narrative and resultant policies and programs necessitate a thorough examination of the larger literature on Black males. In order to assess policies and programs directed toward Black males we need to develop a comprehensive account of what we know about this population and what general trends exist in the literature about them (Howard 2014:12). In the remainder of this literature review, I explore what we know about the educational outcomes of Black males, theories used to explain their lagging achievement, boarding schools and single sex schools.

\section{BLACK MALE CRISIS}

According to Dumas and Nelson (2016), Black boyhood is socially unimagined and unimaginable beyond a crisis narrative; we are unable to see Black boys outside of fears and anxieties about their future lives. The message that Black males are in crisis is definitive. In 2015, The New York Times published an article titled, “1.5 Million Missing 
Black Men," which highlighted the number of Black males behind bars or who have succumbed to early deaths. The author's state:

African-American men have long been more likely to be locked up and more likely to die young, but the scale of the combined toll is nonetheless jarring. It is a measure of the deep disparities that continue to afflict Black men — disparities being debated after a recent spate of killings by the police — and the gender gap is itself a further cause of social ills, leaving many communities without enough men to be fathers and husbands (Wolfers, Leonhardt, and Quealy 2015).

The story told in this article has been told before. During the 1980s and 90s, magazines such as Ebony and Essence highlighted the issues of Black men with articles titled, "Is the Black Male an Endangered Species?" and "Our Men in Crisis." On film we saw depictions of Black men trapped in urban inner-cites rife with gangs, drugs, and criminal activity with movies such as Boyz in the Hood, South Central, and Menace II Society. And in 1995, approximately 850,000 people convened on the National Mall for the Million Man march, where Black men were encouraged to take responsibility for themselves, their families and their communities (Fultz and Brown 2008; Jones ND). Throughout history, media, organizers, and policy makers have placed the social issues of Black males on the national agenda by articulating a dire situation (Brown and Donner 2011; Pratt-Clarke 2010). Ultimately, all of these messages promoting the Black male crisis narrative attempt to elicit public concern by presenting young Black males as culturally and psychologically damaged.

The Black male crisis narrative is implicated within the proliferation of single-sex schools and more notoriously President Obama's My Brother's Keeper (MBK) Initiative. 
President Obama announced the initiative in 2014, articulating stock stories of the Black male crisis narrative: Black males are not interested in education, they are misdirected in the pursuit of careers in sports and entertainment, and they need mentors and role models (Dumas 2016). Initiatives such as MBK have been successful in leveraging funds because, "Fixing men or color_-particularly Black men hits a political sweet spot among populations that both love and fear them" (Crenshaw 2014). Additionally, programs like my MBK and single-sex schools are marketable because they fit within a neoliberal policy regime. Dumas (2016) argues that MBK is an example of a neoliberal solution to the lagging achievement of Black males, wherein Black young men and boys are constructed as damaged and as problems in need of a technocratic public-private solution. It is also important to note that while MBK is intended to be racially inclusive the framing utilized to garner funding and which also informs programming draws on specific tropes about Black male dysfunctionality.

The underlying message of damage and dysfunction within the Black male crisis narrative is shortsighted and skewed. First, the language of crisis implies a deviation from a stable norm, a temporary or short term urgency, and that once the crisis is over conditions will return to the former state, which if not ideal is superior to the current state (Noguera 1997: 221). Additionally, the Black male crisis narrative overlooks the historical relationship between race and inequality (Brown and Donner 2011) and is informed by an equivalency of Black with poor and urban (Pratte-Clarke 2010). This failure to invoke an intersectional analysis has obstructed efforts to address the negative outcomes of Black males, despite a notable consensus concerning this so-called crisis (Brown and Donner 2011; Davis 2003; Howard 2008). 
Howard (2008) argues that education research has often fallen short in examining race, class, and gender intersections in schools. Rather than conceptualizing Black males as a homogenous group suffering the effects of poor urban communities, we need to acknowledge the increasing social class diversity among Black males. Many of the challenges that Black males face are not consigned to their communities nor is it only low-income inner city youth that are facing these challenges (see Allen 2012; Gregory, Skiba, and Noguera 2010; Vincent et al. 2013). These issues also appear in classrooms in the form of a lack of racial awareness and cultural ignorance among school personnel, apathetic teacher attitudes, and poor quality instruction (Howard 2008).

Secondly, the Black male crisis narrative has resulted in policies and programs with unintended consequences. Brown and Donner (2011) were critical of single-sex schools, stating that they are short-term solutions. While advocates argue that they provide discipline and limit distractions, results of these schools are mixed due to policies emphasizing high stakes testing. Additionally, these schools have the potential of further marginalizing and stigmatizing Black males because in order to secure funding schools often affirms the target population's pathology.

\section{COLORBLIND IDEOLOGY}

Many White Americans are quick to claim that we live in a post racial society, that race no longer matters, and the only race is the human race. However, many measures of social wellbeing suggest that race continues to matter in real ways for people of color. The notion that race no longer matters is part of a dominant ideology that justifies and legitimates racial inequality (Bonilla-Silva 2014; Zamudio et al. 2011). Racial ideology can be seen as consisting of three core elements: common frames, style, 
and racial stories. Racial frames set the path for (mis)interpreting information. They are lenses through which individuals filter information and make sense of the social world, particularly a world characterized to persistent inequality (Bonilla-Silva 2014). The dominant racial ideology of the $21^{\text {st }}$ century is colorblind racism.

Bonilla-Silva (2014) identified four central frames of colorblind racism: abstract liberalism, naturalization, cultural racism, and minimization of racism. Abstract liberalism is the foundation of colorblind racism. First, liberalism endorses individualism, universalism, egalitarianism, and meliorism. Abstract liberalism, then uses these ideas in an abstract manner to explain racial matters. For example, Whites can oppose affirmative action policies and appear reasonable and moral because it represents "preferential treatment" for certain groups. This position ignores the people of color are underrepresented in most good jobs and schools therefore it is an abstract utilization of the idea of "equal opportunity." Naturalization allows Whites to explain racial phenomenon as natural occurrences. For instance, segregation can be explained as natural because people gravitate to those like them. Cultural racism explains persistent racial inequalities as the result of the cultural failing of minoritized groups (i.e. Blacks don't value education). Finally, minimization of racism suggests that discrimination is no longer a central factor affecting the life chances of minoritized population and defines discrimination as exclusively overt racist behaviors.

According to Bonilla-Silva (2014) White Americans are able to rationalize continuing racial inequality through a new racial ideology that attributes the contemporary status of African Americans as the products of market dynamics, naturally occurring phenomenon, and Blacks' cultural limitations. Zamudio et al. (2011:21) extend 
this stating that, "The notion of colorblindness is a product of liberal ideology that equates political rights with social equality without interrogating the ways that race and racism play out in contemporary society to produce ongoing social inequality." Ultimately colorblind ideology work to maintain the status quo of inequality in the US. In legal situations, a colorblind approach to institutional discrimination, as used in Brown v. Board of Education, favors a perpetrator perspective by focusing on very narrow institutional practices and allowing racial practices that are outside the realm of legally sanctioned discrimination go unchecked (Freeman 1977). Thus, colorblindness will only allow us to redress the most egregious cases of racial harm, the ones that everyone would notice and condemn. Within schools where a colorblind approach was taken, Lewis (2003) found that race talk was considered dangerous and generally avoided, however this was not an indication that race was considered unimportant. The faculty and staff at the school thought that race mattered in ways they could do nothing about (e.g., Assumptions about widespread group cultural deficits), in ways they did not understand (e.g., Why some children did not respond to the curriculum), or ways they felt uncomfortable (e.g., Large number of students of color scoring low on a state exam). UNDERSTANDING BLACK MALE (UNDER)ACHIEVEMENT

They approach me in a half- hesitant sort of way, eye me curiously or compassionately, and then, instead of saying directly, How does it feel to be a problem? they say, I know an excellent colored man in my town; or, I fought at Mechanicsville; or, Do not these Southern outrages make your blood boil? At these I smile, or am interested, or reduce the boiling to a simmer, as the occasion 
may require. To the real question, How does it feel to be a problem? I answer seldom a word. W.E.B. DuBois

Our understanding about the lagging achievement of Black males has been informed by research on the achievement gap, or the disparities in test scores and other educational outcomes between Black, Latino, and White students. A variety of statistics have been touted in order to document the severity of the achievement gap:

- $18 \%$ of Black fourth graders can read at proficient or above compared to $46 \%$ of White students.

- $16 \%$ of eighth grade African American students are reading at proficient or above compared to $44 \%$ of White students.

- $19 \%$ of African American fourth graders scored at proficient or above in math compared to $51 \%$ of White students.

- $13 \%$ of African American eighth graders scored at proficient or above compared 43\% of White students (National Center for Education Statistics 2015).

These facts and figures have done their job, in the sense that there is consensus that there is a problem and we need to do something about them. However, said action has been informed by cultural deficit theories. The influential Coleman Report, Equality of Educational Opportunity, argued that a combination of factors, including the composition of a school, students' sense of control over their future, teachers' verbal skills, and family background contributed to a student's achievement (Coleman et al. 1966). Despite documenting a number of influential factors, only one, family background captured the public's attention (Ladson-Billings 2006). This is due in large part to the American devotion to the American Dream. The dominant American ideology dictates that you 
could be anything that you want to be, therefore any destiny, including poverty, can be viewed through the lens of personal achievement or failure. Individual level explanations, which often invoke culture, are more palatable to the general public, policy makers, and possibly even researchers (Wilson 2009).

Despite the saliency of individual factors, the work of Coleman et al. (1966) and subsequent scholars Barton and Cooley (2009) demonstrates that the educational outcomes of African American males are affected by a variety of variables. These factors can be divided into four categories: social, school, cultural/familial, and individual factors. Social factors include racism, biases, prejudice, and discrimination. School factors include cultural competency, poor teacher quality, lack of school resources, segregation, curriculum rigor, and academic tracking. Cultural/familial factors are related to families, communities and peers, and include access to resources, academic and emotional supports, role models, mentors, familial involvement, and social and cultural capital. Individual factors include personality, motivation, and self-perception (Ford and Moore 2013). The first three sets of factors refer to variables external to the students, and are crucial to understanding the manner in which Black males are positioned in schools and the policy directed toward them, as such they will be discussed further in the next sections.

\section{Cultural/familial}

Subsequent to the Coleman Report, scholars continued to isolate cultural factors as a major contributor to the lagging achievement of students of color. In 1986, Fordham and Ogbu published, "Black Students' Success: Coping With the Burden of Acting White," which has spurred an ongoing conversation about the relationship of Black 
students' culture and school success. It has been cited 3808 times and continues to be a popular avenue for research in the educational literature (see Downey and Pribesh 2004; Johnson 2014; Tyson, Darity, and Castellino 2005). According to Fordham and Ogbu (1986), the low performance of Black students stems from two major factors: inferior education and negative coping mechanisms, which are incompatible with striving for school success. These scholars argued that inferior education, as an explanation, was limited in its ability to explain why some Black students are successful despite the Black ecological structure (i.e., job ceiling and inferior education) and therefore focused on cultural explanations. They asserted that the reason that Black students do poorly in school is because they are ambivalent towards academic effort and success because of the "burden of acting white," a term used to describe the contradictory nature of schooling for Black children wherein academic success is equated with acting white; school resistance manifests as a fear of acting white.

Several scholars have pushed back against the acting white thesis. Follow-up studies have shown that Black students do value education and reject the notion that their culture is incompatible with educational achievement (Bergin and Cooks 2002; Tyson et al. 2005). While the burden of acting does exists for some students, it is not widespread and cannot be implicated in the Black-White achievement gap (Tyson et al. 2005). Tyson $(2002,2003)$ found that the rejection of school norms does not characterize Black culture, and Black children begin elementary school engaged and achievement oriented, but overtime schooling experiences contribute to students developing negative school attitudes. Furthermore, Cook and Ludwig $(1997,1998)$ found that there is no greater social cost for high achieving Blacks students compared to White students. Additionally, 
high performing Blacks do not have significantly more trouble getting along with peers than high performing Whites (Harris 2006). And even in cases where students did face some accusations of acting white, they did not allow it to affect their study habits or efforts to achieve (Bergin and Cooks 2002).

Evidence also shows that families and communities can also encourage school success. Sanders (1998) found that when students receive support from the family, church, and school simultaneously, the effects on their attitudes about self and importance of schooling are magnified. Similarly, Toldson (2008) found that parents' expectations and involvement had a positive effect on the success of Black males. Parents who help their children with homework and school problems, visit the school and are comfortable talking to teachers, encourage their sons to do well in school, as well as maintain high expectations generally have high-performing children and/children who aspire to go to college (Toldson 2008; Toldson, Braithwaite, and Rentie 2009; Yan 1999). In a study of Black college male undergraduates interested in earning a doctorate in education, Harper and Davis (2012) found that despite being highly aware of how U.S. institutions disadvantaged Black males, participants still believed that education was a way out of a life of poverty (p. 113). Importantly, family members usually shaped these Black men's attitudes and values of education.

While the acting white thesis has been challenged since publication, and followup studies do not support its validity, the acting white theory continues to influence how schools address problems related to Black underachievement (Downey 2008; Harris 2006; Tyson et al. 2005). Focusing on students' culture ignores other factors that contribute to student achievement and absolves schools for their role in the low 
achievement of African American males. Rather than seeing low achievement as an outcome of cultural deficits, we need to integrate both structure and culture in our analyses. This can be achieved two ways. First, we could interrogate the structure of schooling and the impact it has on students. Structural forces are inherent in academic institutions, as Carter (2005: 9) asserts, "Schools are not just places where learning comprises how to read, compute, analyze, and synthesize information; they are also key sites of socialization and cultural reproduction." Stereotypes of Black males do not exist in a vacuum; they permeate society, which includes schools. Therefore, we must ask questions such as: how are Black boys being socialized in schools and what messages do they receive about what it means to be Black and male. Secondly, shifting away from presumed Black dysfunctionality also means that rather than asking why Black males are failing we ask why Black males are succeeding despite all odds. This shift takes focus away from deficit-oriented lens and allows us to begin identifying best practices.

\section{School Factors}

Despite the Supreme Court ruling on Brown v Board of Education, schools across the United States continue to be segregated. Following the court decision, many White families that could afford it pulled their children out of public schools. The percentage of White students in public schools decreased from $78 \%$ in 1972 to $58 \%$ in 2003 . In addition to fewer White students attending public schools, the students that do are not sharing space with Black students. Forty percent of Black and Hispanic students attend schools that are at least $90 \%$ Black and Hispanic, while the average White student attends a school that is approximately $80 \%$ White (Glenn 2012). School segregation is not just an issue of students not sharing spaces; in fact, most segregated minority schools deal with the compounded effects of concentrated poverty. Only $15 \%$ of intensely segregated 
White schools are also schools of concentrated poverty, while $88 \%$ of intensely segregated minority schools have concentrated poverty (Orfield and Lee 2004).

Children in schools of concentrated poverty tend to be less healthy, have weaker preschool experiences, have only one parent, have unstable educational experiences, and attend classes taught by less experienced or unqualified teachers. Additionally, many of these schools are in poor condition and lacking resources (Orfield and Lee 2004). Jonathan Kozol (2012) painted a disquieting picture of these urban schools. Across the country, from East St. Louis to NYC to San Antonio, the inner city schools that Kozol visited were underequipped, understaffed, underfunded, and overcrowded. In East St. Louis sewage backup repeatedly caused school to be cancelled, the science labs were outdated and missing equipment as basic as lab tables. The one lab that was functional went unused because of large class sizes; the teacher felt he could not adequately supervise his students and ensure their safety. In New York City, a school with the capacity for 900 students served 1300, another, which capped at 1000, had 1550 students enrolled. In these schools multiple classes shared space, file cabinets and movable boards were used to give the semblance of privacy.

These conditions that Kozol (2012) documented are not just a thing of the past. In 2016 teachers in Detroit took to twitter to bring attention to the poor working and learning conditions. They posted pictures of mold on the ceilings, buckets set up to catch leaking toilet water, buckled floors, and mushrooms growing on the wall of a classroom (DeVito 2016). It is not only students in Detroit that are suffering. In a story about the roll back of Brown v Board of Education, investigative reporter Nikole Hannah-Jones (2015) told the story of Normandy school district, which was almost completely Black 
and poor. During 2014, a report released by the Missouri Department of Elementary and Secondary Education, indicated that the Normandy School District received zero points for academic achievement in English, math, social studies, science, and college placement. The district had provisional accreditation for 15 years, and in January 2013 Normandy lost accreditation from the state. In the St. Louis area, approximately half of Black children attend schools in districts without full accreditation, compared to four percent of White children. Students in this district also experienced substandard conditions. AP English was held in the science lab, rather than the assigned classroom because of mildew and a non-functioning ventilation system. The assigned teacher was not certified to teach AP English and provided the students with a worksheet that took them five minutes to complete.

Even when Black and White students attend the same schools, they are still segregated through tracking and ability grouping practices. Some scholars believe that schools serve a sorting function and prepare youth for future adult roles while maintaining social structure and organizational patterns of society (Bourdieu 1973; Collins 1971; Oakes 2005). Poor and minority students have been found in disproportionately larger percentage in the bottom ability groups or low tracks (Hallinan 1994; Oakes 2005). Students in low tracks are likely to see assignments as evidence that teachers do not have high regard for their academic abilities (Hallinan 1994). Additionally, students have markedly different access to knowledge and learning experiences based on which tracks they are placed in. Students in high track English classes had access to "high-status" knowledge that would be eventually required for those 
going to college. On the other hand, low track students only encountered young adult fiction and focused on basic literacy skills (Oakes 2005).

Despite a variety of evidence demonstrating negative school effects, schools can have a positive effect on student outcomes. According to a variety of studies, relationship of students with teachers and school characteristics are significant indicators of Black males' experiences in school (Davis and Jordan 1994; Toldson 2008). Teachers who were personally vested in their students' success and had a personal relationship with their students, teachers perceived as fair, those that encouraged their students to express their views and gave extra help when needed were effective in promoting academic achievement in African American males. Additionally, Black males who perceived school as safe were more likely to report high academic achievement (Davis and Jordan 1994; Milner 2007; Toldson 2008).

Schools also play a significant role in college aspirations for Black males. Positive perceptions of school, amiable relationships with teachers, and a safe learning environment are all positively associated with Black males' college aspirations (Toldson et al. 2009). Black students are also more likely than White students to turn to counselors and teachers for help in making educational decisions (Pitre 2006). They are also more likely to report that they had less access to information about college and were not adequately prepared. Particularly telling about the role of schools, Black male students with "no plans" after graduation reported higher levels of academic achievement than White male students who had "other plans," which suggests that Black students are not receiving adequate guidance to select post-high school paths that match their academic potential (Farmer-Hinton and Adams 2006). These findings, combined with the fact that 
Black males with college aspirations reported liking school more than their White counterparts, indicate that school factors may be more important for Black males than White males. This implies that reducing racial discrimination, improving school conditions, and elevating cultural competence are crucial to improving educational outcomes for Black males (Toldson et al. 2009).

\section{Social Factors}

In addition to cultural/familial and school factors, social factors play an important role in the school experiences of African American males. Stereotypes and images associated with Black males operate to magnify the scrutiny directed toward them (Noguera 2008). According to Howard (2014), there are five major depictions of Black males that continually shape public perceptions of Black males and how they experience schooling: the physical brute and anti-intellectual, shiftless and lazy, hypersexual, criminal minded, and the slickster-pimp/gangster (Howard 2014). The work of Ferguson (2001) demonstrates how images of Black males as criminal and as endangered species are used in schools for identifying, classifying, and decision-making. The Black boys in the study fell into categories of troublemakers (suspended at least once) and schoolboys (occasionally handed a referral but never suspended). Originally, Ferguson conceived of the two groups as opposites, but over time realized that was a mistake, as schoolboys were always on the brink of being redefined into troublemakers because of the stereotypes of Black males.

The bodies of Black boys are often controlled through discipline. The work of Ferguson (2001) demonstrated that the notion of Black boys as "bad boys" were created in school through differential judgments, treatment, and punishment as opposed to their White male peers. Similarly, Rios (2011) argued that young men in an Oakland, 
Califronia are subjected to hypercriminalization, where their everyday behaviors are treated as deviant and criminal. Typically boys are given the masculine dispensation of being "naturally" naughty, but for Black boys the masculine display of naughtiness is a threat to the social order and must be controlled (Ferguson 2001). Research has shown that teachers tend to be more lenient with female students who break school rules; this was due in part to the fact that teachers did not feel physically threatened nor intimidated by girls. Additionally, girls were allowed to participate in class discussions, but young men of color who wanted to contribute to class discussions were defined as disruptive and problematic (Lopez 2002).

Scholars using theories of social reproduction argue educators prepare students for their rightful social position. Dominant discourse suggests that the rightful place of Black men is behind bars. Since slavery, images of Black males as brute savages have been used to justify racial stratification (Collins 2004; Pager 2008). These ideas are infused into the fabric of American life and impact our daily interactions. Teachers, who play a crucial role in the labeling and sorting of young people, are influenced by these ideas (Raible and Irizarry 2010). According to Hatt (2011), schools have the "power to create, shape, and regulate social identities through the idea of 'bad boys' that starts as early as elementary school by punishment targeted toward children of color" (p. 477). Many educators view Black boys with chronic behavior problems as bound for jail (Hirschfield 2008), and students recognize this expectation. In an interview, a student pushed through the school to prison pipeline stated, “Teachers don't want to deal with us. They look at you like they expected trouble. They looked at us as being unsuccessful" (Hatt 2011: 483). Understanding how stereotypes and discrimination operate in schools 
is critical. Perceived racism and discrimination, including faculty perceptions of their intelligence, unfair placement in special needs course, and teachers' attitude and behavior toward students, affected students' academic identity and college aspirations (Howard 2003).

The manner in which we understand Black male (under)achievement impacts the policies and programs directed at them. Such programs and policies are informed by a focus on cultural factors such as resistance to schooling, however research shows that schools play a powerful role in experiences of Black males. Furthermore, racism continues to be a significant factor in the educational outcomes of Black males. Singlesex schools and boarding schools are two programs targeted at this population that deserve further study.

\section{SINGLE-SEX SCHOOLS}

Since the implementation of the No Child Left Behind Act in 2001, educators and policymakers have looked for ways to address the lagging academic achievement of African American males (Dwarte 2014; Martin et al. 2010). Single-sex education, premised on the notion that it could better serve the needs of disadvantaged students, has gained substantial interest and popularity as a possible solution to the achievement gap (Dwarte 2014; Span 2010). However, most of the push for single-sex schools has been based on unrelated assertions (i.e., in cognitive, social, and physical development of males and females; gender stereotypes; self-esteem; "nature based" approach to learning; and gender based cultural differences) rather than theory (Dwarte 2014; Fergus and Noguera 2010; Harvard Law Review 1992).

Recognizing that single sex schooling for males was under-theorized, Fergus and Noguera (2010) asked practitioners why they do what they do. They found that schools 
designed to served Black and Latino boys were premised on three points: (1)

understanding their social and emotional needs; (2) understanding how the their academic needs have surfaced; and, (3) targeting strategies for addressing those needs. Practitioners generally cited three social/emotional strategies related to the needs of Black and Latino boys: changing boys' ideas of masculinity, incorporating an academic identity, and developing future leaders and leadership skills. The strategies for responding to the academic needs of Black and Latino males include: addressing the academic skill gaps and teaching boys the basics in order to provide a rigorous and challenging education; preparing them for college; raising academic expectations; and making curriculum and instruction relevant. Other studies have found that proponents of single sex education believe it enables teachers to focus on boys' weaknesses, such as writing and organizational skills (Hudley 1998; Parker and Rennie 2002)

Despite the substantial interest in single sex instruction for Black males there is no clear consensus that it is more effective than coeducation. There is some evidence that single sex education is beneficial to academic achievement, particularly for girls (Riordan 1990; Robinson and Gillibrand 2004). However, the evidence in support of single sex education for males is more varied. In a study that examined reading achievement at a school that transitioned from co-educational instruction to single sex instruction, Dwarte (2014) found that reading achievement for boys was significantly higher during the coeducational instruction than in years one and two of restructuring. There was an upward trend in reading scores in years three to five, but the differences were not significant. Several other studies have called into question the effectiveness of single sex schooling for boys (see Mullholland, Hansen, and Kaminski 2004; Nagengast 2013; 
Riordan 1990). However, Riordan (1990), in his study on educational settings, found that boys of color show more improvement than non-minority students in single sex schools. Minority boys and girls score nearly a grade level higher than their coeducational counterparts. While single-sex schooling may not be promising for boys overall, it may be beneficial to those in minoritized populations.

In addition to varied achievement outcomes, single sex instruction has the potential to perpetuate gender stereotypes and is not always well received by students. Schools play an important role in shaping masculinity (Cornell 1996; Ferguson 2001). Educators have justified single sex schooling by asserting that boys need greater discipline (Harvard Law Review 1992). This emphasis on relating to boys and changing their behavior has resulted in less higher order learning and lower intellectual demand (Martino, Mills, and Lingard 2005). Single sex schools have also shown evidence of the unintended consequences of reinforcing racialized stereotypes of hypersexuality and essentialized notions of gender (Goodkind 2013). Finally, single sex instruction has been found to prompt aggressiveness, competition, female objectification, and male hegemony (Hoffman, Badgett, and Parker 2008).

Boys' responses to single sex instruction have also been varied. For instance, Martino et al. (2005) found that some boys felt they received greater encouragement and safe space to talk about personal issues. Alternatively, Parker and Rennie (2002) found that some students enjoyed single sex education because they were able to talk about sports and say sexist things. Additionally, there is evidence found that most male students did not enjoy single sex education; $66 \%$ of participants said that single sex 
education was not more fun (Hoffman et al. 2008). Similarly, Goodkind (2013) found that students felt punished by being separated by gender.

\section{BOARDING SCHOOLS}

In addition to the single-sex school model, boarding schools are increasingly becoming an option for poor children whose healthy development and learning are not well supported by their school, community, or family circumstances (Mayer et al. 2003). Bass (2013) asserts that boarding schools have the potential to aid disenfranchised students because of their increased exposure to capital benefits. Boarding schools can provide structure, study time, and homework help (Bass 2013). Furthermore, research has found that academic engagement, school climate, and out of school time activities were key contributors to the academic achievement of Black and Latino boys (Martin et al. 2010). Due to the impact of out of school time activities, boarding schools may be appealing to educators and policy makers because it gives schools an opportunity to exercise control over a larger portion of the student's day. Having more constructive outof-school time, or minimizing negative social interactions with a student's home environment, may lead to better and more focused instruction in school and increased student achievement (Curto and Fryer 2012).

Curto and Fryer (2012) assert that placing students in a boarding program could have one of three effects. If the boarding school environment is more positive than the home environment, then the boarding school will yield positive gains. Conversely, if the boarding school environment is not conducive to achievement or causes emotional or psychological distress, then the boarding school may have a negative impact on achievement. Finally, if the positive and negative aspects of placing a student in a 
boarding school balance out then the effects of boarding school will be negligible. Bass (2013) found that the boarding school environment promoted social, cultural, and educational capital for students from high poverty backgrounds. Small class size allowed students to become more comfortable communicating with teachers and they even learned to see adults as friends. This is particularly important because positive relationships with teachers and peers have been found to support academic achievement (Martin et al. 2010; Toldson 2008). Furthermore, students had increased social capital because of the wide variety of activities they were required to participate in (Bass 2013). Participating in school related activities are associated with better grades (Martin et al. 2010). Other benefits of boarding schools include: placing students in safe, less stressful environments; minimizing negative parental and community interactions; and ensuring that students have positive adult role models (Curto and Fryer Jr. 2014).

Despite all of the positive outcomes associated with boarding schools, they also have potential negative consequences. Students who attend boarding school may contend with homesickness, stress, lack of positive parental support or input, and loss of identity (Curto and Fryer Jr. 2014). For instance, Dick, Manson, and Beals (1993) found that stress levels that youth experience could be exacerbated by attending a boarding school, particularly if the student lacks familial support. Also children from lower socioeconomic backgrounds in residential settings steeped in the social and cultural norms of mainstream of a society run the risk of double marginalization or a confused sense of identity (Arieli, Becker, and Kashti 2001). Cookson and Persell (1991) argue that African Americans in upper-class academic institutions have a unique experience where they have the opportunity to observe and, to some degree, become a part of a class 
that is generally closed to outsiders. However, these experiences can lead African Americans in elite prep schools to be caught between two cultures. While the students at OS are not attending a boarding school that serves upper class students, the boarding school model is reflective of that culture and the students may still find their culture at odds with the school culture.

Despite the potential benefits of boarding schools there is limited research on schools that specifically serve students based on economic or social disadvantage, however early research shows some promising results. Mayer et al. found (2003) six boarding schools that selected students on the basis of economic disadvantage, six that based admission on racial and minority status, and 51 boarding schools operated either by the Bureau of Indian Affairs (BIA) or under BIA grants or contracts. There is another set of schools that reach out to disadvantaged students but do not impose disadvantaged status as an admissions requirement. These schools include SEED School in Washington DC and Baltimore Maryland, the School at Church Farm and St. Benedict's Preparatory, Eagle Rock School, and Bootstrap Ranch (Mayer et al. 2003).

SEED schools are charter schools, serving students in grades six through twelve, with a five-day-a-week boarding program. The schools couple an achievement-oriented ethos with a boarding program in order to ensure students have positive and nurturing interactions outside of school (Curto and Fryer 2012). SEED schools have an extended school day, provide after school tutoring, and use data based practices. The middle school curriculum focuses on developing basic skills in reading and math, and in order to graduate high school students are required to take the SAT or ACT and apply to at least five colleges or universities. Curto and Fryer (2012) found that SEED schools are 
effective at increasing the achievement of the poorest minority students; students eligible for free or reduced lunch make more progress than ineligible students in reading. The impact of SEED on student achievement is larger than that of the average charter school.

\section{CONCLUSION}

Based on the literature cited above, the varied messages about Black males in education call into question some of the interventions selected for addressing the achievement gap. Black males are routinely accosted with stereotypes about their intellectual abilities and understood as existing within a perpetual crisis state. The framing of Black males and the problems surrounding their (under)achievement informs the solutions stakeholders engage. Boarding schools and single-sex education are increasingly understood as appropriate for addressing the lagging achievement for marginalized students, however, inconclusive evidence about the effectiveness of these solutions calls their efficacy into question. OS is an ideal case for investigation as it integrates both models of single-sex education and boarding school for Black males. Research on an urban boarding school is poised to provide valuable insight on increasingly popular interventions in urban education. 


\section{CHAPTER III: THEORETICAL FRAMEWORK}

The above literature review suggests that Critical Race Theory (CRT) would be

fruitful in analyzing whether and how the Black male crisis discourse operates in OS and other schools targeted at Black males. CRT was developed by a group of legal scholars who were grappling with the incremental rollback of the Civil Rights Movement during the 1970s. These scholars sought to understand how White supremacy, and conversely, the subordination of people of color, has been created and maintained in America (Crenshaw et al. 1995). In order to do this they believed that new tactics and theories were necessary to understand the manner in which race and racism interacted with American law (Delgado and Stefancic 1993). CRT scholarship now includes several books and articles across disciplines such as education, psychology, cultural studies, political science, and philosophy (Crenshaw et al. 1995; Solorzano and Yosso 2002). While, CRT scholarship spans a broad variety of topics, the central tenets of this theoretical approach coalesce around five themes.

First, CRT acknowledges the race and racism are permanent features of the U.S. and central to understanding how U.S. society functions (Bell 1992, 1995; Lawrence 1995; Solorzano 1997, Dixson and Rousseau 2005). Additionally, it acknowledges the intersectionality of racism with other forms of subordination such as social class and gender (Yosso et al. 2004; Solorzano, Ceja, and Yosso; Solorzano and Yosso 2002). Second, CRT challenges dominant ideology regarding objectivity, meritocracy, 
colorblindness, race neutrality, and equal opportunity. These ideological constructs mask the self-interest and privilege of dominant groups in the U.S and must be challenged and dismantled (Crenshaw 1988; Solorzano 1997; Yosso et al. 2004; Williams 1991). Specifically, colorblindness works to maintain racial subordination (Crenshaw et al. 1995; Gotanda 1991) Third, CRT is committed to social justice, and, as such exposes the interest convergence of civil rights gains and works toward the elimination of racism, sexism and poverty (Bell 1980; Solorzano 1997). Fourth, experiential knowledge is central CRT. By utilizing storytelling and counter storytelling CRT positions the knowledge of people of color as legitimate, credible, and liberatory. Counter storytelling highlights stories and struggles that are often overlooked by those in positions of power (Delgado 1989; Howard 2008; Matsuda 1995; Matsuda et al. 1993; Solorzano 1997), and analyzes myths and presuppositions that make up common culture about race (LadsonBillings and Tate 1998). Furthermore, this tenant rejects a "numbers only" approach to documenting inequality or discrimination (Dixson and Rousseau 2005). Fifth, CRT is transdisciplinary; it analyzes race and racism within historical and contemporary contexts and incorporates knowledge from women's studies and ethnic studies (Howard 2008; Yosso et al. 2004).

Education scholar Gloria-Ladson Billings has been a central figure in developing CRT in educational research. Ladson-Billings (1998) envisions CRT as an innovative theoretical frame for understanding for the role of education in reproducing or interrupting current practices. Social actors continue to deny the significance of race in public and political discourse, however race remains a powerful social construct and signifier. Similar to other scholars (Alexander 2010; Bonilla-Silva 1997; Collins 2005), 
Ladson-Billings argues that conceptions of race are embedded in U.S. society, but over time racism has shifted from overt to covert; new language has been necessary to communicate old racist ideas. Whiteness has been defined as normative and everyone is compared to the standard of Whiteness. School achievement, middle class-ness, maleness, beauty, intelligence, and science have become normative categories associated Whiteness, while gangs, welfare, sports, and the underclass have become marginalized and delegitimated categories associated with Blackness. The juxtaposition of Whiteness to Blackness and other marginalized identities necessitates the "deconstruction of oppressive structures and discourses, reconstruction of human agency, and construction of equitable and socially just relations of power" (Ladson-Billings 1998: 9). CRT is well suited for such a task.

CRT offers us a race conscious approach to understand educational inequality and identifying potential solutions by foregrounding race in the analysis (Zamudio et al. 2011). Howard (2008) considers CRT a framework that allows us to ask, "how do race and racism influence the current state of affairs for young Black men in PreK-12 schools" (p. 959)? CRT has been used in several studies in order to highlight the role of race and racism in educational institutions, however the role of gender for Black males has been undertheorized. In order to address this limitation of previous literature I also draw on Black Sexual Politics, in which Collins (2005:7) "analyzes how relations of gender and sexuality within contemporary African American communities reproduce and/or resist new forms of racism." Social problems such as poverty, unemployment, and incarceration take on gender specific forms. Collins (2005) argues that these issues will not be solved without serious consideration of the politics of gender and sexuality 
because racism is gender specific. Failing to integrate gender into anti-racist politics renders such actions ineffective.

Gender and sexuality have been important factors in explaining the experiences of Black women, and are equally important to the experiences of Black men (Collins 2005; Davis 2003; hooks 2004). The Black male discourse is both a raced and gendered discourse. Historical representations of Black males drawing on imagery of beast have produced a set of images of Black men that define them as inherently violent, hyperheterosexual, and in need of discipline. These messages are present in the schools serving Black males and also the Black male discourse, which informs policies and programs targeted at them. By integrating Black sexual politics and CRT I will center race, class, and gender in my analysis. Additionally, I will shift away from cultural deficit model and highlight the roles of schools in the educational outcomes of Black males. 


\section{CHAPTER IV: METHODS}

The schooling experiences of African American males are situated within the Black male crisis discourse, thus "collective outcomes and disparities must be viewed as products of a cumulative interrelationship between competing ideologies, institutions, and human behavior" (Brown and Donner 2011:27). OS, as one of a very few boarding schools that exclusively serves low-income students and students of color, is affected by the Black male crisis discourse. The school positions itself as an educational alternative, but because of the social context and popular and policy messages about Black males it is important to investigate how the school operates and whether it draws on the Black male crisis discourse. This research paid particular attention to the racial dynamics of the school and investigated the practices and policies at OS by asking the following questions: (1) To what extent is OS premised on the Black male crisis discourse; (2) How do the students, faculty, and staff navigate the boundaries of race, class, and gender; and (3) How do racial ideologies (i.e., colorblind racism and Black male crisis discourse) influence the experiences of faculty and students?

\section{RESEARCH SETTING}

OS is located in a hyper-segregated city in the Southeast. Majority of Black residents reside in the Oakwood community, which is often otherized in comparison to Northridge which is majority White. Local media accounts indicate that John and Judy Everett opened OS in the mid 2000s after a police ride along experience led Mr. Everett to realize that the children in Oakwood had very different prospects than the kids he 
worked with at an elite private school in Northridge. Mr. Everett, due to his experiences as a boarding school student and teacher, was familiar with the advantages of living in a boarding setting. OS was envisioned as an educational alternative for students dealing with tumultuous home lives through the belief that these students could benefit from an immersive educational environment.

The school began with three middle school students, two dorm faculty, and one teacher. It has since expanded to include an elementary school and serves nearly 100 students. According to the school's literature, OS seeks out "low-income young men who benefit from a safe, structured, environment in which high expectations for academic excellence and evidence of character are paramount." Approximately $90 \%$ of the students are African American, while Asian and White students make up about 4\% each. In comparison, 10 out of 13 middle school faculty are White; the remaining three are African American. Additionally, seven of the faculty are male and six are female. Since its founding, OS has had 27 young men graduate from $8^{\text {th }}$ grade. These students often go to local elite private high schools. Sixteen OS graduates are currently enrolled in high school while eleven have completed high school. Among the high school graduates, eight are enrolled in 4 year universities, one is in the military, and one is a graduate of a machinist trade school and saving up to go to college.

In order to attend OS, students must qualify for free or reduced lunch in the local school district. Students also must be able to do grade level work; OS does not have the capacity or resources to admit students with severe emotional or behavioral issues or significant learning differences. I was told that OS is not "cherry picking" the best and brightest kids from the local school district and that OS students' were not "off the charts" 
academically or athletically. The admissions process was described to me as "not completely formalized." Faculty members individually look at applications and informally provide feedback to one another. After reviewing applications, OS extends an invitation for applicants to shadow a current student, during which time, some testing is also conducted. From there selected students are invited to the summer bridge program, which is intended to further assess fit and help students acclimate to the school. Acceptance to OS is dependent on a student completing the summer bridge program successfully. Enrolled students also are required to attend. An excerpt from the first faculty meeting of the school year demonstrates how information from the summer bridge program is used:

Field Note: 8/26/16

Faculty Meeting

Mr. Harrison teaches science and he also lives on campus. He appears to be very knowledgeable and connected to the students. Mr. Harrison gives an overview of the summer program. He goes down the roster and gives detailed descriptions of every incoming sixth grader. The level of detail is astonishing. He not only talks about the students' experiences in the program, but he talks about their families and their home lives. At times I have a hard time keeping up because he talks about student connections with one another. There are a couple of sibling groups and there are some boys who have just developed close knit bonds. Mr. Harrison also gives an update on several returning students who they wanted to keep an eye on. The teachers are very mindful of what is going on in students' lives; they discuss one student whose parents are going through a nasty divorce and how it has affected the student's behaviors at school. Mr. Harrison says that he must be 
careful not to share too many details because of confidentiality concerns. At one point Mrs. Ferguson says that she understands that they can't share details but it helps to know these kinds of things so that they don't make a bad day worse, so that they know when they can push and when they should back off. Mrs. Bell seconds the sentiment.

The summer bridge is used as both an orientation to OS and an assessment tool. The manner in which a student comports himself during the summer bridge program is used to assess how he will fair at OS and can also color faculty's initial perceptions of a student.

\section{The Day-to Day at $O S$}

The school day begins at 7:55 AM with breakfast and ends at 4:22 PM with the last class. In a preliminary meeting with the middle school and elementary school counselors, the OS curriculum was described as following common core guidelines but allowing teachers to adapt the curriculum to their teaching styles and student needs. In the middle school students are offered two different English courses, one focused on reading and writing and the other focused on the mechanics of language arts, Math, History, French, Science, Music, Art Therapy, and Counseling and Student Development. Students alternate between taking swimming lessons and engaging in service learning each week. $7^{\text {th }}$ graders have the opportunity to take Latin and $8^{\text {th }}$ graders take a general studies course taught by Mr. Everett.

After the final class of the day students change clothes and complete their chores. All students are required to participate in sports after school. In the fall that is basketball 
and in the spring that is track and field. During my field observations, Mr. Everett discussed adding soccer to the sports offering in the next academic school year. Also after school students attend study hall where they complete their homework.

\section{DATA COLLECTION}

In order to answer the above questions, I conducted institutional ethnographic research utilizing participant observation, formal and informal interviewing, and document analysis. Ethnography is well suited to answer these questions regarding school culture, activities, and processes because it allows us to gain in-depth understanding of how individuals make sense of their lived experiences; ethnography attends to the social relations and cultural practices of groups (Buch and Staller 2014; Lofland and Lofland 2006; Warner and Karner 2010). Institutional ethnography is similar to other forms of ethnography in that it relies on interviewing, observations, and document analysis. It is different from traditional ethnography in that seeks to uncover the social organization of society (Campbell 1998; Smith 2005). Institutional ethnography starts from our everyday lives and explores social relations and organizations in which we participate, but may not be fully cognizant of. This methodology allows us to uncover the connections across and beyond the boundaries of a social setting and to explicate the ruling relations of a society (Campbell and Gregor 2002; Smith 2005). Ruling relations, being, forms of consciousness and organization are objectified in the sense that they are constituted externally (Smith 2005).

What makes this ethnography an institutional one is the attention paid to the ruling relations and situated standpoints. Standpoint theory, a critical tenant of feminist theories, seeks to understand how social and historical locations shape individuals and 
their knowledge (Collins 2005; Harding 2004). Drawing on standpoint theory, Smith (2005) uses standpoint as a point of entry to discovering the social in a manner that does not subordinate the knowing subject to objectified forms of knowledge. Smith posits that the embodied knower is an expert in all the specificities of her daily doings and the local conditions on which she relies; when it comes to her daily life, she knows her way around in it and how things get done.

Within institutional ethnography observations allow the researcher to see the language used by participants (Campbell 1998). This is then used to gain entry into social organization of the setting (Campbell 1998). Within a setting discourse, which is visible among people's doings insofar as they are produced in the language as talk/text, provides insight into the ruling relations of a setting because a speaker's or writers expressions are mediated by the discourse in which it is framed (Smith 2005). While the embodied knower is an expert on their daily life, they may not be an expert when it comes to the forms of organization that authenticate these experiences. The procedures of institutional ethnography are used to problematize those everyday experiences to which the observer makes us privy (Campbell 1998).

\section{Participant Observation and Document Analysis}

Data collection for this project occurred in three phases, beginning with participant observation. The second phase consisted of interviews with parents and the final phase included interviews with parents and students. Conducting observations allows us to study the personal experiences, daily activities, and social/political context of everyday life from the perspective of those being studied (Buch and Staller 2014). Being immersed in a setting allows the researcher to gain access to meanings, which includes 
culture, norms, understandings, social reality, definitions of the situation, typifications, ideology, beliefs, world views, perspectives, or stereotypes (Lofland and Lofland 2006), and thus gaining access to the social organization of a setting. Over the course of the 2015-2016 academic school year, beginning in September 2015, I spent an average of two to three days a week at OS for over 250 hours of participant observation. Initial observations began with group counseling and student development. Each Monday $6^{\text {th }}$, $7^{\text {th }}$, and $8^{\text {th }}$ grade students meet with the middle school counselors. It was here that this research and I were introduced to students. During the course of my fieldwork, my observations expanded to include most classes, lunch, recess, and basketball games. Participating in and observing group counseling and student development allowed me to be a constant presence for the students and to understand their situated standpoint. While collecting field notes I regularly wrote memos, which were then used to refine interview questions (Jorgensen 1989). During this period I also collected and examined OS documents, which included various school handbooks and a school self-study. These serve as examples of the school's material culture (Lewis 2003).

\section{In-Depth Interviews}

After spending several weeks at OS and becoming familiar with the setting and the people, I began the second phase of data collection by conducting semi-structured, open-ended interviews with faculty (see appendix A). All faculty who teach a regularly scheduled middle school class were interviewed for a total of 13 interviews; this sample included administrators, as they hold teaching responsibilities as well. Additionally, the board chairmen and a volunteer who served in a mentoring role for students were interviewed. On average interviews lasted approximately one hour and focused on 
teaching background, discipline practices, and policies, and perceptions of race and gender at OS. Table 1 below provides more detailed information on faculty participants.

\begin{tabular}{|c|c|c|c|c|}
\hline Name & Years Experience & Gender & Race & Subject \\
\hline Mrs. Avery & 30 & Female & White & RRW \\
\hline Mr. Miller & 1 & Male & White & Social Studies \\
\hline Mr. Harrison & 7 & Male & White & Science \\
\hline Mrs. Bell & 33 & Female & Black & Language Arts \\
\hline Mr. Travis & 6 (12 Social Work) & Male & White & Counseling \\
\hline Mr. Everett & 30 & Male & White & Admin/ General Studies \\
\hline Mrs. Nash & 25 & Female & White & French/Advancement \\
\hline Mr. Ethan & & Male & White & Counseling \\
\hline Mrs. Bennett & 5 & Female & White & Art Therapy \\
\hline Mrs. Ferguson & 26 & Female & White & Admin/ Service Learning \\
\hline Mrs. Everett & 25 & Female & White & Admin/French \\
\hline Mr. Green & 35 & Male & Black & Music \\
\hline Mr. Smith & 2 & Male & Black & Math \\
\hline Phil & & Male & White & Board \\
\hline Mr. Jesse & & Male & Black & Volunteer \\
\hline
\end{tabular}

Observations and interviews with faculty members formed the basis of an evaluation report presented to the school in January 2016 (Clark 2016). The findings indicated that the racial dynamics of the school impacted student-teacher relationships; specifically, there is a lack of trust harbored by many students as they believed that many of the adults could not identify with them personally—or in their personal lives. Based on these findings and the standpoints of students I began the final stage of data collection and interviewed six mothers and five students.

Interviews with mothers (see table 2 for more information), lasted between one hour and an hour and a half. Mothers were interviewed in a location of their choosing. Four mothers were interviewed in their homes and two chose to be interviewed at a public place such as a restaurant. Interviews with students occurred separately. Three 
students were interviewed while at school and two students were interviewed at their home (see Appendences B and C). Purposive and convenience sampling were used to select students and parents that were interviewed. In an attempt to sample for range, parents of currently enrolled students, graduates, and students who were expelled were included in this study (Small 2009). Student participation was largely on a voluntary basis and included at least one participant from each grade level. Additionally, I sought out interviews with two students who were expelled during my fieldwork. The expulsion of these students was a contentious and pivotal event during my observations. These students were selected in order to provide nuance to the event as recorded in field notes. Furthermore, these students' marginalized status had the potential to distance students and facilitate and critical attitude (Sprague 2005).

\begin{tabular}{|c|c|c|c|c|c|}
\hline Name & Race & Age & $\begin{array}{l}\text { Highest Level } \\
\text { of Education }\end{array}$ & Income & $\begin{array}{l}\text { Marital } \\
\text { status }\end{array}$ \\
\hline $\begin{array}{l}\text { Joyce } \\
\text { Bellamy }\end{array}$ & Black & 54 & Associates & $\$ 65,000$ & Widow \\
\hline $\begin{array}{l}\text { Ashley } \\
\text { Slaughter }\end{array}$ & Black & 39 & Bachelors & $\$ 10,000$ & Divorced \\
\hline $\begin{array}{l}\text { Tonisha } \\
\text { Pittman }\end{array}$ & Black & 37 & High School & $\begin{array}{l}\text { "middle } \\
\text { class" }\end{array}$ & Married \\
\hline $\begin{array}{l}\text { Patricia } \\
\text { Kendrick }\end{array}$ & White & 52 & Bachelors & $\$ 150,000$ & Married \\
\hline $\begin{array}{l}\text { Marilyn } \\
\text { James }\end{array}$ & Black & 51 & Some college & $\begin{array}{l}\text { "medium- } \\
\text { income" }\end{array}$ & Divorced \\
\hline $\begin{array}{l}\text { Stephanie } \\
\text { Moore }\end{array}$ & Black & 45 & Associates & $\$ 31,000$ & Divorced \\
\hline
\end{tabular}

This study relies heavily on interviews with faculty and field notes. Interviews with students are not included because I found that students were reticent in their responses and did not provide any new theoretical data (Ferguson 2001). The voices of mothers play a secondary role because they existed on the margins of the school and did 
not offer an insider viewpoint. Their interviews however, did provide an opportunity for triangulating of findings.

\section{DATA ANALYSIS}

Qualitative research is inductive in that concepts are derived from the data collected (Warner and Karner 2010). Interviews, field notes, and documents were coded and analyzed according to grounded theory techniques (Charmaz 2006). As I collected field notes I conducted an initial phase of line-by-line coding paying particular attention to sensitizing topics from the literature. Trends found during the coding process of field notes were used to review interview questions. Initial coding was followed by a round of thematic coding and recurrent themes were linked to issues in the literature (Warner and Karner 2010). These themes serve as the basis of the three findings chapters: "The Social Geography of Race: Residential Segregation and the White Gaze," "Schooling By Whiteness, Schooling for Whiteness: White Racial Framing and Colorblind Ideology at OS," and "This is What Men Do: Respect, Responsibility, and Other Measures of

\section{Character at Oakwood School."}

This study employed a variety of qualitative methods to ensure validity and reliability. While much of this study relies on interviews with faculty at OS, interviews with mothers and observational data were used as a method of triangulation (Warner and Kerner 2010). When speaking about generalizability in qualitative research it is important to note that generalizability refers to the common patterns in social interactions and social life (Warner and Kerner 2010). The findings of this study are generalizable in the sense that the social processes occurring in OS are relevant to similar urban schools. 


\section{LIMITATIONS}

The findings of this study should be considered in light of its limitations. First, this study relied on a Black woman interviewing White individuals about their perceptions of race. This facet of the study design may not have yielded the most forthright responses from participants due to a fear of judgment. To the extent possible, I tried to minimize this limitation by utilizing observational data to triangulate findings. Secondly, the sample of mothers interviewed relied on convenience sampling and was relatively small. The mothers interviewed may not be representative of all parents at OS. Lastly, while OS is similar to other urban schools, these findings are limited to this particular site. More research would be necessary to ascertain to what extent these findings are applicable to other settings.

\section{ETHICIAL CONSIDERATIONS}

This study was approved by the University of Louisville Institutional Review

Board. I entered the setting under the auspices of an internship where I would conduct a study based on the needs of the organization. I met with Mr. Travis, the head of the counseling department, and the elementary school counselor, Jamie on May 27, 2015. From this point on Mr. Travis served as my point of contact for the school. In August 2015, I met with faculty and introduced myself and the research. Before beginning participant observations, informed consent forms were sent home with students. Observations began in September 2015. Interviews were conducted with faculty in November 2015 and were conducted in various classroom at OS. Faculty signed informed consent forms prior to being interviewed. Interviews with students were conducted either at school or at their homes. They were reminded that their parents 
signed informed consent and were provided assent forms. In order to protect the confidentiality of participants I assign pseudonyms to the school, the neighborhood, and each individual participant.

\section{RESEARCHER POSITIONALITY}

This research is rooted in Black feminist epistemology, which argues that all knowledge is constructed based on location, history, culture, and interests. Additionally, knowing is partial, local, and historically specific (Sprague 2005). Black feminist epistemology argues that the standpoint of Black women offers a distinctive basis. Black women have been brought into contact with dominant groups but have remained marginalized. This marginalization is beneficial because it distances women from hegemonic thoughts and facilitates a critical attitude (Sprague 2005).

Black feminist epistemology sees the character and the biography of the researcher as a tool for interpreting and evaluating the truthfulness of the idea (Sprague 2005). Therefore it is important to acknowledge my position as the researcher. I am a Black woman who completed her elementary and secondary schooling in the public education system and currently serve as an advocate for students of color. I grew up in a low-income community and had the opportunity to attend one of the best schools in my district. I have nieces and nephews that are still students in the system, which is at times promising and at others discouraging. I am both a participant and observer of the social world (Collins 2000). I care deeply about educational outcomes of students of color. This is not my first nor will this be my last project concerned with the educational experience of African American students. It was important for me to remain reflective about my position because of my identity as an African American woman as this 
positionality has the potential to affect how I interpret my findings. Gouldner (1970) suggests that as researchers we must ask the same questions about ourselves that we ask about others and question why we are choosing the theories that we are choosing and what that means for the research we are conducting, as such I journaled after fieldwork and each interview. 


\section{CHAPTER V: THE SOCIAL GEOGRAPHY OF RACE: RESIDENTIAL SEGREGATION AND THE WHITE GAZE}

Frankenberg (1993) proposed social geographies of race as a means for exploring the ways racism helps shape our daily environments. According to Frankenberg, physical landscape is constituted and perceived by means of social processes; our daily environments are shaped by historical, social, and political processes, thus, it is important to understand how physical space is divided. The social geography of race frames ideas, shapes and limits what we see, and how we interpret the physical worlds. OS was developed in a highly segregated city; the Oakwood community is like many other economically disadvantaged urban inner city communities. Social and economic factors related to segregation and poverty shape the perceptions of practitioners working at OS, as well as outsiders. It is characterized by high poverty, high unemployment, high crime rates, and poor education. OS promoted itself as a straightforward avenue for ameliorating many of educational deficits that low income males face; however, a closer examination of the demographics of the school and the city in which it is located begs questions of the role of race, class, and gender. Assumptions about race, class, and gender are embedded in the school, therefore the avenues selected for addressing the lagging academic achievement of students may not be as straightforward as actors at OS believe. The racial and income inequality shape the opportunities available to residents of Oakwood, making OS an attractive option for parents. Additionally, these dynamics inform faculty and staff about what types of programming may be best for the selected 
student body. There are a set of basic beliefs about what works best for Black males that is largely informed by the Black male crisis narrative and the evidence presented in this chapter suggests that faculty and staff at OS subscribe to these ideas.

In this chapter, I explore the social geography of race and how it shapes perceptions of the community, the students, and their families and therefore shapes the accepted avenues for ameliorating educational inequality at OS. Educational policy is shaped by globalized political, economic, and spatial changes that have redefined cities (Lipman 2012). Wilson (2009) identified several political and economic forces that have produced the conditions in inner-cities: FHA loans, redlining, suburbanization, and an economic shift from manufacturing based economy to a service based economy. The combination of these processes spurred the departure of high income families and left behind some of the most disadvantaged segments of population, along with deteriorating social conditions including a lack of basic social services and substandard schools (Wilson 1987). OS's location in a highly segregated community creates the prime condition for a school like this to open. Increasingly policy makers have been challenged to address the widening achievement gap and often neoliberal policies which favor privatization and free market strategies such as charter schools are chosen.

The segregation in the city where Oakwood is located creates an environment where Blacks and Whites interact very minimally, attaches a stigma to the Oakwood community, and positions OS as means for racial contact. Faculty, volunteers, and community members construct students in accordance with stereotypes of urban inner city families. Students are defined as coming from single-family homes, and dogged by 
absent fathers and "bad" mothers. This framing of students and their families in turn encourages paternalism and exclusion of parents from the school.

\section{RESIDENTIAL SEGREGATION AND URBAN GHETTOS}

OS is located in a highly segregated city in the Southeast and the school is named for the stigmatized community in which it is located. Eighty percent of the population in Oakwood is Black, compared to $22.6 \%$ in the city (See Table 3).

\begin{tabular}{|c|c|c|c|c|}
\hline \multirow{2}{*}{$\begin{array}{l}\text { Race alone or in combination with one } \\
\text { or more other races } \\
\text { Total population }\end{array}$} & \multicolumn{2}{|c|}{ Oakwood } & \multicolumn{2}{|l|}{ City } \\
\hline & 62,143 & 62,143 & 751,485 & 751,485 \\
\hline White & 13,672 & $22.0 \%$ & 568,908 & $75.7 \%$ \\
\hline Black or African American & 49,852 & $80.2 \%$ & 169,610 & $22.6 \%$ \\
\hline $\begin{array}{l}\text { American Indian and Alaska } \\
\text { Native }\end{array}$ & 340 & $0.5 \%$ & 5,730 & $0.8 \%$ \\
\hline Asian & 74 & $0.1 \%$ & 21,743 & $2.9 \%$ \\
\hline $\begin{array}{l}\text { Native Hawaiian and Other Pacific } \\
\text { Islander }\end{array}$ & 5 & $0.0 \%$ & 1,077 & $0.1 \%$ \\
\hline Some other race & 133 & $0.2 \%$ & 8,255 & $1.1 \%$ \\
\hline Hispanic or Latino (of any race) & 309 & $0.5 \%$ & 34,389 & $4.6 \%$ \\
\hline
\end{tabular}

Furthermore, Oakwood suffers from high unemployment and poverty. Approximately $37 \%$ of families in Oakwood live under the poverty line, compared to $12 \%$ in the city. Over half of the households in Oakwood have an income under $\$ 25,000$ per year, whereas only $26.2 \%$ of the population in the city makes under that amount. Lastly, unemployment in Oakwood is $12.5 \%$, approximately twice that of the city (See Table 4). 


\begin{tabular}{|c|c|c|c|c|}
\hline & \multicolumn{2}{|l|}{ Oakwood } & \multicolumn{2}{|l|}{ City } \\
\hline & Estimate & Percent & Estimate & Percent \\
\hline \multicolumn{5}{|l|}{ EMPLOYMENT STATUS } \\
\hline Population 16 years and over & 46,334 & 46,334 & 597,548 & 597,548 \\
\hline In labor force & 26,510 & $57.2 \%$ & 393,140 & $65.8 \%$ \\
\hline Civilian labor force & 26,510 & $57.2 \%$ & 392,295 & $65.7 \%$ \\
\hline Employed & 20,719 & $44.7 \%$ & 355,687 & $59.5 \%$ \\
\hline Unemployed & 5,791 & $12.5 \%$ & 36,608 & $6.1 \%$ \\
\hline Armed Forces & 0 & $0.0 \%$ & 845 & $0.1 \%$ \\
\hline Not in labor force & 19,824 & $42.8 \%$ & 204,408 & $34.2 \%$ \\
\hline \multicolumn{5}{|l|}{$\begin{array}{l}\text { INCOME AND BENEFITS (IN } 2014 \\
\text { INFLATION-ADJUSTED DOLLARS) }\end{array}$} \\
\hline Total households & 23,393 & 23,393 & 306,511 & 306,511 \\
\hline Less than $\$ 10,000$ & 5,876 & $25.1 \%$ & 26,190 & $8.5 \%$ \\
\hline$\$ 10,000$ to $\$ 14,999$ & 2,438 & $10.4 \%$ & 18,852 & $6.2 \%$ \\
\hline$\$ 15,000$ to $\$ 24,999$ & 4,618 & $19.7 \%$ & 35,351 & $11.5 \%$ \\
\hline$\$ 25,000$ to $\$ 34,999$ & 3,132 & $13.4 \%$ & 34,192 & $11.2 \%$ \\
\hline$\$ 35,000$ to $\$ 49,999$ & 2,906 & $12.4 \%$ & 44,774 & $14.6 \%$ \\
\hline$\$ 50,000$ to $\$ 74,999$ & 2,482 & $10.6 \%$ & 54,060 & $17.6 \%$ \\
\hline$\$ 75,000$ to $\$ 99,999$ & 1,144 & $4.9 \%$ & 34,272 & $11.2 \%$ \\
\hline$\$ 100,000$ to $\$ 149,999$ & 694 & $3.0 \%$ & 34,244 & $11.2 \%$ \\
\hline$\$ 150,000$ to $\$ 199,999$ & 45 & $0.2 \%$ & 11,786 & $3.8 \%$ \\
\hline$\$ 200,000$ or more & 58 & $0.2 \%$ & 12,790 & $4.2 \%$ \\
\hline Median household income (dollars) & 21,652 & $(\mathrm{X})$ & 47,692 & $(\mathrm{X})$ \\
\hline Mean household income (dollars) & 30,776 & $(\mathrm{X})$ & 67,896 & $(\mathrm{X})$ \\
\hline \multicolumn{5}{|l|}{$\begin{array}{l}\text { PERCENTAGE OF FAMILIES AND } \\
\text { PEOPLE WHOSE INCOME IN THE PAST } \\
12 \text { MONTHS IS BELOW THE POVERTY } \\
\text { LEVEL }\end{array}$} \\
\hline All families & & $36.9 \%$ & & $12.3 \%$ \\
\hline With related children under 18 years & & $51.7 \%$ & & $20.3 \%$ \\
\hline With related children under 5 years only & & $62.7 \%$ & & $21.2 \%$ \\
\hline Married couple families & & $11.9 \%$ & & $4.6 \%$ \\
\hline With related children under 18 years & & $15.5 \%$ & & $6.9 \%$ \\
\hline With related children under 5 years only & & $9.4 \%$ & & $6.5 \%$ \\
\hline $\begin{array}{l}\text { Families with female householder, no } \\
\text { husband present }\end{array}$ & & $48.4 \%$ & & $32.0 \%$ \\
\hline With related children under 18 years & & $58.6 \%$ & & $41.3 \%$ \\
\hline With related children under 5 years only & & $76.4 \%$ & & $50.2 \%$ \\
\hline All people & & $41.7 \%$ & & $16.7 \%$ \\
\hline
\end{tabular}




\begin{tabular}{|c|l|l|l|l|}
\hline Under 18 years & & $56.1 \%$ & & $24.6 \%$ \\
\hline Related children under 18 years & & $56.0 \%$ & & $24.2 \%$ \\
\hline Related children under 5 years & $67.8 \%$ & & $28.3 \%$ \\
\hline Related children 5 to 17 years & $51.5 \%$ & & $22.6 \%$ \\
\hline 18 years and over & & $36.0 \%$ & & $14.4 \%$ \\
\hline 18 to 64 years & $38.4 \%$ & & $15.5 \%$ \\
\hline 65 years and over & $21.2 \%$ & & $9.1 \%$ \\
\hline
\end{tabular}

Income inequality and segregation characterize Oakwood and shape perceptions of the area in the city. The racial segregation, high unemployment, and low-income, along with nightly news stories about the crime and dysfunction in Oakwood feed into what individuals believe about Black people living there. In many ways, the community represents what sociologist Elijah Anderson $(2011,2012,2015)$ terms as the "iconic ghetto," which "has become a highly negative icon in American society and culture, serving increasingly as a touchstone for prejudice, profound source of stereotypes, and a rationalization for discrimination against Black people in general.” (Anderson 2015:13). This framing of the community as ghetto fits within American ideals about individualism and boot strap ethics. If individuals believe that Oakwood community members live in poverty due to individual choices, then individual focused solutions, which also fit within a neoliberal policy paradigm, will be favored.

In the subsequent pages of this chapter, I demonstrate the ways the community fits the narrative of the iconic ghetto in the eyes of community outsiders. Because ideological biases suggest that Oakwood residents live in the ghetto at their own volition, the community is scorned and devalued. The individuals working at OS are not immune to or detached from outsider perceptions. Comments from Mr. Everett, the founder of the 
school, illustrate how widespread and entrenched negative beliefs about Oakwood are embedded in the city. He stated:

I had a board member of the OS who was a Catholic Priest, who on my third day on the job called me and said, "I'm going to take you to the part of city that White people don't go to. You will never go there unless I take you." We spent the day, my third day in the city driving around Oakwood because he had lived in Oakwood and been the Pastor of churches in Oakwood.

This initial experience of Mr. Everett speaks volumes about the negative perceptions of Oakwood. The board member mentioned above recognized that upon entering the city, community members, particularly, White ones would tell Mr. Everett that Oakwood was to be avoided and that there was nothing of value there. Mr. Miller confirms that newcomers are shied away. He offered:

Just really actually, when I meet people, I live in Northridge, and I talk to people over there about how I work on this side of the city. They're like, 'Oh, be careful,' they make little jokes like that, and it almost offends me a little bit because I'm like, 'You don't even know what it's like over there.' I grew up in the [Northeast], where we have 375 murders a year, and here, it's like a drop in a bucket compared to that. When I hear people say stuff like that, it just seems very ignorant to me that people say that. This really isn't a dangerous area. I have not felt unsafe once since I've been in this city, or even in Oakwood, or whatever. I think people see, maybe, an African-American male who's got raggedy clothes on or something like that, maybe a working class guy, and they probably make assumptions about 
him that aren't true right off the bat. Whereas you saw a White guy in a suit and tie, you think something different.

Whites living outside Oakwood do not actually need to travel to Oakwood to develop these negative perceptions and share them with others, and as Mr. Miller highlights many do not. Furthermore, many of the people that Mr. Miller comes into contact with assume that he shares their negative perception of the Oakwood community, however based on the city in which he was raised and his actual experiences in Oakwood he took umbrage at the suggestion that he was ever in danger.

Visiting and even working in the Oakwood community does not necessarily provide a clear and comprehensive image. Despite coming to the neighborhood Mr. Everett still seized upon negative aspects of the community that are tied to the image of the iconic ghetto:

It's hard not to drive the streets of them. A board member made a point of driving the neighborhood of Oakwood and it's not hard to see the substantial income inequality between Oakwood, south of Main Street, what the Mayor now refers to as the Berlin Wall of Main Street, as appropriately so, and the North Side. There's a striking difference in the socioeconomic and I think that's the thing that strikes you first hand. You know where we're sitting now? You drive down these six blocks and there are 6 or 8 or 10 boarded up houses. There aren't any boarded up houses on the other side of town. You're struck by the poverty.

Mr. Everett described this experience as seminal in the opening of OS. After going on this drive he began working with a local youth shelter and started a summer program for 
underprivileged youth at the school where he worked. According to Mr. Everett, it was through that work that he became familiar with what he believed to be the issues of Oakwood, which include poverty, transience, and crime.

Both Mr. Everett and Mr. Miller highlight two key points about Oakwood. First, the poverty is highly visible through boarded up homes and shabbily dressed Black men. And, second, these are taken as signs that Oakwood is dangerous and undesirable. This combination of attributes suggests that societal notions about race and class are shaping ideas about this community and the people who live there. While Mr. Everett and Mr. Miller went beyond what many others do by travelling to and working in the area their perceptions of Oakwood are still shaped by the stigma attached to the community. Mr. Everett became familiar with the so-called "issues" of Oakwood through his work at a youth shelter and through a summer program for disadvantaged youth. These initial experiences are in many ways limited and show only one side of the Oakwood community. This becomes problematic, as we see that OS is positioned as an avenue for White contact, and simply coming to the neighborhood does not change perceptions.

\section{OAKWOOD SCHOOL: A MEANS FOR WHITE CONTACT (BLACKNESS WITHIN} A WHITE SPACE)

Despite being a numerical majority Black community members and students at OS have to operate within White spaces and/or deal with White dominance (Whiteness dominates social contact). OS depends on wealthy donors, many of whom are White; this financial dependence invites the White gaze into the community and centers Whiteness in the school. 
Through its fundraising efforts OS has invited White people to a space that they would not otherwise travel. The decision to name the school after the Oakwood community indicates that this may have been an intentional aim. While this aim is not articulated as a part of the mission of the school, it is certainly a source of pride. According to Mr. Everett,

It's hard to change the perception of an institution. For a long time, we were better known in Northridge than in Oakwood because the school became, and you'll understand this, kind of a Northridge story. The best example of that is we had a front page article in the paper above the fold a couple of years ago, it appeared on a Sunday. When the boarding boys came back I made a point of asking the guardians if they had seen the article in the paper. Not one of them had.

Everybody in Northridge had seen the article in the paper but our families aren't reading the paper, they're not listening to the same television shows, so they're not getting the same kind of information.

As a result of fundraising efforts and relationships school affiliates developed in the community, OS became a darling child of people in Northridge who would not otherwise step foot into Oakwood. While Mr. Everett does not explicitly make a value judgment about mainstream newspaper, the implicit message is that students and their families should be reading the newspaper-they should have known about the positive coverage of their school. Print news is historically White, and according to Mr. Everett not a source of information for his students and their families. Ultimately this local newspaper is what introduced many White families to OS, comparatively many Black families who send their students to the school learn about it through word of mouth. Thus, it is likely 
that the framing and information about OS that Black families and White families receive is very different. Whites, with a White frame of reference, introduce other Whites to OS, and based on the widespread devaluation of the community it is possible that these individual hold negative perceptions of the Oakwood community. This process positions OS to be described as an outlier to the community.

Once outsiders (Whites) learn about OS, they are invited into this space. Phil, the board chair for OS, further discusses the phenomenon wherein Oakwood has become something to bring people to Oakwood that would have not otherwise come.

Jelisa: So Oakwood School, the name of it, is reflective of the city's dynamics and the demographics of the city which is very bifurcated. What was your perception of Oakwood before you beginning your work with the school and how does the way that the city is divided impact your work with the school?

Phil: Oakwood, geographically is my upbringing... so I said to John or Judy, this is part of me coming home. This is part of me understanding how it works. [My hometown] was the roughest environment I've ever been on the street in.

Oakwood didn't frighten me. So that's very important. Because John and Judy and I and the board wondered why would anybody wanna be afraid of Oakwood, just because we're reading the paper. Everyday there's a shooting. Two things happened when we started OS. One, John and Judy wanted to call it the OS 'cause they didn't wanna put their name on it, [local business] name on it, or anybody's name on it. They just wanted it, it's Oakwood -to bring attention, a realization, an embracement of Oakwood. The second thing is as board chair and 
developing our board, I told everybody that joined, every function, everything we do, every meeting, every celebration is gonna be in Oakwood. We don't go to Northridge. We don't go downtown and rent the halls in the Marriott. What we do... if you wanna be involved in Oakwood, you gotta come down to Oakwood. What that did is what you started to say about the division at Main Street and this community. That started dropping, chiseling that wall down, because it all happens here. I can remember, I'm gonna have to say this was six or seven or eight years ago, my youngest son is 16-years-old driving a car. At the time I was parenting all by myself, wanted to get involved and help John Everett coach the little basketball team. So I remember it's a cold day and a little snow flurries. And he had his car and I said okay. You gotta be at this door at 5:30. John will meet you, take you downstairs and you gotta be there at 5:30 cause down in the basement cell phones don't work and everybody's shut up. They're gone. Shut down is the word. I can remember 20 minutes to six, my son calls me and says, "Dad, we have a problem." I said, "What kind of problem we have son?" He says, "Well, I'm standing out front of the OS and there's nobody here and the doors are locked and there's some African American guys standing round my car." I said, "So what?" He says, "Well, what should I do?" I said, "You oughta wait for John to come up. You obviously didn't get there on time, so that's okay. You're cold." I say, "Just go back in your car and drive off." He says, "Really?" I said, "Yeah." What that did with that little boy, when I say little boy, 16-yearold boy, he no longer was scared of the Oakwood. Nothing happened to him. 
Nothing happened to his car. John came up 10 minutes later. He goes in and out of Oakwood just like you and I do.

Phil's recounting of this story highlights the role of the mainstream media in shaping perceptions of the Oakwood community. The newspapers where White families are learning about OS, is the same newspaper that describes the Oakwood community as crime ridden and dangerous. Phil continued and added:

The Oakwood community deserves the respect that whatever headlines that go on that's negative, for whatever reasons, the OS's been protected. It's not because we built a fence around it. It's not because we have cameras. $99.9 \%$ of the Oakwood community know we're doing something good and do not bother us. We never get vandalized. There was an incident on the street, outside right before school got out for Christmas, had nothing to do with OS. But the point being is I think we're protected; and it should be protected by the drug dealers, the people carrying guns, as well as the mayor and the governor and myself. And that's what I think of Oakwood.

Phil explicitly states that John and Judy wanted the school to bring attention to, a realization of, and embracement of Oakwood, and as board chair he was worked to ensure that that happened, mainly through holding events at the school. This suggests that an ancillary facet of OS is rooted in the stigmatized status of the Oakwood community. This played out by bringing Northridge residents to Oakwood to see that there is nothing to fear, similar to the experience of Phil's son. However, because negative messages are continually circulated about the community in which the school is 
situated it is possible the school is taken as an anomaly to the community and success may be attributed to the White individuals involved in opening and working with the school.

Mr. Harrison, the science teacher, professes that the strategy discussed by Phil, is having the intended effect:

Yeah. You see the parents that actually do come over here and they see the school, they see the neighborhood. Board members who probably have one opinion years ago that have been to the school, now I think that their opinions have changed, and all it took was actually coming here.

OS is an organization that draws people who, based on negative perceptions of the area, would not typically travel to Oakwood. Mr. Harrison asserted that once these individual make contact with Oakwood through OS their opinions changed, however, it is likely that their perceptions are changed via a narrative of racial transcendence, wherein the students of OS are seen as overcoming their community.

Beyond just ameliorating educational deficits for low-income males, OS recognized the stigma attached to the community and positioned itself not only as an avenue for countering stereotypes through exposure, but also in shaping students to contradict the stereotypes of Oakwood and in doing so centered the role of White actors in ameliorating educational deficits. Character development is a major component of OS and through character education students are supposed to overcome the challenges posed by their community. Thus Oakwood students are constructed as being different from others in their community. As a result, OS is not challenging perceptions of the 
community, rather they are molding a number of Black boys to fit White ideals of acceptability. The contrast of OS students to the rest of the community is further highlighted by Phil's assertion that Oakwood is a decent community. He states that community members, understand and protect the school, however he sees the community as made up of drug dealers and people carrying guns.

\section{UNDERSTANDING STUDENT NEEDS}

In the previous sections, I demonstrated how the social geography of race and the icon of the ghetto shapes outsiders' perceptions of the Oakwood community. Here I argue that the social geography of race also shapes teacher's perceptions. Teachers at OS acknowledge the complex interplay of social, cultural, and academic needs of their students. However, according to the teachers, the social and cultural needs of students are most salient. This framing of students' needs is rooted in a presumed understanding of Black males and urban communities.

\section{Academic Needs}

Typically, when faculty members discuss academic needs it is either accompanied or eclipsed by social and cultural needs. For instance, both Mrs. Avery and Mr. Miller mention academic needs but follow up with discussing and focusing more on students' social and cultural needs. According to Mrs. Avery,

Many of them have academic needs, and I think... but certainly some of them more than others have been just glaringly passed through. They come in with huge deficits; it's very obvious in reading, huge deficits in reading. If they can sit quietly, I think they just keep on plugging away. My goal is to do two things, to 
bring them into more of a participation in their own education, and to remediate the reading, to bring them up to the grade level, at least. Again, that's really hard to do at 6th grade year, because there's so many other things that they're working through, in middle school too, you know, it's a time of great adjustment for anyone, figuring out who they are and what they want to be. I think another particularly challenging thing for these kids is they don't have as many role models of African American men in their lives, who do get up and go to work, and are successful, however you define that. You know, bring home a paycheck, and buy the things that you want, that's a success, and they don't see that too much, so I think it's really hard to picture yourself, so that's another, I think, issue for these boys. Picture themselves as successful, picturing themselves in high school, picturing themselves in college, I think.

Initially, Mrs. Avery places onus for the lagging achievement of students on school systems, where passivity and compliance is valued and rewarded. Mrs. Avery recognizes that this type of schooling disadvantages her students. However, she goes on to implicate the families of students—absentee fathers are just as much to blame for the lagging achievement of Black males attending OS. She indicates that as students are figuring out who they want to be they are limited by a lack of successful African American men, indicating a cultural understanding of student needs. Mrs. Avery draws on a common deficit narrative that African American males are irresponsible parents and are not active participants in their children's lives. This notion of "missing Black men" is rampant in educational and popular discourse and because it fits within popular narratives it will be more readily received than criticism directed at schools. Lastly, Mrs. Avery ignores the 
role of extended family and fictive kin in child rearing, the alternative roles that men play, and the importance of community as well. Mr. Miller also acknowledged academic needs by offering,

I think that some of them have academic challenges. I know that one eighth grader in particular has some serious reading troubles, which I think you can overcome, but it's going to take a lot of work, both on our part and his part. Then, I think some of the other challenges is [sic] some of the kids clearly crave attention. I have kids that climb all over me, that get really upset when I miss their basketball games, that are saying my name all the time, knocking on my door and running away, or they're mispronouncing my name on purpose. It's all done in the effort of trying to get my attention, trying to get me to pay attention to them. I think that can be an issue sometimes, but sadly, it's not really their fault that they're that way. It's because they're not getting it at home, or ever, but I think that can be one of the major problems. A lot of kids will act out or misbehave because they want attention.

Similar to Mrs. Avery, Mr. Miller acknowledges the academic needs of students, but quickly turns toward social needs. He defines academic needs as easily fixable through hard work, and focuses more on the need for attention. The suggestion of hard work speaks to the myth of meritocracy and depends on cultural explanations for continuing racial and income inequality wherein people just are not working hard enough. In unpacking students' needs, he removes students from blame, however, parents are conceived as the root cause of the challenges that students are facing within the school. He suggests that the lack of attention that students get at home manifest into behavior 
problems at school. Both Mr. Miller and Mrs. Avery locate the origin of student needs in the deficits of students' home lives; the academic needs that students enter OS with definitely draw concerns, however these problems are exacerbated by other issues that students experience in their home lives, and thus are actually cultural problems. This conceptualization of academic needs begins to suggest that even though teachers acknowledge that these needs exist they are exacerbated or contextualized by social and cultural needs of students.

Mr. Smith, a Black male in his 20s and who prides himself on coming from a similar background as the students, contradicts the claim that students have academic needs and reaffirms the importance of social and cultural needs. He stated:

They tight academically, academically these boys can go to any school in the country they want to go to, but they don't ask for your GPA when you getting a job, they don't ask for your GPA when you have a child, they don't ask for your GPA when you got a girlfriend, nobody cares about that at that moment. We need to be preparing them when life throw you a curve ball, and that's what scares me about these kids; they so straight and narrow that when they get hit with outside environment things I'm scared they're not going to know how to handle it. Basically they sheltered here, it's a big shelter so they not going to know ... Like with DeVante, that's not a bad kid, he got a temper, I know so many people with way worse temper then he got, but I think that we need more people here to help see why he has that temper. 
Mr. Smith downplays the importance of academics, to him academics, or more specifically the students' GPA isn't the thing that will be asked and assessed throughout their lives. He believes that these students need to know how to handle unforeseen circumstance that they will face as a result of their social location as low-income Black males. The common theme throughout the comments from Mr. Miller, Mr. Smith, and Mrs. Avery is that the needs are deeply impacted by their communities, their home lives, and their racialized and gendered identities.

Whether teachers say that students have academic needs or not they can all agree that they have social and cultural needs that impede their academic pursuit. This framing of students' needs shapes the approaches taken within the classroom. Mrs. Bell, a middle-aged Black woman who teaches Language Arts, explicitly ties students' social needs to their academics, which in turn shapes how she approaches course materials. Mrs. Bell offered:

Whenever we start learning something new, especially now things are getting a little rougher. We're through with a lot of the reviews from the grade before and we start working on things that they haven't seen as much, that's unfamiliar. They get real frustrated. I have to tell them, "We'll just try a little bit today, and then put that away and do something else and come back to it." They get frustrated when things get a little challenging. Sometimes you lose some of them because they feel like they can't do it. I said, "No, you just can't do it now." The challenge is when they have new materials and when it is something that is hard. I tell them, "Sometimes you don't get this all now. We might have to go over it." I'm setting them up because as they get higher, things are going to really get hard. I want 
them to understand that, "Okay, we got to open our minds and listen; not look out the window because we don't get it." I'm trying to help them to be focused.

Mrs. Bell stands apart from the other teachers both in how she approaches and understands students' needs. While she focuses on socio-emotional skills- she centers her pedagogy on addressing it. Mrs. Bell is less concerned with locating the origin or the problem and more concerned with addressing it. The ways that other teachers discuss the challenges students face defines the problem as outside of their purview, (i.e., parents caused it and should fix it). This is particularly concerning because the school removes students from their homes and thus lessens their ability to address many of their children' academic, social, or cultural needs.

While several faculty members mentioned academic needs they are overshadowed by social and cultural needs; academics play a minor role in the school. Mr. Ethan, in discussing the benefits of OS compared to public schools, suggests that he doesn't know what academics are like at comparable public schools or OS.

It's the long way of saying I don't know what the expectations are like academically at [local school district]. I assume they're more rigorous here. I don't have a way of necessarily measuring that but I assume and if they're trying to get kids into more elite schools, then I assume you would need to ramp it up a bit.

Mr. Ethan assumes that academics must be good here because they try to get students into elite schools, but what he ignores is the social and cultural capital that is at play that opens doors for students at Oakwood to local elite private schools. This incomplete 
assessment of academics at Oakwood begins to demonstrate the secondary role of academics at the school and Mr. Miller further solidifies this by explicitly stating that academics are secondary:

Here, I feel like grades come second. Even academics come second to character building. They're trying to mold these kids into men. They're trying to make them accountable, responsible, trustworthy adults. I had to get used to that when I was first here.

Mr. Ethan's limited awareness about the academics, and the other teachers framing academics around students social and cultural needs, all support Mr. Miller's assertion that academics comes second to character building at the school. Even when academics are explicitly discussed they are contextualized by students' social and cultural needs.

\section{Students' Home Lives: Social and Cultural Needs}

In understanding students' academic needs, faculty drew on what they knew about their homes lives. This also plays out when they discuss students' social and cultural needs. In addition to students' struggling to deal with frustration, faculty see a desire for attention as a major need of the student body at Oakwood. According to Mr. Travis:

I think that their needs ... some of them it's most fundamentally that they need someone to pay attention to them and to notice them in what they do, what they've ... how they've grown. They just need the most basic thing that any infant needs which is being seen, being valued. Those are the most fundamental things. I think that that's not always there for them when they have that. I mean it's the real world that it's not always there for all of us. I think that in some cases they 
had a real lack of that in relation to most of other middle school boys who are in private schools here or who are in public schools here. I think that they need now that.

This is assessment of the need for attention is not just based on conjecture, but the actual lived experiences of teachers within the school. Mrs. Bennett, the art therapist, talked about her struggles in maintaining class order; in particular, she was concerned about simply passing out paints without being dragged in every direction by the students needing her:

I'm just trying to hand out paints and paintbrushes and things, and it's like ... I don't know like they just popping up all over the place and I just don't understand how it ... So, I think one of their needs is just sort of attention and to be heard and to be seen without judgment. So, I try to do that much. I think there are challenges, kind of along with that, impulsivity and just to learn to be patient just a little bit or to trust themselves that they can do it. Again, that frustration tolerance I think is a big challenge for them and for me to help them with that. I think those are the big ones.

While Mr. Travis and Mrs. Bennett focus on the students' particular need for attentionor, at least in an external behavioral display—comments from other faculty demonstrate that this need for attention originates from practices within the homes. For example, Mr. Green states:

The biggest need and challenge, I think, is the fact that the parental support, sometimes it's fractured. Often times. We have kids that live with mom, but dad is 
still in the picture. They're with dad sometimes. They're with mom sometimes. Some kids are in as many as 4 households, because they're with those grandparents too. Even though everybody's got a piece of this kid, are they all working together to make sure the child actually gets what they need? If one parent is into the arts and the other parent is into sports, "Well, I'm not taking them to that. That's what he gets with the dad." Or when he's with mom. They have to get together. I think making people understand that is a challenge.

Mr. Green understands the students of OS as coming from single parent homes and this becomes problematic as students' experience inconsistency in terms of where they sleep and types of support and encouragement they receive. According to Mr. Green, conflicts between parents may cause students' needs to go unmet. Mr. Smith echoes this sentiment by asserting:

They need somebody to show them that, "Hey I been dealt this hand too, and you see how I turned out?" I think the biggest things with these kids they just need love, I can see a lot of these kids get love from home, but it's that tough love, it's that different kind of love. It's the love of, "Look boy, you at this good school you better do good, you better not get kicked out of this school." I think a lot of these kids just need a hug, like if you really [inaudible 00:29:43] man it's going to be all right...They need a daddy to be honest with you. I think a lot of these kids have a daddy, but I think a lot of these kids have the daddy I had. They're daddy, but well you know, they there sometime, sometime they ain't there. With my biological dad, we ain't start talking until I was like 19/20 years old. 
Mr. Smith situates students' needs within a particular understanding about childrearing in urban communities. According to this teacher, the students need a gentle type of love contrary to the "tough love" he perceives that they receive at home. Additionally, he notes that they also need a father figure, which he suggests they are lacking at home. In popular imagination, and discourse, many Black males are growing up in female singleheaded households. This conceptualization of Black youth is embedded within Mr. Smith's understanding of his students' needs. Single-family homes are a source of dysfunction for students; however, it is not just the family structure that is problematic. Mr. Ethan further elaborates on the dysfunction that he presumes takes place in students' homes. He stated:

They need sane parents. Parents who want to parent. Parents who are interested in parenting. Parents who are self-aware of their parenting. They're self-aware of their own issues and passing it down the line. I think that's where a lot of struggles come from, a lot of things we see as behavioral issues at the school really have been long gestating, maybe over generations. Just a generational wound that never gets healed. I think we just need parents who are stable, we need a staff who's stable, just a system that's stable.

According to several Oakwood staff members, it is not just that students are living with their single mothers that is problematic, but it is the parenting that these mothers practice as a result of their upbringing. In many of the staff's discussions, fathers and other male figures were almost wholly absent from students' lives and, therefore, continued to frame students within a homogenous discourse of female, single-headed homes. Additionally, 
Mr. Ethan's conceptualization of student needs suggests that the generational transmission of dysfunctional parenting must be stopped.

The structure of the school is intended to deal with the dysfunction within students' homes, however this creates some distrust and contempt between the school and families.

Field Notes: 11/4/15

Faculty Meeting

Mrs. Avery exclaimed that the kids go home and their parents never see or discuss report cards with students. Mr. Harrison told the group that DeVante doesn't give his report card to his parents. He goes to the other kids' homes and hides them so they never even make it to his home. Following this there was some discussion between faculty members about whether or not it would be a good idea for Mr. and Mrs. Everett or Mr. Harrison take about five minutes to talk to each child about his grades. Mr. Harrison and Mr. Everett said that they don't have any problems with that, but Mr. Harrison suggests that the responsibility be put on the parents. The report cards should be sent home and the parents have to return something signed saying that they have seen the report card. Mr. Everett also suggested that each teacher could discuss the grades. Any time he gives a grade and the comments may be a little harsh he pulls the student aside and talks to him.

This moment at the faculty meeting is particularly interesting because instead of immediately integrating parents into what the school is trying the accomplish, faculty 
suggest that they step in and do something that usually happens within homes and between students and parents.

Despite faculty perceptions of dysfunction within homes of OS students, parents I interviewed suggested that their children were not experiencing the lifestyles upon which the school is predicated. Joyce, grandmother of a former Oakwood student, stated:

He's not one of the kids that's going to be running the street, playing with the neighborhood kids, up in somebody's house that we don't know. He's not been in a house where there's profanity, and smoking, and drinking. That has not been his childhood. He goes to church every Sunday. He sings in the children's choir. He ushers on the usher's board. He's "yes ma'am" and "no ma'am." He was opening and closing doors for ladies and being a gentleman before he came to Oakwood School. They didn't teach my grandson that. I know they weren't ready for that, but I told them one day. I said, "First of all, he was being taught to be a gentleman before he come here to Oakwood. You all didn't teach him that." I deeply regret sending him. I deeply regret it because I think it haunted him emotionally.

Joyce's description of her grandson mirrors what some to the parents stated and challenged the manner in which faculty constructed student needs. While faculty may be accurate about the challenges that some students, face it is important to recognize that that is not the experience of the entire school body.

\section{PATERNALISM AND PARENTAL EXCLUSION}

The faculty's framing of students' needs and the characterizations of their families demonstrate the logic underlying the boarding school model utilized at the 
school. According to the rhetoric within the school and the school's structure, students need to be pulled away from home because students are not being "properly" raised at home. When asked about the decision to make OS a boarding school, Phil offered,

I think my answer to this was, right, I mean if you talk to John or Judy, they may have a little different shade. My answer is almost any boy, every boy that's come into the OS program at the $6^{\text {th }}$ grade level, middle school level is behind. Behind a year and a half, two years, in district academic testing, behind in development, behind in security, confidence, all the above. I think to get them caught up to receive a full ride scholarship to a private high school in the area, we got to get a lot of work done in three years. Which meant we had to confiscate 'em. We had to take 'em in. And just our curriculum, how it's the morning... when they wake up at 7 , lights are out at a quarter to 10 . They go to school 2 hours longer than any [public school] kid does. Still have mandatory athletics. Still have an hour and forty-five-minutes study hall. Still clean their rooms and latrines. You know, so we just needed all their time and energy. And if they would grip this opportunity right and get on board, anybody graduates from here, does and did receive a full ride to high school. Today we have nine boys in college. Full rides. So now we have turnover, but our turnover ain't near the percentage at [the public schools] Okay. So the model's working.

Phil's role as the board chair positions him in a critical role on the school's administrative team, particularly in shaping the mission and direction of the school. According to Phil, students must be "confiscated" in order to bring them up to grade level. He talks about needing more time in order to achieve their goals, the avenues of which are the extended 
school day and extracurricular activities. These two methods do not require the students to live at the school and thus this is not a full explanation for the choice to board students. Mr. Everett provides a fuller picture of the decision to board students at the school, connecting it to the issue of homelessness. He explained, "A boarding school because we knew that there were a lot of homeless kids and they needed a safe and stable place to live." The responses from Phil and Mr. Everett are both closely intertwined with faculty understanding of students' needs and home lives. These explanations about choosing to develop a boarding school model go back to students being framed as having dysfunctional and unsupportive home lives.

In addition to deeming it necessary to pull students out of their homes to address their educational deficits, several faculty members conceived of their role as parental. Mrs. Everett said:

I just see how God, for my whole life, was training me for this moment, really. My role, anyway, almost all of the guys have a mom. I can't be their mom. I understand that right off, I see what John does and I see his heart and I know how the kids glom onto him. I'm being very honest now, my role isn't to be really their mom. Maybe their grandmother. Except I'm more of a disciplinarian.

Mrs. Everett knows that she cannot be a "mom," however she conceives of her role as parental. In some respects, this is part and parcel of a boarding school, particularly for dorm staff. However, the boarding school model is historically based on a belief that parents were not teaching their children everything they need. Consistent with Mrs. Everett, in discussing students' needs, Mr. Smith, also dorm staff, stated that the young men that attended the school needed a "daddy," "That's what these boys, they just need 
more adults to just be there for them, be a parent they don't have. I think that's the biggest need." Mr. Smith frames the students as not having a father figure at home and that is one of the things that they need from the school. Faculty's understanding of students' needs and the manner in which they conceptualize students' families encourage paternalism. Framing, and imagining, that the sole pathway for students to attend the school is that they come from broken or dysfunctional homes encourages faculty to take on a parental role. The boarding model further encourages positioning faculty in this manner with the students spending a large portion with the faculty and staff and not their families.

OS only encompasses grades six through eight. What then becomes of students when they graduate? Mrs. Avery explained that this has been a question within the school that they have chosen to address. Mrs. Avery explained:

One of the frontiers we're also exploring is when they graduate, when they've been here for three years, and go back to this unstructured situation that they came from, that's a hard road of hell for most of them. This young man went back to his grandmother who was entirely supportive, but he was in a private school, he has no cell phone, he has no computer, he has not internet at his house. You go to school, and live one life, and then you come back, and then you live another life, and there's no way for him to communicate with his peers after school. That's not a normal high school experience, nor a healthy one. He was acting out, and he was angry, and I got that. He did come and stay with us for a couple years, and now is in college. I think it wasn't until the middle of his senior year, that he actually really felt, "Yeah I can go to college." 
Mrs. Avery initially focuses on how limited economic resources impacted this young man's ability to do the school work, but she also ties this to cultural norms of college aspirations. According to her account, it wasn't until being out of his home for several years that he believed that he could go to college. There is an implicit assumption that if he would have remained at his grandmother's home which was supportive he wouldn't have gone to college because college going wasn't a cultural norm in the community.

Despite this general acceptance of parental duties and sense of distrust for the style of parenting going on in the homes there are some faculty who express desires that parents would be more involved:

Mr. Ethan: Why aren't parents doing some of these things? If you need drivers, why aren't parents stepping up like, "Oh yeah, I'll drive my kid to a basketball game." Something like that. Why is... The kids do get a lot. Free food, free clothing, free basketball uniforms, free transportation places, scholarships, promotion to elite high schools whether it might not always be [inaudible 00:23:41] ... We'll get to that later. They get a lot; and free psychological assessment, free psych ed assessment. That's huge. Getting psych social educational assessment, that's expensive and can be amazingly helpful in learning about learning disorders or how to improve your child's educational ... That's awesome, but I feel like it's very often one-sided on the side of the school and I feel like there could be a little more engagement on one side or the other somehow. It's gotta be on both sides, somehow there's gotta be that connection but I think that's really important and just not done enough. 
Jelisa: Ideally, what would parent involvement look like to you?

Mr. Ethan: Volunteer hours, even if it's just like driving kids to a play. You shouldn't have to beg last second like they did today for like, "Oh, all of a sudden we need a driver." No just have that lined up with the parents. It's pretty simple. Chaperoning time here if there's a faculty meeting. Instead of having to leave a faculty member out, you could have everyone there and just have a parent watch the lunch for an hour. Helping with putting together [stupid things 00:25:22], I don't know, promoting the school. Stuff like that. If I feel like this school's a great value, be up there saying like ... Getting donations, or spreading the word, or ... Educating community on what the school's all about. Just stuff like that I think would be huge.

Jelisa: Probably help build some trust, too.

Mr. Ethan: Absolutely, and also it'd take a lot of pressure off the staff to be the disciplinarians.

Jelisa: Because then it's not just the parents finding out about it at the end of the year.

Mr. Ethan: At the end of the year or something like that. Like, "Oh crap mom's here. I got to keep it together today

Mr. Ethan, believes that parents should be more involved. He outlines avenues for involvement: driving to activities, chaperoning during faculty meeting, promoting the school, and fundraising. His assessment about parental involvement misses several key 
factors. First, he ignores that parents are promoting the school, as evidence by the fact that many of the applicants learn about the school through parents of students attending OS. Secondly, expecting parents to engage in fundraising ignores the fact that parents may lack the social and cultural capital necessarily to bring in donations. Finally, observations and interviews from parents suggest that parental involvement may be lacking, not due to a desire or willingness on the part of parents, however it is not well supported or received.

The barriers to parental involvement was demonstrated first, by a failure of school actors to communicate with parents, which was an issue for all parents interviewed. Secondly, help was not accepted and parents who wanted to be involved faced roadblocks, and finally parents are explicitly asked not to be present in the school. Each parent discussed a lack of communication in their interviews. For some parents this was understandable because of the limited staff, but for others this presented a bigger problem. Ashley, a mother of an Oakwood alum, stated:

There were some communication issues, and I don't think it was intentional. I think it was just more growing pains for them as far as learning how to evolve and do things differently and be in contact with the parents because it was like the kids were totally cut off. I think they did some things ... it was more like basketball schedules and things, just a simple, "Where y'all having the game at? I'm trying to find y'all," at the day of the game. Nobody answered the phone and try to do GPS, and that type of stuff. 
While Ashley was understanding of the communication issues and deemed them unintentional she acknowledges that the students at Oakwood are cut off and it was difficult for her to be involved because of the ineffective communication. Patricia, a surrogate mother of an Oakwood alum, initially said that the school had open lines of communication, “They're very communicative. If there's issues they call me. If I have issues I call them. It's all good.” However, when I probed relaying what I heard from other parents she stated:

Yes, that's true. Now that you say that, there was a lot of times where things were last minute. You're like, "Wait a minute, you need to plan a little more ahead of time." That's a good point that I'd forgotten about that, yes. There weren't as many people working there back then. You can't expect the Everetts to keep up with everything on top of the kids.

Patricia and Ashley were both very understanding about the communication issues they experienced at the school. For them, finding out about a basketball game at the last minute was simply a minor annoyance. However, when a lack of communication means that you don't know about the trouble your child is experiencing until he is expelled, as in the case of Tonisha, it is more serious. Furthermore, choosing not to make time to inform parents sends a message of disregard. When discussing her issues with communication with the school Tonisha, mother of two Oakwood parents, stated:

I didn't know there was things going on over there with my son that I had not a clue about until it came time for him to be expelled. As much as I'm over here in you all's face, and wanting to know what's going on with him, and you all tell me 
he's doing so good, and he done passed these tests that he's doing that, but when I get his report card, I got straight F's and D's. I got a problem with that. Or he was doing something and you didn't tell me, but you wait until you ready to expel him to tell me oh and by the way. Okay, well why didn't you call and tell me that while that was going on so I could've came up right then and there, and we could have took care of this. You waited until he's expelled and you putting him out of the school. Now I'm finding out about it.

Tonisha describes herself as a regular presence in the school, however she still felt excluded from important information about her son and ultimately denied the opportunity to intervene in a manner that may have kept her son in the school. Rather than engage parents and allow them to be part of disciplinary efforts they are excluded until a serious problem arises, or in this case when it is too late.

Tonisha's experiences along the faculty conversation about discussing grades with students indicate that the school does not welcome parental involvement, which is something that Stephanie explicitly said:

So it's like, then they talk about, well they want more of the parents to step up. But they don't really. They stay that just to be saying that, but they really don't. Because every time you offer other than, yeah you can go help in the kitchen. You can bring some food. But in the office, they don't want no help. Naw, they...girl ask...okay 6th grade, 6th and 7th grade I was very active, because I wasn't working. So it gave me a lot more time. Well 6th grade I was working but I had flexibility. So I had lot more time to be involved. I told Mrs. Everett on 
numerous occasions. I told [office staff] anytime you need something call me. I can fax do whatever, you know what I'm saying. Copy. Whatever you need me to do. Sit in the office, while y'all do whatever. I'm willing to help.

The acceptable role for parents is limited to bringing food or working in the kitchen. They are not partners in teaching or raising these young men. In fact, they are something to be controlled, which is demonstrated by Marilyn's attempt to visit her son during his first months in the school when he was experiencing homesickness. She recounted:

He would call me crying, I'm crying. Mr. Everett is like, "Please don't call again." When I went in, I said, "Okay. I'm going to come have lunch and dinner with him every day." They were like, "Mrs. James, you can't come for two months." I went in wanting to see him every day. He just cut up, cry, cry, cry and then told me, "Okay, you can come have lunch with him." I went and had lunch with him. We both crying. He fell out on the floor. So then they told me you can't come back for a while. We thought the visit would help but it hasn't...

Jelisa: How many consecutive days did you come before they said, "Okay, you gotta...

Marilyn: They nipped it right when I registered when I told them I was coming every day. They cut me off. "Uh-uh, Mrs. James, you can't come." They said for two months. I said, "Huh?" I'm thinking, two months? I said okay, I'll fix them. I'm gonna get on the PTA. I would go over and talk to Ms. Tina and I would say, "Go get him for me." And she's all, "I'm not going to get in trouble for you, Mrs. James." You know? If I have friends and they would drive by and they see him 
outside, they gloating and then they'll call and say, "He's okay. I just seen him outside playing." You know, stuff like that. So things like that help. I didn't miss any ball games. Every chance I had, I was at the school. It just makes me wonder how come all parents aren't there? I guess I'm an older parent, so I look at it different.

The request for Marilyn not to visit her son at the school is framed as letting him get adjusted to the school, but when the other parental experiences are taken into account it appears that telling Marilyn not to visit was related to a lack of trust for parents and their subsequent exclusion.

\section{CONCLUSION}

OS is located within a marginalized community, characterized by high poverty, high unemployment, and racial segregation. Oakwood fits within the narrative of the "iconic ghetto" in the eyes of outsiders, who often times shy newcomers away. OS capitalizes on the positioning of the school within a marginalized community and positions itself to be a source for White contact for the area and an avenue for challenging stereotypes. If anyone wants to be involved with OS they must come to the Oakwood community. This ancillary mission of the school, to challenge the narrative of the Oakwood community, centers Whiteness. The thing that makes crossing the "Berlin Wall of Main Street" is the work of White people. Additionally, these efforts position students as individuals who are transcending the negative aspects of the community. Thus, while faculty members, believe that the perceptions of individuals coming to OS are changed, it is highly likely that they will believe that OS students are outliers. Mr. Everett, despite years of working in the community had a limited understanding of the 
community and Phil, when discussing community members centered on drug dealers and criminals.

The role of the iconic ghetto is further highlighted by faculty framing of student needs, while academic, social, and cultural needs are all discussed, social and cultural needs play a central role in the framing of students. Parents are deeply implicated in this understanding of students. Several faculty members suggested that students hailed from single family homes. A consistent theme is that parents are not doing their jobs in socializing their children. OS is premised on the notion that inadequate socialization impedes academic pursuits, logic follows that addressing/re-socializing students will play a significant factor in ameliorating academic deficits; there is an implicit belief within the school that students just need to be taught better. However, not all students attending OS fit within this framing and parents argued that they the children already had many of the attributes that OS professes to instill. 


\section{CHAPTER VI: SCHOOLING BY WHITENESS, SCHOOLING FOR WHITENESS: WHITE RACIAL FRAMING AND COLORBLIND IDEOLOGY AT OS}

The U.S. is a racialized social system, meaning that it is a society in which economic, political, social, and ideological levels are structured by the placement of actors in racial categories (Bonilla-Silva 1997). Racialized systems are subject to change, however the hierarchal structuring of actors in racial categories remains. We have transitioned from a social system centered around slavery, to Jim Crow, to mass incarceration (Alexander 2010). In each of these systems Whites have utilized a racial ideology to justify racial inequality. During slavery African Americans' supposed lack of humanity was used to justify the brutal treatment of slaves. Contemporary racial inequality in the US is justified by a colorblind racial ideology, which explains racial inequality with non-racial factors (Bonilla-Silva 2014). Relatedly, White racial frames have been used to interpret and defend White privileges and advantages as meritorious (Feagin 2013).

OS, in large part due to the racial demographics of the school, operates within a White racial frame. First, as demonstrated in the previous chapter, OS is based on assumptions about what Black males need because of the community they live in; race, class, and gender informed the opening and operating of OS. Additionally, this White racial framing and the construction of students within the Black male crisis discourse 
encourages a White savior identity for many adults working within the school. Secondly, White racial framing and the concomitant White identity constructs allow faculty to engage in a variety of strategies which allow them to avoid discussions about race and also trivialize the impact that race has on their students' lives and the operating of the school. Finally, White racial framing involves White innocence from racism and relatedly the construction of race as a non-White issue. In this chapter I explore how White racial framing operate within OS and are situated within the dominant racial ideology of colorblindness.

\section{WHITE SAVIORS AND THE "SAVING” OF BLACK BOYS}

The construction of students and their families as problematic puts OS in the position to "save" students from their families, communities, and poor cultural upbringing. The Black male crisis narrative, which many single-sex schools draw on, encourages individuals to think of themselves as "saving" Black males from themselves and their communities. Specifically, the Black male crisis narrative and deficit framing of students and their parents provides an ideological basis for the mission of OS. Many of the faculty, staff, and volunteers undertake their work at OS under the auspices of saving boys. For example, Mr. Harrison realized that he began teaching due to a "liberal guilt" and analyzed the inherent problems of liberal guilt as a driving force for educators:

Anyway, I got the job at [a local all-boys school] and then I can't count the number of little epiphanies that I had along the way. That initial motivation that I had, I realize that even that was this kind of liberal guilt. That's not helping anybody either, because I started seeing that in droves, all over the place. White teachers who think they can come into Oakwood and do something. That in and 
of itself is big, this idea that "Oh well, those poor Black people in Oakwood, they need us to help them pull their bootstraps up," and that kind of thing.

Mr. Harrison demonstrates the manner in which a White liberal guilt is rampant in the field of urban teaching and encourages a White savior complex. The White liberal guilt that Mr. Harrison describes is similar to liberal ideology, which Zamudio et al. (2010) define as an ideology that equates political rights with social equality without interrogating the ways that race and racism play out in contemporary society to produce inequality. Mr. Harrison realizes that "liberal guilt" was a driving force behind his pursuit of a teaching career. Additionally, he understands these feelings as common amongst teachers working in marginalized communities. Finally, he defines this type of impetus for teaching as ineffective. Mr. Harrison went on to add:

The whole school in general, it's ... Hmm. The whole school seems to me predicated on the fact that we have students that are Black. That ends up, you end up with faculty members who come here for, almost like that liberal guilt thing. You have teachers that show up because it's a school with a lot of Black kids who when they go home and they talk to their friends and family, they talk in real serious tones about it and they're like, "Yeah, I work with those poor, poor children." A lot of the donors of this school and a lot of the people on the board, there's this pity that seems to kind of be underlying some of the things. That's really bothersome. It seems to be a necessary evil right now, like to get into some people's pocketbooks. It's like, "Sure, you're kind of an ignorant old person but you're also really wealthy and you're giving us money to actually help the kids. So we'll put up with your misguided views on certain things." 
I'm not sure how the school moves away from that. I'm not sure if the school moves away from that. That seems to be more of a racial construct in society as whole that we're kind of playing off of to help the school. There is ... Can you ask the question again?

Beyond that undercurrent we hardly ever talk about it. We don't talk about the fact that it's mostly White teachers teaching mostly Black kids. That doesn't come up. Race is not an issue that we talk about that often. You get some of the superficial ways in some of the classes. In social studies and reading/writing workshop, they'll read about Selma or they'll do a presentation on the civil rights movements. There's that very superficial, "Let's talk about that." There's not a lot of rich discussion about what does it mean to be a Black man in society. We'll have mentors come in and talk about that but they're not people who are here a lot, who have the kids trust, who've built a relationship with the kids. Mr. Jesse, he focuses more on the Bible and wisdom and some of that stuff but, again, doesn't talk about the experience of a Black man in society.

I think we don't do enough looking at our refugee kids, they have a really rich experience background that never comes up. The attitude seems to be, "Let's ignore race while we're here so you can focus on your school work." To a certain extent, I get that. These are issues the kids are going to have when they get to high school. We're not necessarily doing them any favors by not talking about it.

There are little issues that will pop up discipline wise and behavior wise that come about because of it. You get Merci feeling like an outcast because the other kids 
don't talk to him because he's darker and he's African. How do we have that real conversation with the kids? [students] being mixed and being light colored gets them ostracized sometimes. How do we talk about how ridiculous it is that we judge people by the shades of skin color? We don't have those real conversations. Instead it's, "Oh, you're talking about race. Consequence. Let's move on and do something else." It's not ... Race isn't really dealt with for what it seems like we are.

It's been successful so far just in so far as there haven't been any real issues where a kid's felt like their race has been a huge issue. There hasn't been an issue where there's just blatant racism on the part of one of the White teachers. The racism ends up taking more of what I would say an insidious form of that kind of pity kind of thing. Teacher, "Oh well, he's from a really rough background, he doesn't know any better." It's like, "No, he knows better. Come on, Jesus." It's not talked about directly but I think there are little toxic elements that are underlying things that we tend to brush under the carpet versus actually do anything to encounter or engage in a real way. I don't know, that's a lot to unpack I guess.

In the above comments Mr. Harrison hits on many of the themes explored in this chapter. Individuals adhering to a liberal ideology may emphasize hard work and ignore critical structural factors that shape educational inequality. Additionally, this liberal ideology draws on deficit narratives which emphasizes cultural factors. Teachers who come into communities believing they can save their students by teaching them how to work harder are poised to fail for two primary reasons. First, because it is a false assumption that students aren't working hard, and, secondly, because they will ignore other factors at play. 
Finally, such teachers may alienate students by ignoring their efforts and denigrating their community (or even families).

While Mr. Harrison provides a critical analysis of White liberal guilt and the concomitant White savior complex that exists in the field of urban education, evidence suggests that OS, in its quest for funding and volunteers, attracts individuals with a White savior identity. OS is able to provide a cost-free private education through "philanthropy and the generosity of the community" (Mr. Everett). Many of the first teachers at OS were volunteers, lunch is provided through donations, and majority of the office staff are volunteers. Language surrounding mission-driven work appears across several interviews. When describing faculty and staff at the school, Mr. Everett stated:

They have to be mission-driven people. I say in the interview process every year that if you're looking for a job, you've come to the wrong place. This is not a job. You're going to give up salary. You're going to give up ... we try to make benefits comparable or better. You're certainly going to give up salary; you're going to have long hours here. You're not going to get the pat on the back or the title or the office or the parking space that you might get somewhere else. It's about the kids and if you want to come and get your arms around the mission of the school, which is to take kids who under other circumstances would not live purposeful lives given that handout and opportunity, come. Other than that, go find a job somewhere else. It's just that simple. The answer is that there are a lot of mission driven people in this world. Talk to [lower school admin].

According to Mr. Everett working at OS is not just a job; he repeatedly uses the phrase "mission" to describe the work of the school and its employees. Furthermore, his 
language suggests that OS is marketed to volunteers and donors in the same fashion that one might market a mission trip to a third world country. Specifically, he frames students as fated for a life lacking purpose and productivity without the intervention of this White institution and White actors. Additionally, Mr. Everett stated:

The other side of it is, I say this all the time, this is an act of faith, literally an act of faith. It's an act of faith in the Providential and it's an act of faith in the generosity of the community. The thing that I think is important to remember, even if it bellied up today, if it ended today, you would still be able to say for the period of time it was here, it made a difference in the lives of those kids who were here. You don't get to say that about tomorrow. Tomorrow is tomorrow. You get to say that about today and that's the best you can do.

Here, Mr. Everett draws on Christian ethos which influences and justifies his personal work. This same Christian ethos is embedded in OS and provides validation for the work being done there. Similarly, Phil stated:

This dives back into your question about the word mission. How it was created and how it was first brought to the forefront is John and Judy Everett in their very unselfish way wanted to do something, give something back and they chose this as the mission to do it. Okay? Then and that was the beginning. Okay they hit the start button. But they couldn't be this far, just two people can't carry this on their back. This isn't Noah's Ark, right. So they had to get the village behind them. Well it starts with one. Goes to five. Goes to 10 on to a 1,000 . I think 
there's...somebody told me the other day there's 3,000 volunteers that's been through this place.

Phil reasserted the importance the mission aspect of OS. The mission is embedded in the origin of the school and it is also used to attract volunteers. Phil further described the work of educating low-income boys in a marginalized community as a "mission" and established it as something warranting the support of the community. Across comments from Phil and Mr. Everett a common theme is the desire to give back, especially to those less well off.

Mrs. Ferguson supported the accounts of Phil and Mr. Everrett as she also described how people, including herself, are attracted to the school:

The mission of the school. The opportunity to help these boys change kind of the statistical trajectory that they seem to be on...That's good. I'd say, like I said what drew me was the mission, I think the mission is strong. I think it is. I think we stay to the mission, which is good. It's challenging, but the boys are challenging. In stating that OS provided an opportunity to help "change the statistical trajectory" of the boys suggests that the White savior mission upon which the school rests draws on both deficit and crisis narratives about Black boys. The Black male crisis narrative is often used to leverage funding. OS depends on wealthy donors willing to contribute funds to support the mission of the school and many of those donors (and volunteers) 
believe that the students at OS are underprivileged, lacking resources and character, and in need saving.

\section{WHITE IDENTITY AND THE AVOIDANCE OF RACE}

Despite OS being premised on the juxtaposition of privileged White adults and disadvantaged Black youth, race as it pertains to students' experiences and perceptions is largely ignored. However the racial identities of White faculty members is examined and acknowledged within and across the school. According to Lewis (2003), racial identity affects schooling experiences in multiple ways. It affects how students experience school and it also affects what teachers and administrators bring into the classroom. Racial identity also plays a role in how individuals think about race, engage in conversations about race, and undertake anti-racist actions. At OS, faculty reflect on their personal racial identities but are less likely to engage in discussions about race or take actions that challenge White supremacy. In a school premised on racial and socio-economic inequality, an inability or unwillingness to discuss or act on issues related to race limits the work that the faculty and school can do.

OS, as a result of being in a racially segregated community, provided opportunities for faculty to reflect on their racial identities. However, several faculty, as a result of their previous work in marginalized communities, began to think about their racial identity before working at OS. Whether they began thinking about race before or after being employed by OS, they generally engaged in thought processes which allowed them to avoid the true implications of race in students' lives. For example, Mr. Miller stated: 
How often do I think about it? There was a transformational educational experience I had in graduate school, maybe all in any kind of my higher educations. My two multicultural psych classes, because I was forced to do a lot of self-exploration in understanding my place in American culture, understanding how ... I do have conscious or unconscious bias constantly. It's not necessarily my fault but it's socialized into me. At the same time, it's persistent and I have to deal with it. I have to be mindful, I have to be aware of it and work on it.

Mr. Miller expresses a racial awareness and consciousness that preceded his work at OS, however he also engages in a discursive strategy of distancing racism. Although he is aware of potential bias he may hold, he makes a concerted effort to place the blame elsewhere. Mrs. Ferguson distanced herself from racism in a similar fashion, stating:

He [a former student] would say in US history, we would talk about the South and plantations and, "Why did y'all treat us that way?" He'd say, looking at me, "Why did y'all?" And I'd say, "First of all, I was born in Canada. And I was born in 1967. We're talking about 200 years ago." But he would just personalize it. It's like, how to help him take the historical knowledge - again, this is all the stuff that's happening on the college campuses - how do you take that historical knowledge and not let it drag you down, but move forward? I'd love to have the magic bullet and help these kids with these conversations, because I think that they're really important conversations that are being had all around at the college level that when they're in jobs, it's never going to stop. What's your answer? Do you have an answer to that? 
Mrs. Ferguson prioritizes her need to distance herself from racism, pointing to her nationality and age before allowing a student to engage in a conversation and potentially gain understanding about racism in the U.S. This discursive move may be related to her unsurety about how to help the student process his reaction to learning about slavery without getting “dragged down.” Mrs. Ferguson’s pedagogical approach to teaching about and discussing racism is stifled by fear. First, she expresses a fear of being labelled racist and secondly, she expresses a fear regarding how students will understand and process the history of racism. Approaching teaching about racism with a fear limits the possibilities of scrutinizing the harsh realities of racism. Thus, while Mrs. Ferguson values conversations about race that are happening on college campus, her reaction to such a conservation in a middle school class is not conducive to creating dialogue or understanding. Furthermore, the distancing strategy utilized by Mr. Miller and Mrs. Ferguson constructs issues of race and racism as other people's problems as evidenced by Mrs. Ferguson asking me, a Black woman, "What's your answer?" When issues of race and racism are defined as other people's problems, individuals can rationalize their inactivity as logical because of their limited role. Thus, faculty can work in a school such as OS and focus on academics or building character and never address the racism that disadvantages their students because it's not their problems nor are they in the position to fix it.

Mr. Harrison also began thinking about his racial identity before beginning to work in the school. He recounted an experience following his first interview for a local public school: 
This lady, as we were walking out, it was just she and I. She said, "Look, you're a White boy from Northridge. You're never going to be a teacher here." For the first time in my life, it was like who I was ... All the things that I'd been able to do in school: The grades that I'd had, the scholarships that I'd gotten, all the clubs and activities and things that I was able to excel in, it was like none of that mattered because of my skin color, who I was, and where I was from. I was so unbelievably frustrated. Not necessarily because I wanted that job so much. It was just that feeling that things were outside of my control and affected my chance of getting a job. That really shook the spoiled, White college kid in me. All of a sudden, it's like this is the most minuscule taste of what so many people in this world go through on a daily basis. Then it became even more important to me to prove her wrong. If I could prove her wrong, then maybe, in some way, I could make up for the way I was raised and this fact that I had been, for so many years, the recipient of this great privilege, I guess, that had nothing to do with things that I'd accomplished, but just who I was, where I was born, and that kind of stuff.

This experience led Mr. Harrison not only to think about his racial identity, but also to reflect on the amount and type of privilege that he garnered as a result of his race and social class. As a result of this experience, he began his teaching career in marginalized communities as a way of proving this individual wrong. In many ways his response to recognizing his racial privilege was self-serving and centered on White fragility.

Contrary to the experiences of Mr. Harrison and Mr. Miller, Mrs. Avery, did not begin reflecting on her racial identity until later in life. She stated: 
I think I think of it more now than I ever used to, because I grew up in a White world. I'm 60 years old, so when I was ... I grew up in Boston, I went to Catholic school, Irish Catholic, so there were only Irish Catholics that I knew, and then once I got married I lived in Connecticut, and in a very White environment. I never thought about it then because there was nothing to think about. That's [inaudible 00:52:43]. Coming here, again, I didn't really consider it. This was a great personal opportunity for me to continue to teach, and I really enjoy that, and I am sure that if I hadn't come to this school, I would have not ... My husband would have been in [the city] for 4 years, and I would have been here for a year, and I would have gone back to the Northeast where my family is, and he could have commuted. I never really considered it as a race thing.

Coming into the school Mrs. Avery did not take race into account across her previous experiences, due in large part to living in White spaces her entire life. Mrs. Avery's life experiences allowed her to normalize White privilege. Encountering a majority Black population has spurred her to reflect on her racial identity more than ever. Mrs. Avery's normalization of Whiteness means that when she began her work at OS she was not prepared to understand or deal with how race affected the lives of her students. Mrs. Avery's avoidance of race stems from her normalizing Whiteness.

All of the teachers quoted above confessed to thinking about their racial identities, especially with regard to their work at OS or in seminal experience prior to joining the staff, such as Mr. Miller's narrative. However, thinking about racial identity does not translate into meaningful conversations, interactions, and teaching about race in the classroom. This is due, in large part, to how these reflections on racial identity were 
focused on a very personalized, individual level and also centered Whiteness. Both Mr. Miller and Mrs. Ferguson distanced themselves from racism, Mr. Harrison expressed White fragility, and Mrs. Avery normalized Whiteness. None of these strategies are conducive to understanding how students experience race and racism nor are they useful in taking mindful steps to work towards change.

POSTER, FOODS, AND FESTIVAL: A SUPERFICIAL ACKNOWLEDGEMENT OF RACE

While some faculty members avoid discussions about race and racism others acknowledge it on a superficial level. According to Ladson-Billings and Tate (1995) many schools rely on ethnic foods, cultural artifacts, and/or dances as a way of focusing on the students' racial and ethnic identities. In many instances as faculty responded to questions on how they recognized students' cultural backgrounds they expressed activities that were in line with a poster, food, and festivals strategy. For example, Mrs. Nash, who serves as both the French teacher and the grant writer for the school, talks about the way that she personally focuses on the students' culture. One thing she does is a project on Francophone Africa, but beyond that she recognizes that the school is limited.

I would say in terms of curriculum I integrate a lot. In terms of the school, well, you heard me bring it up. I think it's a hard thing to talk about, for us to talk about. I think there is an awareness that there are White teachers here and the administration and the leaders are White. Luckily that's changing. I think that there's a real effort to make that change now. My humble opinion is that we need to find ways to be open with each other about it and find a way to talk about it. 
Mrs. Nash realizes that beyond acknowledging the racial demographics at OS the school is limited in engaging in conversations about race. This contradiction of race consciousness and race blindness described as a facet of the school by Mrs. Nash is similar to the contradiction expressed by individual faculty members who thought about their racial identities but avoided discussions of race. The combination of a predominately White staff and a predominately Black student population, and the challenges that that posed, was often an elephant in the room - it was acknowledged in varying ways but never acted upon.

In failing to acknowledge the significance of the racial dynamics of OS, faculty also failed to successfully affirm students' cultural backgrounds. Mr. Ethan provides a critical analysis about the manner in which race is integrated into the school.

So we have the posters on the wall of Muhammad Ali or the Little Rock Nine... Or, you know, a lot of the other civil rights big moments. That's on the wall everywhere but I don't know how much of that is integrated or how much of that just kind of blends in the background after a while. I think there's an increasing awareness in it, I hope, in trying to understand and deal with it.

Doing a project on Francophone Africa may, in many ways, be similar to simply having posters on the wall. These types of projects tend to focus on "big moments" or are singular occurrences. As such, they could appear superficial and repetitive to students, and thus fade in the background as Mr. Ethan fears. Additionally, "big moments" are often situated in the past and not immediately connected to students' lived experiences nor do they attend to the racial divides that exist in the school and broader society. 
African American and low-income students are often underserved because of different forms of subtle and insidious racism, rooted in the past, one of which is a devaluing of students' culture. Given that OS exists to serve marginalized populations that have not been served in traditional educational settings, a focus on "big moments" or singular projects that may fade into the background does not affirm students' cultural backgrounds or address the causes for educational inequality. This "helicopter view" reproduces static teaching that can disengage and disempower youth, especially young Black males. Mr. Ethan also reaffirms Mrs. Nash's assertion that conversations about race are limited but there is an increasing awareness about the challenges that the racial dynamic of the school poses.

In addition to superficially acknowledging race, "race work" becomes the work of Black teachers. A quote from the math teacher, Mr. Smith, highlights the relationship between a superficial acknowledgement of race and the assignment of race work to Black faculty:

I guess through them posters that's about it, the posters that be on the wall, that lets you know that they Black, other than that never. From what I've seen, I'd like to use that as a side bar, from what I've seen that's the only way. They ain't teaching them how to be Black men, but like I said earlier it's hard to teach you how to be a Black man if you ain't never been Black. That's not a knock to just anybody, but I think when you're trying to prepare a Black man how to be a Black man, you have to have a Black man somewhere in the equation teaching how to be a Black man. I think as far as race, [they use] those posters because none of them know. They didn't know who Booker T. Washington was, not one student 
knew who Booker T. Washington was. I brought up some Black movies, I'm talking about historical like Red Tails, they ain't never seen it. Yeah, that's about it, I think the posters, that's the only way they get them ready.

Mr. Smith both criticizes the use of posters and the limited curriculum addressing Black history and provides an analysis to why this occurs. Furthermore, he reaffirms the need for Black male involvement by taking the stance that Black men must teach Black menespecially so that they can learn about their identities as Black males. According to Mr. Smith, Black history is not taught because there are few Black teachers available to teach it. Put another way, he views teaching race as the responsibility of Black people. The failure to teach Black history is deemed by Mr. Smith a failure to get students "ready" for the world they will experience as Black men.

This line of thinking exists amongst White teachers as well and ties back to a tendency to treat race as a "problem" for Blacks. Following this logic, Black people should be the ones to deal with race and they are also positioned as being responsible for teaching White faculty members about issues of race. Mrs. Avery stated, "A, they're men, B, they're African American, I've never been either. It's really hard to ... I try to just reflect back what they're saying to me, so that they can hear it. I don't know what else to do.” Mrs. Avery places a great distance between herself and students because of race and gender. In many ways she is stymied by her identity as a White woman because she had never seriously considered race before working at OS and also because issues of race are constructed as a Black problem. 
As White teachers actively avoid or superficially acknowledge race, "race work" is consigned to Black faculty members. During a faculty meeting, DeVante, a student who had been on the brink of expulsion several times throughout the semester, is discussed and "race work" was cosigned to Mr. Smith:

Field Notes: 11/4/15

Faculty Meeting

John started the conversations by saying that he has no justification for why he is still there. He's had many chances; others have been expelled for much less. Most recently there was some kind of incident where he lied about having money and where he got it from. Faculty seemed divided on what they wanted to do and Mrs. Avery put Mr. Smith on the spot. She asked what he has to say. He said that he hasn't known DeVante as long as everyone else so he can't say... he offers that he has connected with him and he has shared things with him. He relayed that DeVante was frustrated because they didn't ask him why he lied about where he got the money. He also said that they tried to take him away from his mother and that they always think that he is guilty. Furthermore, his mother sends very different messages than he gets in school. Faculty members praised him for pulling it together at the basketball game and not lashing out, and his mother wanted to know why he didn't lash out. During the discussion, Judy mentions that she had talked to DeVante's mom and she was getting off work at 4pm and would come to the school to discuss DeVante. It was decided that it would be best to have Mr. Smith talk to her because he had connected with DeVante. There was some push back against this, a couple of people, specifically Mr. Travis and 
Mr. Harrison, wanted to know what would be said that's different from what has been said in the past. John said let's be clear what we're dealing with here is a Black/White issue. Mr. Smith assured them it would likely be the same thing, but it's different coming from a Black man - especially a Black man who grew up in the same circumstances. He knows what it's like and knows that there are two paths that one could take.

In this faculty meeting we see how issues of race become framed as issues for Black faculty members. Mrs. Avery put Mr. Smith on the spot to speak up about this issue, perhaps because she recognized that Mr. Smith and DeVante had a close relationship. Alternatively, she viewed issues of race as the responsibility of Black faculty members and wanted to hear "the Black" perspective. Mr. Smith, as a Black man, was positioned as an expert on matters pertaining to Black males. Also in this exchange we see that despite race being a "Black responsibility" Mr. Smith's authority is challenged. In this way Blackness is marginalized, both in terms of the additional labor Mr. Smith must undertake and the efforts he must make to show himself as qualified to do such.

Mr. Miller also recounted this experience in his interview stating, "I know that when we had that issue with the eighth grader, when we got Mr. Smith, one of our few African-American staff members, when we got him to speak to the student's mother, it was a lot more effective than when-you were in that meeting." In this instance race is essentialized by both Black and White faculty members, thus Mr. Smith is positioned as someone who can "handle" this issue because of his identity as a Black male. Additionally, his race-gender identity has allowed him to connect with students in a manner not achieved by other faculty members. The presence of Mr. Smith and the 
relationships he built in the short time he worked at OS highlight how race-relations between faculty are strained.

When race is constructed as a Black issue then Black faculty members are put in a position of educating White faculty members. Mr. Ethan, a part time school psychologist articulates what this looks like. The counseling department consists of three staff members, including two White men who work part time in the middle school and a Black woman who works full time in the elementary school. While the schools generally function as two separate entities (i.e., elementary school and middle school) the counseling department works closely together across both units. Counseling staff have weekly meetings where they plan and strategize for counseling efforts. For Mr. Ethan, these meetings are very informative to his understanding of how Whiteness shapes the school and his personal understanding of race. He recounted:

That's tough because it is so run by White people. Everyone in the position of authority, to a certain degree, strong authority or in a leadership position is White. Besides Jamie who's been frigging amazing and I'm so glad that Mr. Travis and I are with her because she's been just amazing teaching me and Mr. Travis today about like, "Oh yeah these board members? Full of shit." So, you know, gaining education.

Mr. Ethan highlighted that White leadership causes issues of race to go unaddressed. The fact that everyone in a position of power is White should not mean that issues of race should go unaddressed, but that is the case at OS except in the rare instance where a Black faculty member steps in. In the counseling department Jamie becomes a voice 
emphasizing issues of race and when issues arose about DeVante, Mr. Smith intervened and had a discussion with his parents. In the instance that Mr. Ethan references, Jamie is put in the position to educate White faculty members about race. And in the case with Mr. Smith, he is put in the position to be a racial spokesperson and intervene on behalf of the school with a parent.

The ghettoization of race, the process by which "race-work" is cosigned to Black faculty, happens in this school because, as Mr. Ethan discussed the school leadership is White, but also because White faculty members feel ill-equipped to talk about race. Mrs. Avery highlighted this disconnect as she discussed how she affirms students' cultural backgrounds:

Again, I try to teach a curriculum that will certainly engender conversation, and by the time they're in the 8th grade, I do the Little Rock 9, I do "To Kill a Mockingbird." I don't know what to teach them. What I try to say is that you have to hold up your head and do what you think is right, and that's a school philosophy. That will not always keep them safe, and that's heartbreaking, but there's nothing else you can say. Past that I don't know what to tell them. If you're secure in what you're doing...

Mrs. Avery confesses to not knowing what to teach the students and uses the school philosophy to rationalize and focus on character development even though she knows that will not keep her students safe. Mrs. Avery has not thought seriously about race for most of her life and now being in a school serving majority African American students she is 
limited in what she can offer, particularly considering she explicitly claims an inability to teach about race and racism.

\section{COLORBLIND DISCOURSE AND THE MINIMIZATION OF RACE}

In the previous section, I demonstrate that despite individual teachers being conscientious about their racial identities they do not take on the responsibility of addressing issues of race-or even engaging in conversations and teaching. In this section, I demonstrate that being attentive to race and recognizing racial differences is not mutually exclusive with adhering to a colorblind ideology. In fact, the overall school culture at OS is one that encourages colorblind ideology and further legitimizes the notion that race is a Black issue.

According to the school's literature, OS targets "low-income young men who benefit from a safe, structured, environment in which high expectations for academic excellence and evidence of character are paramount." Similarly, the mission of OS is to provide a safe and structured environment for boys in grades Pre-Kindergarten through 8th grade in which academic rigor, character development, and responsible action help establish the foundation for a purposeful life. Finally, the philosophy of the school states:

Oakwood School is a free, private, college prep-elementary and middle school for at-risk young men. Admission is open to boys who are on free or reduced lunch, are capable of doing academic work at grade level or above and who would benefit from a safe environment and high expectations. Oakwood School strives to address the issues boys in our community face by creating for its students an environment of high expectations not dependent on culture at large. Through the 
school's rigorous academic and personal standards, we encourage our students to attain the highest possible level of scholarship, intellectual growth and responsibility and character (OS Self-Study 2015).

All of this school literature suggests that race is not a significant factor in school; rather, social class is presented as the most salient factor in the lives of the boys whom the school serves. However, race and class are difficult to disentangle particularly in a neighborhood such as Oakwood where $80 \%$ of the population is Black. A similar racial distribution exists within the OS student population; approximately $90 \%$ of the students are African American. The issues that the school professes to address are shaped by the segregated communities in which many of the students live in. Furthermore, as discussed throughout the previous chapter, the assumption that the boys face low expectations and are in need of character development is based on an assumption of what life is like for a Black male.

The decision to select the Oakwood community as the location and namesake for the school signals that the school is a Black school. Mr. Travis acknowledged the perception the name of the school creates by stating, "I would say that having the school here in the neighborhood is, it was an all-Black school before." He went on to offer:

I think it's becoming diversified. It's not as identified just with Black children but also with really anybody who's in the neighborhood or [city] who could benefit from this place. I don't think that John and Judy ever intended it just to be a Black school. I think that they found it based on what they observed and what they knew 
about children living in [the city] who are poor. That's what they founded it on, what their chances were.

Despite the school becoming diversified a disproportionate number of African Americans are low-income and live within the Oakwood community, thus it is highly likely that many within the city still perceive the school as a Black school. Social class is racialized and thus the name, location, and mission of the school operate as coded language indicating that OS is indeed a Black school. Furthermore, the students' life chances are shaped by their race, class, and gender.

Coded language is used throughout the mission and philosophy of the school which further supports the assumption that OS is a Black school. The intentions of Mr. and Mrs. Everett do not exist in a vacuum and are shaped and perceived by others who recognize and interpret this coded language. The observation and desire for colorblindness expressed by Mr. Travis appeared in interviews with other faculty members as well. For instance, Mrs. Avery corroborated that OS was not intended to be a Black school and race is largely ignored. She described:

Race. It's kind of interesting because as James points out, by percentage, we are probably one of the more diverse schools in Oakwood. Which I hadn't thought about, but we are. I don't know that they think about it too much.

Similarly, Mr. Miller stated:

I think that we try to be culturally sensitive as much as possible, but only being here a few months, it's hard for me to really see more than that. Frankly, at the end of the day, I don't think too many people focus on it. At least I don't, maybe 
the kids do more than I pick up on, but to me, these are just kids. The fact that they're mostly African-American doesn't really faze me most of the time.

Both Mrs. Avery and Mr. Miller confessed to not thinking about the race of their students very often despite the fact that the school is based on racialized perceptions about Black communities. Further, Mr. Miller makes an implicit assumption that because race doesn't come up in conversation very often that individuals aren't thinking about it. However, he himself discussed a past experience that demonstrated that just because students aren't talking about race does not mean that they are not thinking about it. He recounted:

These were kids that, race never really came up in class a lot, or they never really talked passionately about it, but on this particular day, the kids were in tears talking about times they've been racially profiled, about times that they felt that people have been racist to them. They spoke very passionately about it and it was a little bit of an eye-opener to me to hear kids, 14-year-old girls. I'm picturing one student particularly in my mind, just in tears talking about times that her mother had gotten pulled over and probably shouldn't have, times where family members of hers have been arrested for no reasons, things like that. A lot of the problems people were complaining about, they were occurring. They're certainly happening. That was a very eye-opening experience for me.

Despite knowing first hand that silence on issues of race does not mean that they do not deeply affect the lives of students, Mr. Miller still maintained that if students aren't talking about a particular subject, like race or racism, then it is unimportant —or worse, not happening. African Americans carry the burden of having to prove that things are 
"certainly happening" for Whites to acknowledge the racism that Blacks experience. It took a student being in tears and talking with passion for Mr. Miller to understand her lived experiences and the challenges that she and her family faced due to race and racism. This willful nescience suggests an endorsement of a colorblind ideology and a desire to live in a post-racial society; however, it may inhibit trusting relationships between students and faculty because students may be unwilling to open up about their experiences with racism if they feel like they will be questioned or disregarded.

A desire to live in a post-racial society despite the limits it places on studentteacher relationships is further demonstrated by an occurrence in in the elementary school recounted by Mrs. Avery:

[A teacher] down in lower school has told a funny story last year, they were at the zoo with the four or five-year-olds. There were a lot of White people at the zoo, and one of the students commented on it. Beatrice said, "Well you know, White people like to go to the zoo too." She said, "I'm White." He looked at her, and he goes, "No you're not." Beatrice is Irish Catholic like me, you know, it's like, yeah we're pretty White. From that little point of view, no you're part of my life, so you're not. That goes away, obviously. I don't know how you would teach that in America. It's unfortunate. [Yeah it is]. That a five-year-old can look at an Irish White lady and go, "You're not White," because you're not what I think about. [You're just you]. Yeah, exactly. You're important to me, I look forward to you. You're nice to me, you hug me. 
First, we see that Black children as young as four or five years old are beginning to develop an understanding about race. This further detracts from the assumption that just because students are unable or unwilling to articulate their thoughts about race that they are unaware. This particular child assumed that because his teacher spent a large amount of time with him in a community where a majority of individuals are Black that she must also be Black. In a sense, he is beginning to realize that race matters in how he will be treated. In contrast, Mrs. Avery interprets this child as being colorblind and recognizes that his idealism, unfortunately, will disappear with age. Similar to Mrs. Avery Mrs. Everett sees colorblindness as an ideal. She stated:

Well, I think for getting along here and now, here that in this world it's important that they know who these people are who went before them. The Martin Luther Kings and the [inaudible 00:38:59], or whatever. I also believe, with my heart, that their identity and I will say this, in Christ, does away with all color. All barriers like that. That, to me, is more important. When we get to heaven, there's not going to be male and female and black and white and yellow. I want them to find, I will say I would want them to find their identity in Christ rather than in their family ... I mean, I think it's important that they have that identity in their families too. That they know who they are, where they come from, to some extent, of course, where they're going, but I don't think I have a traditional expectation for kids.

Mrs. Everett desires students to transcend race because race doesn't matter in God's eyes. Mrs. Avery deems racial consciousness as unfortunate. The perspectives of Mrs. Everett and Mrs. Avery amount to a desire to exist in a post-racial society. The idealization of a 
post-racial society can be rationalized by religion. However, it is also possible that such an idealization of a post-racial society is situated in a White racial frame that views race as a negative or something to overcome. Furthermore, acknowledging the myriad ways that race matters in the lives of students would require deep reflection and work from faculty members, work they may be unwilling to engage in.

The desire for colorblindness exists both within and beyond the institution. In addition to this large scale societal desire for race not to matter, as expressed by Mrs. Everett and Mrs. Avery, colorblindness shows up on a smaller scale at OS. According to Mr. Travis:

Again I don't think that there's anything within our system to do that. I think that the idea is that these boys are students here at the school first. There are expectations for them and they all have to go according to that expectation of how they behave themselves, how they are as citizens of the community. We have a White student, we have refugee students. We don't have any different combinations for them, different food for example or different classes. I think that things could be done in subtle ways. For instance, the refugee community we try to make an effort to have contact with their parents, people who work in refugee community. We try to be as open to them as possible and learn but I won't say that there is something systemically that we do.

Mr. Travis' understanding of race and how to affirm students' racial and ethnic identities is in line with the posters, food, and festivals strategy undertaken by multiple faculty at OS. Additionally his comments espouse a desire for non-White students to transcend 
race and an universal understanding of boyhood. Several faculty members attest to viewing OS students simply as boys and thus there is no systematic way of dealing with issues of race. This then translates into faculty members struggling to affirm students' cultural backgrounds beyond posters, food, and festivals. Finally, Mr. Travis professes that the school is open, however, the ways in which race is framed is not open nor inclusive.

It is not only White faculty members who subscribe to colorblind ideology. For instance, Mrs. Bell stated:

They have to learn to accept and get along with many different kinds of people; because all of us, wherever we are, you are going to be around other people who don't think like you do, who don't look like you do. I think we have such a mix that you don't even pay any attention. That's what we want, because a lot of times, if you just hang with people who are just like you; you're afraid of other people, or you don't respect them, or you don't accept them. I think it's important; because when they get out in the work force and when they go to higher education, they're are going to be surrounded by all kinds of different people. So let's learn from each other and keep moving.

Mrs. Bell reaffirmed that colorblind ideology is a desired facet of school culture and explained that she wants her students to be able to transcend race. Similar to White faculty members, Mrs. Bell viewed race from a negative perspective; race is viewed as a liability to students in the workplace. This conceptualization of race relies on White racial framing by imagining Black students as unwilling or unable to get along in diverse 
situations. Generally oppressed people are not the ones that have a problem getting along with the dominant group. In fact, Black people must travel to and function within White spaces as a condition of their existence (Anderson 2015). Mr. Green described a similar desire for students:

When I was young if there was a Black person on TV, an alarm sounded. "Hey y'all, there's a colored girl on TV." Everybody would drop what they were doing and come to the TV and sit there in wonderment that there was actually a Black person on television. That's not ages ago. That was my childhood. For someone like the Everetts to see that we need to do more to let people know that this is world for them too. I think the whole climate of the school does that. Then, what I really like about it is the fact that it doesn't always have to be ... As long as you project that idea that everybody is important and all lives matter, no matter what color you are. All lives matter. I don't think that message gets out in public school. In public school I think it's still very much a thing where only certain people matter and certain people don't matter.

Mr. Green realized that is was not so long ago that seeing a Black entertainer on television was cause to celebrate, yet he invoked a popular colorblind refrain, "all lives matter" which arose in response to the Black Lives Matter Movement. Mr. Green's comments suggests that he desires a post-racial society even though we are not at that point. This is further extended when he indicated that he downplays experiences with racism in conversations with students: 
Well, I haven't really gotten into that, because I don't want them to have an expectation and then have it be a self-fulfilling prophecy. Occasionally I have shared things that happened to me. Then, usually I'll end up saying, "Well, you know, of course it's not like that now." Well, I have had a face a lot of that stuff. I'll share a story every now and then of the time I was in a competition and there was one judge whose score was so low ... I would have won. I got 98 from one judge, 96 and 88 or something. Her score was 53. Then, we found out later on that the girl who won that competition, that was her grandmother. I'll share that story, then I'll tell them, "At first it seemed like it was a racial thing, but it ended up being something else. That's called nepotism." We have these other isms that can interfere with us too. That's why we always have to be as great as you can be and see what happens after that.

For Mr. Green, it is important that students don't get bogged down by racism and he wants them to acknowledge that there are other ways that they can be disadvantaged than the color of their skin. This is very similar to the way that Mrs. Ferguson responded to students' questions about race, rooted in fear about how students will respond to and process information about racism.

\section{CONCLUSION}

Faculty at OS draw on one or more of the following White racial frames: the White savior complex, avoiding conversations about race, superficial acknowledgement of race, or minimization of race. Each of these frames bars individuals within OS from engaging in meaningful conversations about race. First the White savior complex, which is integral to the funding of the school, draws on crisis and deficit narrative about Black 
males. This White savior framing rationalizes the character education curriculum at OS which I further explore in Chapter 7. Secondly, the framing that is used to avoid discussions of race are not conducive to understanding race and racism. Nor is it conducive to engaging in meaningful changes related to racial inequality in education. Third, the posters, food, and festivals strategy is used as a substitute for meaningful conversation about race and demonstrates that faculty do not have nuanced understanding of how students experience race and racism. Additionally, this strategy may be interpreted as meaningless by students. Finally, the minimization of race and colorblind language operates to erase the experiences of non-Black students attending OS. OS is based on assumptions about the Black experience, however admission to the school is not limited to Black students. The ways in which race is framed marginalize students who don't fit into the imagined Black experience.

The desire for a colorblind society and for students to transcend race translates into the methods chosen to bring up the lagging academic achievement of students. Because actors within the school believe that the students attending the school are "just boys" they are able to rationalize focusing on character - which I explore in the next chapter. In instances where faculty recognize that students are disadvantaged by their racial and gender identities they adhere to character education as a protective factor. However, we know that character does not save Black men from deadly or violent encounters with the police 


\section{CHAPTER VII: THIS IS WHAT MEN DO: RESPECT, RESPONSIBILITY, AND OTHER MEASURES OF CHARACTER AT OAKWOOD SCHOOL}

One must go no further than the Oakwood School website to begin noticing that character education is embedded within the fabric of the school. Character education is defined as "an inclusive concept regarding all aspects of how families, schools, and related social institutions support positive character development of children and adults" (What Works Clearinghouse 2014:1). Character, in this context, typically refers to the moral and ethical qualities of individuals and the demonstration of those qualities in emotional responses, reasoning, and behavior (What Works Clearinghouse 2014). Character is an integral part of culture and climate at OS; it was fully woven into the school. Across the center of the website is the phrase, "To be a man is to be responsible." It is followed by the philosophy of the school, recall:

Oakwood School is a free, private, college preparatory, Pre-K through Eighth school for young men. Admission is open to boys entering Pre-K, Kindergarten, First Grade, Second Grade, Third Grade, Fourth Grade and Sixth Grade who are on free or reduced lunch, are capable of doing academic work at grade level or above, and who would benefit from a safe environment and high expectations.

Oakwood School strives to address all of the issues boys in our community face by creating for its students an environment of high expectations and personal 
responsibility. Through the school's rigorous academic and personal standards, we encourage our students to attain the highest possible level of scholarship, character, and intellectual growth.

The language used within the school philosophy, particularly verbiage such as "high expectations" and "responsibility" reappears in language used in student-teacher interactions and discipline within the school. Furthermore, faculty regularly discussed encouraging responsibility and maintaining high expectations as a source of pride for the school.

A focus on character in a school shaped by the social geography of race and colorblind ideology, as demonstrated in the previous chapters, compels us to pose some additional questions about race and gender in the school. In particular, what does it mean for the school to be shaped around pillars (i.e., respect, responsibility, trust, perseverance, and forgiveness)? And, in what ways is character education, particularly, through notions of respect and responsibility, laden with racial ideologies? In answering these questions I explore the logic underlying the character education curriculum at OS, wherein socializing students is viewed as a key function of education. Additionally, I explore how character education became institutionalized at OS, providing structure for student's daily activities and discipline. Finally, I examine the aspects of character, respect and responsibility, that are most emphasized at the school.

\section{TEACHING AND INSTITUTIONALIZING CHARACTER}

Notions of character are not relegated to the mission and philosophy of the school as hollow words, rather they are integrated in the school and rate among one of the things 
that the school does best according to faculty. When asked, "What does OS do best?" Faculty members offered a variety of answers that are reflective of the mission and philosophy of OS, such as providing structure, providing high expectations, addressing the needs of students, and character building, which stood out most. When asked what the school does best, Mr. Miller stated:

I think character building, because I think that's something that public schools, at least the ones that I worked at, they don't care about...Here, I feel like grades come second. Even academics come second to character building. They're trying to mold these kids into men. They're trying to make them accountable, responsible, trustworthy, adults. I had to get used to that when I was first here. I would say, 'You're just a kid,' or I'd say things like that, and teachers and students would call me out on it. 'No, we're young adults.' By saying that over and over, it does drive that idea home. I think that this school, the fact that it's a boarding school, the fact that they can be insulated from all the distractions that might happen at home, it really allows the school to turn kids that would otherwise, I like to use the word 'knuckleheads,' who would otherwise be knuckleheads, into responsible adults.

Based on Mr. Miller's assessment character education is a critical component of the OS curriculum. The ascendancy of character delineates socialization as a key function of schooling. Specifically, OS seeks to teach students accountability, responsibility, and trustworthiness, character traits which when exhibited signal manhood. The focus on teaching character, particularly traits which signal manhood suggests that the school does not believe that students are being taught how to be men at home. This coupled with a 
population perceived to be living in female headed households fits within narratives that women can't teach boys to be men and further encourages paternalism on the part of the school. Finally, this line of thinking fails to acknowledge any standards or expectations for character that parents may have for their children. Instead, the school is defined as a key intervention to properly socializing children and teaching them how to be men.

Mr. Miller is not the only faculty member that envisions the purpose of education as socializing. Mrs. Avery echoed:

Well I think the character education in the school is as important as the learning education. In the United States, we teach US history 3 times, we teach it in 4th grade, we teach it in middle school, we teach it, mostly, as juniors in high school. If you miss one of the battles at any point in time it's been covered, but I think if you miss an opportunity to really, at least try to focus students on the more important part of life, which is the ... What we consider the pillars, the responsibility, and we're mostly this year focused on responsibility, the community spirit, the personal integrity, I think that will serve them in life. I think that as you go through your education, as you go to college, there's so many opportunities to cheat, or take the short cut, and we're hoping that those lessons are the ones that stay with them.

Here, while Mrs. Avery does not place a premium on character education, she does place cognitive skills on equal footing with non-cognitive skills, such as measures of character, and believes that schools should capitalize on the opportunity they have to instill values into their students. This type of view supports paternal behaviors of the school. 
Additionally, she highlights responsibility, community spirit, and integrity as desirable character traits that students should develop while at OS. Both Mr. Miller and Mrs. Avery take the position that schools are the key socializing agents in the lives of students, which suggests a belief that parents do not do their due diligence in raising moral adults. Finally, Mr. Everett demonstrates that the importance of character education is not just singular views of faculty members. He stated:

The primary and most important responsibility of every adult here is to teach those kids. Broadly conceived, teach the kids, hold the door, stand up when somebody comes to the table, put your napkin in your lap, learn to use a knife and fork, all of the "Yes, please" and "No, thank you". In addition to when you're in the class, in addition to learning to do some work problems.

Mr. Everett centers and expounds on the teaching that happens outside the classroom. When he explains that the primary responsibility of faculty is teaching, he is not referring to a language arts or math curriculum, rather he is referring to a character curriculum. Similar to Mrs. Avery, Mr. Everett conceives purpose of the education as extending beyond imparting knowledge. He is focused on teaching students to be respectful, which is one of the most emphasized aspects of character at OS. Mr. Everett's expression of these views about the purpose of education, especially as a leader of OS with the authority to steer the direction of the school, speaks the level of importance of character education. Through Mr. Everett's leadership, teachers who are selected to work at OS are ones who would be willing or are already committed to developing of character. 
If one views the purpose of education as socializing, or teaching character, then it is logical that a character education curriculum would be selected to provide structure to the school. Literature on character education suggests that core ethical values should be the basis of the school with character education (Lickona 1996). Schools with effective character development have a set of organizing principles or "cognitive hooks" around which they organize (Elias 2009). At OS, these are the pillars to which Mrs. Avery referred to above. In the cafeteria, which is located in the basement of the school, there are five square columns lining the east side of the room with each column adorned with one of the following words: responsibility, trust, forgiveness, respect, and perseverance. These pillars, which provide support to the foundation of the building, also symbolize what OS would like to instill in the young men as the foundation of their character development. Mr. Travis recounted the origin of the pillars:

The idea of the pillars came from an observation that someone made in the counseling department that there was really, as structured as this place was supposed to be for the boys, there were a lot of things that weren't very structured. Trying to figure out a way to bring as much as of structure as possible to where we are as a school and how would the boys be able to know for instance the rules of the school, the processes of the school, what could get you suspended, what could get you in trouble, what's the process for being expelled, what's the process for being accepted into the school.

He went on to add: 
Philosophically, what they are, are our best idea of what we think are good things to base being a human being on. Obviously, the responsibility to oneself and to others is important so that we are acting intentionally, so that we're good stewards of our words and of our actions, and forgiveness, persistence.

Mr. Travis asserts that the pillars are constructs around which the school is shaped. He specifically notes that the pillars are tied to rules, discipline, and admissions, meaning that who enters and is asked to leave the school is tied to the expression and development of character. Additionally, the pillars are the OS's best understanding of good things to base being a good human being on. However, the language used at the school renders these as characteristics of a good man.

Language around character is used in discipline and is present in the student handbook, student-teacher interactions, and course curriculums, including counseling and student development, music, and science. The confluence of these factors suggests that character education does provide structure for OS. For instance, during one counseling session focused on empathy students demonstrated how character is integrated across the curriculum:

Field Notes: 9/21/15

Counseling and Student Development

Mr. Travis asked if the boys knew what empathy was. Tyler said yes, it was one of their science vocabulary words. The adults in the room, myself included, were understandably confused. How does empathy end up as a vocabulary word in science? Tyler explained that they had to learn about empathy after a classmate was expelled last year. 
OS students made fun of a classmate that was expelled, which Mr. Harrison rationalized as a lack of character. He deemed the behavior of his students worthy of a lesson in empathy and thus took time away from the science curriculum. Character also was integrated into the music curriculum; Mr. Green discussed:

I try to emphasize those [the pillars]. In fact, I had them all write them in the book, even though they knew them, and we talked about each one. Earlier in the year I took one a week to talk about. I even went so far as to write the rhythm of the word on the board so they could see what this is, it's the 8th note. Responsibility was, I think it's still around here somewhere. I wrote each one out so they could see movement. We got a chance to use the drum too, pound out—-the rhythm and then say the word, then, what does it mean to you.

The decision to create a lesson surrounding responsibility in the music curriculum further communicates the importance of character at the school. Students hear the importance of character from all faculty members and in multiple different ways. At OS empathy can be a vocabulary word in science and the word responsibility can be used to teach rhythm. Mr. Miller discussed having students write an essay on responsibility in social studies and Mrs. Avery, while she did not point out a particular assignment attuned to character development, integrated it into her teaching philosophy. She stated:

Well, you know, I taught in [the Northeast], before I came here, in a gifted program. If I wanted to talk about the Iditarod, many of the students had already been to Alaska, they'd been on the cruises, they'd seen the glaciers, whatever. They came with great background knowledge, but ... I think my children the same. 
There are compromises to be made, and so the parents of these students, for the most part, were not available to them a lot. You're doing the same thing; I think it started early on. You want the student to know that their efforts are on their own behalf, you're not doing it to please anyone else, just the self-reliance, the selfawareness, across the socio-economic spectrum. I probably started with those kids who would, seemingly, if you've been to Alaska on a cruise, you've had great world experience, and yet if you're acting out, or not using the gifts that you've been given, then there's nothing in it for you at the end of the day.

Across faculty members character development is woven into their classrooms through lessons such as science and music, and also in teaching philosophies as demonstrated by Mrs. Avery. For Mrs. Avery, character development is not something that is necessary simply because students are low-income. In all of her teaching experiences, both with wealthy children and low-income children, she has to be mindful that developing character should be an important part of a teacher's job. Mrs. Avery's integration of character education in her teaching philosophy suggests that while she did not articulate any specific assignments, character education would be a guiding force in how she approaches her work as a teacher.

A commitment to character development is not something relegated to the individual practices of teachers, but it is also institutionalized at OS. Students are assigned daily chores, which are intended to foster the development of character. Mr. Travis discussed: 
I think that they also are good at communicating by deeds, passing along some of the character that is hard to get in other places. For example, having the boys do work. Checking things. Teaching those small things that you can't in a regular school. The little issues of character. I think that those are able to be taught in a way...For example, something like moral courage. If you harm the property or the furniture of the school [we] want to know who did it, it takes moral courage to come up and admit that you did something. Just having that discussion with boys in the practice and other boys hearing all of that, those are things I think where the school is at its best.

Students are expected to complete daily chores and their work must be checked off by a faculty member before they can move on to the next activity. Additionally, faculty are expected to teach character by modeling behavior. This is further supported by a discussion that occurred in a faculty meeting during which Mr. Everett said it was important that they be at the lunch table with the students so that their bad habits can be corrected. The faculty specifically mentioned a couple of students who had poor table manners that had now improved. They noted that there was one student who was particularly messy, but now he cleaned up and reminded other students to keep their area clear.

According to a number of school staff, a key responsibility of OS faculty is to carry out the mission of character development. Character education happens in classes through assignments and activities, as well as outside the class, in places such as lunch. Students are expected to behave in ways that reflect the pillars of the school. Above all 
else students are expected to be responsible and respectable which I will explore in the next sections.

\section{CENTERING RESPONSIBILITY AND MANHOOD}

Amongst all of the pillars at OS, responsibility is the character trait that is most visible and salient within the school. The concept of responsibility is present in official documentation, such as the mission, philosophy, and school website. It is visible in the physical setting as well; the word responsibility can be seen in both classrooms and hallways. In the main thoroughfare of the middle school there is a large bulletin board titled "Responsibility." All the students' pictures are posted on the board and faculty are encouraged to write in the space provided if they see a student doing something exceptional or exhibiting responsibility. Additionally, each classroom is outfitted with a responsibility chart. During the first faculty meeting of the school year, Mrs. Bell led up a discussion about responsibility charts by explaining the behavior rubric that the teachers should use.

Field Notes: 8/26/15

Faculty Meeting

Mrs. Bell presents the chart to her colleagues. The design of the charts draws the reader's eyes to the word responsibility. It sits dead center and is double in size to the rest of the text on the chart. Also during this faculty meeting Mrs. Bell suggests that conduct scores on the report cards be replaced with responsibility scores. According to her, this change would shift the discourse toward a more positive angle and be reflective of the motto of the school ("To be a man is to be responsible"). 
This discussion, and the fact that it was at the beginning of the school year, speaks to the importance of responsibility. This initial meeting sets the tone for the rest of the school year, and situates responsibility as a central focus. Responsibility at OS is defined as concrete behaviors that any one regardless of gender could exhibit (i.e., doing your work, sticking to your word) and it is defined as a masculine construct (i.e., being a good husband, being a good son, provide for family).

The fact that behavior can be tracked in terms of responsibility means that concrete behaviors are attached to responsibility as defined at OS. Mrs. Bell understands responsibility in relation to school work. She stated:

Then by the 8th grade I expect ... They actually have more activities going on and more interruptions in the 8th grade; so they really have to get their act together in that 7 th grade to hold on in the 8 th grade. Then they have to be responsible for it, "Okay, you've got all these classes, you've got all these different little interruptions. Everything has to still be done. Even if you go to the ballgame. Even if you go to the soup kitchen." I'm teaching them to be more organized in that 8 th grade and be responsible for that work and no excuses.

Mrs. Bell wants her students to be responsible for any material they may miss and to be able to handle competing duties. Similarly, Mr. Green, in reflecting on the school motto, offered:

Oh, yeah. I think it's most succinct and most perfect motto we can have. I'm telling you guys I see all the time, "Even if you don't go to college, there's a great need for people who can build, who can repair stuff, who can put on a roof, who 
can do plumbing, electrical, and who can be responsible. There are a lot of people out there, and I tell them, because I own property. I tell them about it, about how hard it is to get somebody that you don't know if they're going to show up. You don't know if they're going to run off with the money. You don't know if they're going to do shoddy work. Responsibility, if you're responsible you can be a wealthy person, because if you can do that stuff, man. A guy told me, he left a contractor he used to work with and started his own roofing company. He's raking in the money, because he shows up, he's reasonable, he's got references. That's really important no matter what they do. I think it's really good. It doesn't say ... A motto that says, "Being a man's being responsible," doesn't mean that everybody has to go to college and be an A student. It applies to everyone.

For Mr. Green responsibility is defined as showing up when expected and doing what you said you would do. Furthermore, according to Mr. Green responsibility pays. Because of his understanding of responsibility Mr. Green is able to offer a value-added reason for why students should be responsible. Students are repeatedly told that they should be responsible and that it will make them men. However, they are not always given relatable reasons for why they should be responsible. Here, Mr. Green, talks about the ways that that responsibility can pay off in the present.

Responsibility has meaning beyond these concrete behaviors such as showing up and doing your work. Mrs. Everett, while articulating similar concrete behaviors, centers on a more abstract definition of responsibility that defines it as a masculine construct. She detailed: 
Responsibility, of course, is just, I think it's what the school is about. I mean I think about one of the things, if you put food on your plate, you have to eat it. You're responsible for what you put on your plate. If you don't, there will be consequences. Having a kid, to see a kid, grow into realizing that when he does break a rule, there are going to be consequences, and him just taking that like a man. I take my consequences and then I move on. That's really exciting to see a kid grow like that, because how many people do you know that, first of all, can never accept that they did something wrong? When you see the little kids, and actually you see some of the kids here, in those early days, they immediately point to the other person. "Why isn't Darryl here, why isn't Darren here? Because he hit me too." That's one of our, I think about growing good husbands here. Growing good sons. Growing good citizens. People who can get up and go to work in the morning and do a good job and not try to skate around the edges.

A student eating all of the food on their plate, or accepting consequences, is a seen as a sign of responsibility in the eyes of Mrs. Everett. These are types of behaviors that would warrant an " $\mathrm{R}$ " on a responsibility chart. The manner in which responsibility is defined by Mrs. Everett and as demonstrated by the school motto is a masculine gender construct. In order to be men, students must accept consequences, they must show up for work, and they must provide for their families. A student accepting a consequence not only demonstrates responsibility, but also manhood. Mrs. Everett's conceptualization of responsibility foregrounds these youth being good husbands and sons, which may not be a strong rational for a middle school boy to be responsible. 
Responsibility is not only gendered but it is also raced and shaped by negative perceptions of Black masculinity. Comments from Mr. Miller demonstrates the interplay of race and gender in defining responsibility:

I think it's very important. Like I was saying, I think the biggest pillar that we teach here is responsibility. At least, I think it's the most important one that we teach. I think that being a man is being responsible, I think that says it right there. You're a kid until you've learned responsibility. There are 30 -year-olds in this world that are still children in my eyes because they've just never learned to be responsible. I think that I know, sadly, in communities like this a lot, a lot of men are absent in their children's lives, a lot of the fathers are. I think a lot of that has to do with lack of responsibility. By teaching responsibility to these kids, hopefully we can break that cycle a little bit, or at least put a dent in it. I think that's where a lot of these problems can stem from, especially for boys like this, not having a positive male influence in their life, it can be hard on them.

Mr. Miller does not explicitly discuss race; however, he situates his discussion of irresponsibility within the Oakwood community. As discussed in Chapter 5, urban communities such as Oakwood are marginalized and stereotyped as dysfunctional—in particular, students hailing from Oakwood are framed as living in single parent households. Mr. Miller invokes the absent Black father and defines their absence as irresponsibility. Furthermore, he privileges teaching and learning responsibility from a male-centered perspective. His argument hinges on the notion that women can't teach boys to be men. The goal then at OS is to raise "good" fathers - those who will be in their children's lives. Mr. Travis, similarly, asserted: 
We have a tremendous amount of irresponsible behavior that goes on; men behaving irresponsibly everywhere in our world. I think that learning that word, being responsible for your words and for your actions, obviously it's a fundamental part of having a civilized society. In that sense it's good. Equating over and over and over again a man and responsibility are great. I think sometimes there can be too much of a focus on these boys being men or young men and not boys. I know we all have an ideal. We all have to shoot for something, sometimes we start calling... saying act like a man. We say that probably too early for boys who aren't even close to being that.

The emphasis on responsibility feeds into the Black male crisis narrative. Across comments from Mrs. Everett, Mr. Miller, and Mr. Travis, there is a sense of urgency (most important thing being taught and early emphasis on what it means to be a man). Because the problems that Black males face are so significant the school chooses to focus on character. They emphasize responsibility and stress manhood even though they recognize that such intense focus may rob students of their boyhood.

The discourse from the aforementioned faculty members suggest hegemonic understanding of masculinity, tied to being a provider for one's family. Mrs. Avery also defined responsibility in terms of hegemonic masculinity. Mrs. Avery stated,

Yeah, we are trying to raise them to be responsible men, and to value women as people, you know the whole pulling out the chair, and not eating until a woman eats, and it seems archaic in a way, but it does give them pause. I'm a man, this is the way I should treat a woman. 
Here she defined masculinity in relation to women and femininity. Focusing on responsibility as it relates to manhood suggests a commitment to hegemonic masculinity, which can be understood as a pattern of practices that allow men's dominance over women (Connell and Messerschmidt 2005).

While masculinity is tied to hegemonic masculinity, faculty members do recognize the potential pitfalls of focusing on responsibility as a masculine construct. In the statement highlighted above, Mr. Travis discussed irresponsible behavior but he also acknowledged that focusing on responsibility pressures the students to grow up and take on an adult role sooner than necessary. Mr. Ethan, in recognizing these same issues, stated:

Responsibility. I think that's a word that gets used a lot but doesn't have a lot of context to it for the boys to a certain extent. It's almost like ... Some of them have said in the past like ... I don't know. Maybe you were there for one of those things like the boys have basically said, 'You know, these things have been said over and over to us but they're kind of hollow because no one even gives us any context of what that even means.' To be a man is to be responsible. What the hell does that even mean?... It's very abstract and you're talking to sixth grader, 12year-old, 11-year-old about what it means to be a man. That's a ... It's so complicated.

Manhood and masculinity as a byproduct of being social constructs are complicated. Mr. Ethan, perhaps in recognizing that manhood and masculinity can take on different meaning in different context, criticizes the abstract notion of responsibility, particularly 
as it relates to manhood and masculinity. Students are repeatedly told that to be a man is to be responsible, which may not have any sticking points to students' lived experiences. Relatedly, Mr. Harrison stated:

[Laughter] That is focused on a lot, what it means to be a man and what a man does. All of our discipline seems to come back to, "This is what men do." It's, now ... What it means to be a man, that is different to different people. I'll talk about Jacob, his sixth grade year on a fast break, two kids on the other team fell over, he stopped to help them up. I talk about that as, that's what a man does. It's possible, but I've never heard this, but it's possible that another man would tell them, "No, a man would play the game and compete." It's possible that down the road that we're going to have conflicting ideas about what it is to be a man. Then that will be confusing when we're explaining it to the kids. As of now, it seems to, everyone has a unified vision at least as far as what we express to the kids about what a man is; being responsible, picking up after yourself, carrying yourself well, being proud of the work that you do, being honest with people. There seem to be these broad platitudes that we all seem to agree on about what a man does. I think the question we have to ask ourselves, again this is probably an uncomfortable conversation that we won't have, are these things that men do or are these things that good people do? I worry sometimes that by making it about men, we create the impression that women aren't responsible. "Well, a man's responsible, a woman - Ehhh, whatever."

Mr. Harrison recognizes that discipline is highly gendered and individual definitions of manhood and masculinity may vary. Even if unintentional, much of the communication, 
discipline, and consequences revolve around "what it means to be a man." A critical point of analysis is that the institution has "crafted" the standard for manhood and then requires the students to live up to these goals, ideals, and expectations. While Mr. Harrison perceives it as "lucky" that everyone is able to come to a consensus on what it means to be a man, he fails to recognize that parents are left out of the defining process. This exclusion works against any efforts to build community with parents and may cause challenges for students during their weekly transitions between home and school.

In at least one instance, a student received contradictory messages about manhood and masculinity, which proved challenging as he navigated school and home. DeVante was a student that was regularly the focus of attention during faculty meetings and was often on the brink of expulsion. However, several faculty members admitted that he made marked strides while being at the school. DeVante was a student that received conflicting messages from school and home. Recall during a faculty meeting in November, DeVante was up for conversation after an incident of him lying about where he got $\$ 20$.

Field Notes: 11/4/15

Faculty Meeting

Mr. Everett began the conversation by admitting that there was no justification for why he was still there and that other students had been expelled for less. There was debate amongst the teachers with about half of them wanting to keep him and the other half ready to let him go. Mr. Ethan said that he feels like they've had this discussion at least twice a year and Mr. Travis echoed his sentiment. On the other side of the argument, Mrs. Darcy pointed out how much progress she's seen 
him make. They talked about how he hasn't been carried out of a basketball game like he was last year. Either Mr. Smith or Mrs. Darcy mentioned how he had been able to calm himself just from a look from the coach. Faculty members praised him for being able to control his emotions at a recent basketball game, however someone mentioned that his mother wanted to know why he lashed out.

While the school is actively working to develop desired character traits in students, they may be, as in the case of DeVante, getting contradictory messages at their homes. For Mr. Harrison, helping a fallen player on the opposing team was an act of responsibility and manhood. At the same time, this same behavior could be interpreted differently by a parent. DeVante's mother had a different conceptualization of what it means to be a man and viewed it as a problem when her son controlled his emotions rather than lashing out.

\section{TRUST, DISTRUST, AND TRUE SELVES}

While trust is a pillar of the school and an attribute expected of students, it is not as engrained into the built environment nor as regularly expressed in actions as responsibility. However, it is present in official school documents, the student handbook serves as a resource to help orient students and their families to the school and communicates the importance of the pillars of the school. On the first page, in the introductory letter to parents and students, it states, "We believe in character. We believe in the importance of truth and honesty. It is our expectation that all members of our community will respect and adhere to these values." This language surrounding character and the pillars of the school are reiterated throughout the handbook. Later in the section on discipline the handbook reads: 
Honesty and trust are the foundations of strong character and are imperative to the success of Oakwood School and its students. The goal of our disciplinary philosophy is to create, preserve and promote honesty and trust by providing students with a common set of standards which define expectations, set limits for social behavior, and foster a sense of responsibility for the school, the community, and for the students themselves (OS Student Handbook).

While responsibility and respect are the most articulated values of the school, the language used within the student handbook suggests that trust and honesty are crucial in building the overall character traits the school seeks to establish.

The pillars are ideals to which OS strives toward - the language surrounding these pillars are weaved throughout the school. However, some faculty convey that with the exception of responsibility, and for some even responsibility, the pillars are not being used to their full potential. Mr. Ethan offered:

I think they're good ideals but right now they're not necessarily being attended to. Just like anything, I think they need more clarity and purpose, more clarity in content, but I think that's just a general thing that needs to happen, kind of like I already said. I don't know... I don't know if they mean anything to the kids because they haven't really been reinforced anyway and even some of the things can be very situational. Trust is a huge issue and that's one of the pillars that's not really being attended to. I think the most out of all of them. I think part of that's a very cultural issue, maybe racial issue, because the boys don't trust us to a large extent. 
Mr. Ethan asserts that the pillars need more clarity and purpose and that at this point are functioning mainly as ideals. According to him this is problematic because the pillars may be meaningless to students, particularly as it pertains to trust. Mr. Ethan begins to provide analysis toward the limited amount of trust within OS. He believes that racial and cultural dynamics impede efforts to build trust between OS students and faculty.

Mr. Ethan's assessment of trust is supported by evidence from observations. The issue of trust came up several times during the fall semester in counseling and student development. A discussion amongst $8^{\text {th }}$ grade students about trust and confidence shed light on the source of distrust in the school.

Field Notes: 11/09/16

Counseling \& Student Development

Mr. Travis introduces today's topic: trust and confidence. He tells the students that this is the first time in a couple of weeks that everyone has been there because people have missed for shadowing and he didn't want to have this conversation without everyone present.

Mr. Travis asked if they knew what confidence meant. Andre offered that is was having faith in your abilities, like I'm confident. Mr. Travis explains that it could also refer to having trust in someone. The discussion then shifted to what do they feel about the trust in this group.

DeVante said that they will never have his trust again because they tried to take him away from his mom. He explains that the told them something and that CPS came to school and told them that he could be taken away from his mom, him and 
his sisters. Gabriel called Mr. Ethan a "Fed" and repeated it a couple of times during the discussion.

Hiro wanted to know how they tried to take him away, and then he asked Mr. Ethan why he told. Mr. Ethan said that it was a private matter that he was unwilling to discuss. Someone said/did something that Mr. Travis said was disrespectful. Gabriel said send him out like you sent me out for asking how much time we had left, "I still don't understand that."

DeVante said that they call CPS because they don't understand getting whoopins because "they don't live our lives." He said that they will never gain his trust back.

DeVante explicitly expounds on Mr. Ethan's assessment of trust. First, he creates an us versus them dichotomy. Secondly, he defines cultural understandings and behaviors as a root cause of this division. For DeVante and most other students in this eighth grade class, whoopins are normal and natural and because faculty do not lead similar lives they do not understand this experience. Additionally, faculty members are constructed in the same cognitive space as other White institutional actors, such as the "feds" or police officers. For many Black males, the police are to be distrusted because of exploitative and abusive dynamics. This language suggests that faculty members, like the "feds", should not be trusted. The class discussion continued and almost every student indicated that he could relate to or understand getting whoopins:

Mr. Travis poses a question of what are the different type of whoopins? Andre said A-whoopins and then there are whoopins 
Mr. Travis says that he was spanked as a kid and that sometimes his dad would kick him in the butt.

Jarvis said that his mom doesn't whoop him too much and that is doesn't hurt and it's over quickly. His mom mostly talks to him about whatever it was that happened.

DeVante said it's because he's big. Jarvis even said that his sometimes afraid for his mom when she gives him a whooping because of the size differences. This was in response to a discussion about how kids will start to move around when getting a whopping and then they could get hit anywhere.

Somebody said that Hiro gets whoopins. He then goes on to explain how he got a whooping because he was $4^{\text {th }}$ in the school. In elementary school he was first in his class, but that slowly declined and he got a whooping last year because of it.

Gabriel talked about getting slammed by his brother. He described it as scary, but seemed to indicate that this got through to him.

Several times during the discussion DeVante said I don't know why y'all are telling them these things.

Jacob mentioned standing and holding something heavy, like books, up for hours.

Mr. Travis asked the other adults to chime in... he makes eye contact with me and I tell him that to me there is a difference between whoopins which can be very ritualized, your mom tells you to go get the switch and you get the whoopin and then there are beatings which cross the line and you just get beat. Mr. Travis 
extends this and offers that it sounds like beatings are out of control. He asked the boys what is used in beatings vs. whoopins. Gabriel says anything. We also come to the conclusion that you could be hit anywhere.

Throughout the remainder of the discussion faculty are constructed as other. Mr. Travis' revelation that he got spankings was largely ignored and did not change the amount of distance that students placed between themselves and faculty members. Students also made effort to include Hiro, who is Asian and often an outsider. While many of his experiences are different he relates to whoopins as well. Finally, DeVante's interjection of "I don't know why y'all are telling them these things" continues to frame faculty as untrustworthy.

This lack of trust is rooted in the racial and social class dynamics of the school and attendant social and historical implications. Mrs. Everett said:

And then trust, yeah trust is a really interesting thing because when you're 11 and 12 and 13, you know everything and then you have these White people coming to you and saying, "The way that you thought about that all of these years really isn't the way that it is." I can say that until I'm blue in the face and they're really not going to hear me because they don't trust me...It took some time being around here, too, to understand how important that trust is and how it really is lacking. Why should a young African-American kid trust a White [person]? There's, I mean, what experience has he had, and if he has any experience, it may have been a bad experience. My job is to be as respectful and as trustworthy to them as I possibly can. Just let me model trust for you. That's what it takes. 
Similar to what Mr. Ethan noted above, Mrs. Everett recognizes her social location in relation to the students. Furthermore, she recognizes that her identity as a White woman encourages distrust because White people have not given Black youth much reason to trust them.

Trust is crucial to building relationships, but the racial and class dynamics of the school pose challenges. Mr. Ethan stated:

I understand that they don't trust me. It's not like Caucasian Americans have given them a reason for people to trust them, anywhere in the world let alone here. But it's not easy because I want them to trust me and I do have their back as much as I can. I am trying to learn as much as I can. I do try to be as open minded as I possibly can be but it's just ... How much of that can I get across? How much of that is [inaudible 01:12:02], or how much of that is visible and how can I build trust? It's like the toughest thing for me right now [inaudible 01:12:14] reestablish.

The comments above demonstrate an understanding of how race impacts the trust being built in the school, but data from observations suggest that class may also be a powerful factor at work. Because of their legal obligations to report suspected child abuse or neglect, schools are often times at odds with the parenting practices of poor and workingclass families who are likely to use physical punishment (Lareau 2003). Lareau (2003) found that low-income parents gave directives to their children without providing reasons rather than drawing their children out and encouraging them to think through the implications of their behaviors for themselves. This strategy for child rearing is not in line with the standards promoted by professionals such as doctors or psychologists and 
often results in strained relationships between poor and working-class families and schools, which is characterized by a sense of caution and distrust. The evidence above suggests that this very dynamic occurs at OS. Mr. Ethan constructs trust as an outcome of specific actions, however, in the eight grade counseling and student development group, when questioned about the decision to call CPS he did not respond in a manner that would engender trust. He told students that it was a "private matter that he was unwilling to discuss." While there are limits to what he can say because of professional psychological standards, this type of response shuts down conversation and defines his decisions and behaviors as off limits for discussion. Mr. Ethan later described his discomfort to me, which was visible by the way he shifted his body out of the circle. He stated that he was uncomfortable and worried that students would say something that he would have to report. Faculty, particularly ones working within a therapeutic function, are placed in a bind wherein they are asking students to trust them and to let them know what is going on in their lives and that same information they may have to report and destroy any trust that may be built.

The lack of trust between faculty and students suggests that students may not be presenting their authentic selves within the school context. Mrs. Bennett made an astute assessment about the transitions that students must make between their homes lives and their school lives:

I like and believe in art as a mode of expression and communication and a way to figure yourself out, to sort of be more self-aware of issues. It seems, to me, that middle schoolers in general, middle school boys in particular, could really use an opportunity to use art in a way that is, especially these boys because they're asked 
to make these transitions between home and school twice a week which are pretty major transitions to be able to help them to figure out who they are, who's the thread of their true self that stays true throughout all of those transitions. We all put masks on and some of the activities we've done are masks and things like that. So, one of the things that's great is to be able to give them that expressive outlet in a school setting and one of the challenges is for them to express themselves and then contain that before they walk back out into social studies classrooms. Let me turn that off.

Additionally, Mrs. Ferguson stated:

It's interesting because [a lower school faculty] and I were just talking this morning because she said that she confronted some of them about, "Who are you really? Are you who you are here, the expectations here, or are you who you are on the weekends? And who do you want to be? Being here is one thing. It's very protected and it's very sheltered, but when you're out on the weekends, " because she overheard someone talking about some stuff, "When you go to high school, those worlds are going to merge, so who are you going to be? Are you going to be what we've tried to help instill in you, this integrity and responsibility, and being true to yourself? Or are you going to be somebody else because you think it's cool and all that stuff?"

Both Mrs. Bennett and Mrs. Ferguson acknowledged the transitions that students must make weekly. Mrs. Bennett speaks to how student may have to perform their identities within the school setting and how this may vary from their experiences outside the school. 
Because of the emphasis on character development there is a hyper-focus on student behaviors. Student behaviors are scrutinized and regularly corrected. This may limit students' ability and willingness to demonstrate their true selves. Furthermore, the behaviors that students may engage in to navigate their communities may not be well received within OS. It is widely recognized that not adhering to the behavior code could result in harsh sanction, including expulsion.

Mr. Smith recognized the narrow constraints to which the boys' behavior is subjected and organized his teaching and relationships accordingly. He described himself as more laid back than other teachers and on more than one occasion when I visited his class students had down time. During the same faculty meeting surrounding the potential expulsion of DeVante, Mr. Smith talked about the relationships that he has with students and how they feel comfortable telling him certain things because they know that they can trust him.

Field Notes: 11/4/15

Faculty Meeting

In describing his relationships, he also informed other school staff members that he can't betray the students' trust. Mr. Harrison said something about having to share information because you don't want to become "that person." Mr. Smith reassured the staff members that none of the students had come to him yet with anything major. But they trust him because he doesn't always have to give a consequence. He is more interested in how can we fix it, and how can we make it better going forward.

Later in an interview, Mr. Smith offered: 
That's what I think the school lacks is everybody want to be the ... I'm not going to say everybody, but the people in administration, everybody want to be the big dog. Everybody want to be the one who puts fear in these boys, everybody want to be the one who tells everybody else what to do. Really it don't work like that, they will never fully help these boys the way they could help them if that's the goal, and that's the motive behind everything, because these boys, they're not going to talk to them, they're not going to let them in, and you can't really help somebody who's shielding themselves from you, you can't do that. They will never open up to them, because everything is always a punishment, everything is always $\mathrm{a}+\mathrm{b}=\mathrm{c}$, and it can't be like that.

Mr. Smith makes an astute analysis about how the structure of the school stifles the ability of faculty to build meaningful and trusting relationships with students. Mr. Smith's behaviors and his understanding of students placed him as an anomaly among the faculty. Because students trusted him with information that they would not share with other faculty, Mr. Smith's integrity and commitment to a shared purpose was questioned

\section{RESPECTABILITY AND THE SUCCESSFUL STUDENT}

Responsibility is the most visible and articulated character trait at OS. Respect, while not as visible within the built environment, is equally emphasized and it is intimately tied to whether a student will be successful at OS. Often times a student's ability to remain a student at OS is tied to whether or not they are deemed respectful by school staff. Students are expected to be respectful in both academic and social spaces and in interactions with peers and faculty members. 
Recall from the student handbook, discipline at OS is intended to instill character, thus many disciplining moments were motivated by lessons of character, especially respect. Generally arguing with faculty members is considered disrespectful. During an interaction in math class where students were completing brainteasers, Mr. Smith made it clear that he would not tolerate arguments:

Field Notes: 10/8/15

$6^{\text {th }}$ Grade Math

Again, Timothy is the only one that gets the answer right, he tells the class blue, which is the color of his eyes. A couple of the other boys were on track because they said mine. Which I assume they meant the color of their own eyes. Jerome is frustrated that his answer is wrong and he tells Mr. Smith, "you said a man.” Mr. Smith responds, "No, I didn't. I'm not going to argue with you."

Mr. Smith, who described himself as more laid back than the other teachers, allowed for very relaxed conversations between him and many of the students, but respect was a line that students could not cross even in his class. By telling Jerome that he will not argue he asserts his role as an authoritative figure, and constructs himself as someone who should not be questioned. A similar occurrence happened in Reading Writing Workshop where students were reading aloud.

Field Notes: 11/4/15

$6^{\text {th }}$ Grade Reading Writing Workshop

"Timothy what page are you on? What's the problem?"

"He made the point...I" 
Mrs. Avery cuts him off. "You argue a lot. You need to stop."

Additionally, in Social Studies the issue of arguing came up from a different teacher:

Field Notes: 10/8/15

$6^{\text {th }}$ Grade Social Studies

As Mr. Miller is doing his rounds, checking student progress, he stops and talks to Darryl. One of the facts they have to include in the report is famous people from their state. Darryl asked if he could include some football player, Mr. Miller tells him no, he's not from there, he only plays on that team. Darryl argues that he's going to use him anyway. Mr. Miller tells him "I'm tired of arguing with you and the other teachers are tired too."

In each of these incidents, students arguing with faculty precipitated their behavior being corrected. These occurrences demonstrate that respect based on giving deference to the teacher and accepting what they say as fact. In correcting students' behaviors and in some cases, cutting off students' rebuttals, the perspective of the teacher is privileged and discontent on the part of the student is silenced. In interactions such as these students may learn that their perspectives are not valued and may be less likely to contribute in class and to display their true selves. Also, interestingly enough, each of these moments surrounding arguing occurred in $6^{\text {th }}$ grade classes. The lack of this type of behavior in $7^{\text {th }}$ and $8^{\text {th }}$ grade classes may indicate that older students have learned not to argue with teachers and may be the ones less likely to display their true selves, especially as we recall the conversation about trust occurred with the $8^{\text {th }}$ graders and counseling and student development. 
In addition to these ethnographic observations, the issue of respect appeared in interviews. When asked about disciplining students, Mrs. Avery stated:

I think on the scale I am more forgiving. I think what they do is really hard. I think they have a really long day, so I have a broader sense of ... It's okay in my class, they can slouch to a degree, for instance, until they look they're in a lounge chair, in which case I ask them to sit up. I have the table so if they need to stand, they can stand, because a lot of them can't sit all day. It's more I need to feel that they're being respectful to me as I am respecting their needs. I need them to be kind to one another in my classroom. If they start being catty or picking on each other, I shut that down right away. In the big picture I think it's fairly loose in here. Once it deteriorates past you're being totally disrespectful now, and do give them plenty ... I warn them.

While Mrs. Avery professes to giving students more latitude, they are able to slouch or stand in her class, she still sets the standard for an acceptable range of behaviors. Furthermore, she expects students to acknowledge the freedom they are given in her classroom. She later offered:

For the most part I don't do a lot of discipline because I don't feel I need to. If a kid every once in a while, for whatever reason, if a kid ... I had a kid rip up a test on me. I was like, "Well now you need to leave." If you can approach me, if you can't ... The test was announced, you didn't study for it, not my fault. I had a kid, he got a bad grade, he rolled up the piece of paper and crumpled it, and threw it away. I said, "I spent time on that, you spent time on that, I write all these things. 
You need to read what I said besides the grade. Take the paper down to the office and read."

Mrs. Avery defines herself as more forgiving than other faculty members and recognizes the difficulty in attending a boarding school. She recognizes that students are confined within the building, have little to no privacy, and their behaviors are subjected to scrutiny 24 hours a day. However, she takes a staunch stance that students should respect her contributions and makes it clear that she will not tolerate disrespect. In many ways she defines respect as being appreciative of her contributions. While claiming to recognize students' needs, this conceptualization of respect centers her and her work interactions with students. Furthermore, instead of electing to have a conversation with a student who rips up his test about why that behavior is unacceptable she sends that student out of her classroom. Thus Mrs. Avery's assertion that she doesn't do much discipline because she doesn't need to, may not be fully accurate. Just because she is not handing out a consequence does not mean that that the student won't receive an additional punishment once in the office. This type of outsourcing of discipline was not well received by students. At least one student proclaimed, that when he did something in a particular class, faculty would "run tell their daddy." These types of interactions further impede efforts to build trust.

While the above examples only demonstrate disrespect being called out in the moment, according to Mrs. Bell, often times, disrespect was a reason for suspension or expulsions. She stated: 
Most of the time when they get suspended, all those kind of things, it doesn't happen out of this classroom. It's something they've done to either disrespect somebody, or disrespect a student in a way, or start a fight or something like that.

Mr. Harrison corroborated this stating:

My first year here there was a lot of that, "You offended me so that's why you get a consequence." It wasn't, "You did something wrong. You broke a rule. You violated some principle of the school." It was, "You caught me at a bad time and gave me the wrong look." As those have gone down, discipline issues have gone down for the kids. They feel more comfortable because they know what's expected. They know that they can play around with an adult and that's not something that deserves a punishment. They are better at knowing some of the adult's boundaries.

The perception of disrespect is often the impetus for suspensions and expulsions, and according to Mr. Harrison, when he first arrived at OS suspensions were arbitrary and based on whether or not faculty members felt a personal slight. Disrespect is highly subjective and what is disrespectful to one teacher may not be disrespectful to another, thus students may not have a clear idea of behavioral expectations and may find themselves suspended without understanding why. Additionally, a student's ability to remain a student at OS was largely dependent on his ability to show respect and how an adult felt about him in the moment. 
Because disrespect is a key factor in suspensions and expulsion, respectability is a key variable in a student remaining and being successful at OS. Mrs. Everett defined a successful student in the following way:

He's the kid who has somebody at home that really cares. Really cares about his education. You know what, it almost doesn't matter about ... He's got to bring a willingness with him and a willingness to undergo authority. I see that as a real part ... Some kids, if they have one foot in the streets, they're not willing to come here and be under the authority that is required at this school.

Being a successful student is connected to having a support system at home and a desire to do well, but the key factor to being successful at OS is the ability to undergo authority. Students are expected to acquiesce to what school actors say, succumb to hierarchal relationships, and display deference. Because the leadership at the school is White, undergoing authority means accepting a White cultural ethos, which refers to the way Whites perceive, interpret, and interact with the world (Parsons 2008). The interplay of this White cultural ethos and hierarchal structure, seeking acquiescence and deference, re-establishes a traditional White power structure wherein Black men are placed in a subordinate role.

At OS an at-home suspension is intended to spur reflection about whether a student should remain at the school. Mr. Everett stated:

When you're sent home we always inform the parent and the parent comes in. If you're sent home it raises a real issue about ... what we say to them is, "You go home with your son and the two of you talk about whether this is the right place 
for him because he can't continue to act the way he's acted if he wants to come back." Then we end up saying to them, "You know the drill. You know the expectations. You better conform to them."

Mrs. Everett used the language of undergoing authority, while Mr. Everett discussed conformity. In both instances they desire students to demonstrate deference and respect.

The emphasis on character, especially with regard to conforming and acquiescing to authority, means that there is a narrow range of acceptable behaviors for students at OS. Mrs. Bennett recognized this and attempted to provide a safe space for students to express themselves. She said:

Because this a therapeutic group and not a classroom and trying to keep this space safe for them to express themselves which is hard to give them the freedom to express themselves but then also needing to keep it safe for everybody else. That is challenging. The middle schoolers are always, "You tell us we can express ourselves, but we can't," and I'm like, "You can't disrespect somebody," but you can like, you know, "Yes you can express what you need to express." I don't know. So, that's a challenge I'm still trying to work with. I don't want to have different standards from the rest of the school, but I want them to be able to, if they're angry, express that here because I think it's healthy to be able to get it out, and to teach them to express that anger in appropriate ways that don't themselves or other people. I think that is just an ongoing conversation.

Mrs. Bennett recognized that students' emotions can be stifled in attempting to remain respectful and she wanted her classroom to be a place where students could express 
themselves without fear of consequences. The need for an ongoing conversation suggests incongruence between who they want the students to be (e.g., "men of character") and how they allow them to find themselves within the school. In fact, "finding themselves" is not a part of the students' development or something that the school allows; instead, the school endorses pre-identified characteristics that the students must live up to at all times. Students who do not exhibit these behaviors/characteristics or present themselves in alternate ways are at risk of being sanctioned.

Mr. Smith also understood the tight rope that students must walk and called into question why they behave the way that they do:

I didn't even know all the pillars to be honest with you, but I think that all of those are attempted to be taught to the kids every day, I think the kids do have all those traits. The reason that they have the traits is the only thing that bothers me a little, because it's much like ... This is an extreme example, it's much like a ... I ain't comparing Mr. Everett to Hitler, but I'm saying it's much like a Hitler type thing, to where you do this stuff because you scared of what's going to happen to you when you don't do it. I think the kids do have potential to be very respectful and all this, but I think the reason they do a lot of this stuff is because they're scared what's going to happen if they don't do it...I think it's being taught, but I do think that fear is the driving motivation behind a lot of these things that's being taught. I don't think they do good just to do good, I don't see that. I see a couple kids sometimes they do good just to do good, but these kids I think they're respectful, I think they ... Trust, no they don't, but I think they put up a wall to make it seem 
like they trust people because they're scared of what's going to happen if they don't do that stuff. That's my spiel on those.

Mr. Smith challenged the very premise of the school and argued that the character education that is carried out at OS is motivated by fear. According to Mr. Smith, students are afraid of the consequences of not following the rules or being disrespectful because these behaviors could result in expulsion. OS is built up as this great savior and being expelled could be devastating to students, thus, according to Mr. Smith they behave and they show respect because they want to remain in good standing and they want to remain students at OS. This dynamic discourages students from displaying their true selves and building trusting relationships.

\section{CONCLUSION}

There is an implicit belief held by many within OS that schools should serve a socializing function. The curriculum, language, and interactions identify character, which is raced and gendered, as the aim of socialization at OS. Notions of character are embedded in the fabric of OS. Character constructs are present in the mission and philosophy of the school, student handbooks, and language used in everyday interactions. The social context in which OS is situated (see Chapter 5 and Chapter 6) suggests that the Black male crisis narrative and colorblind ideologies inform and support the logic of the character education curriculum.

Responsibility, which is emphasized above all other character traits is largely

defined as a masculine construct. Embedded in discussions of responsibility is the image of the absentee father, a critical component of the Black male crisis narrative. The 
socializing undertaken at the school is in many ways intended to offset the effects of living in single parent households. As faculty work to define and teach character parents are excluded, inhibiting the development of trust and posing challenges for students as they transition between school and home. In addition to parents being excluded, students generally perceive faculty as antithetical to them. The combination of these two processes along with a hyper-focus on character development make it difficult for students to express their true selves. Students are expected to adhere to a behavior code which in many ways denigrates the communities in which they live and the lessons they may be learning. OS, with this character education curriculum sends the message that in order to be successful students must undergo White authority and adhere to a White cultural ethos. 


\section{CHAPTER VIII: DISCUSSION AND CONCLUSION}

This critical race study of OS sought to understand how racial ideologies operated within the school and shaped school culture. My findings suggest that there is a complex interplay of racial ideologies operating at multiple levels at OS. First, at a societal level, through the social geography of race, the "iconic ghetto" shapes perceptions of students living in the Oakwood community and attending OS. Secondly, at the institutional level, colorblind ideologies are employed by faculty thus allowing issues surrounding race to go ignored, this is particularly striking as OS is an organization predicated on racial inequalities. Additionally, this colorblind ideology is used as justification for everyday practices in the school, specifically a character education curriculum. Finally, colorblind ideology operates on the interpersonal level, impacting how faculty interact with students. This chapter further explicate the major themes outlined above and place them in discussion with literature on race and urban education. Additionally, I discuss the social and educational implications for this work and address possible directions for future research on this topic.

Recall the tenants of CRT are as follows: 1) acknowledging the permanence of race and racism and its intersections with other forms of subordination; 2) engaging in a critique of dominant ideologies regarding objectivity, meritocracy, colorblindness, race neutrality, and equal opportunity; 3) working toward the elimination of racism, sexism, 
and poverty through exposing interest convergence; 4) privileging experiential knowledge through storytelling and counter story telling; and finally, 5) engaging in a transdisciplinary framework (Solorzano 1997, Dixson and Rousseau 2005; Yosso et al. 2004; Solorzano, Ceja, and Yosso; Solorzano and Yosso 2002; Solorzano 1997; Yosso et al. 2004; Solorzano 1997; Howard 2008; Ladson-Billings and Tate 1998). DeCuir and Dixson (2004) asserted that CRT has not been utilized to its full potential because researchers tend to focus on counter storytelling and the permanence of racism (see also, Dixson and Rousseau 2005). My goal is to extend the role of CRT in education research beyond these two tenants by situating my findings within 1) the permanence of race and racism and 2) a critique of liberalism. In my work these two tenants are closely intertwined.

In this study utilizing Dorothy Smith's (2005) institutional ethnography I move from understanding how the ruling relations of American society are enacted by actual people within an urban boarding school. Drawing on CRT, I understand race and racism as ruling relations of American society. CRT argues not only are race and racism permanent features of American society, but they are also central to understanding how U.S. society functions (Ladson-Billings 1995). As I demonstrated in Chapter 4, individuals living in the Oakwood community and the students attending OS are imagined within the context of the "iconic ghetto," wherein the Oakwood community is devalued and constructed as a place to avoid. The imagery of the iconic ghetto can be understood as what Patricia Hill Collins (2005) refers to as a controlling image, meaning that like other controlling images, the iconic ghetto, functions to mask social relations and make racism, sexism, and poverty appear normal and natural. 
According to Anderson (2011) city spaces are typically conceptualized as a mosaic of White spaces, Black spaces, and cosmopolitan spaces. And within the segregation of city spaces White people usually avoid Black space while Black people are required to navigate White space as a condition of their existence (Anderson 2015). On the surface, OS appears to challenge this segregation of spaces by naming the school after the Oakwood community and requiring White individuals who want to be involved to come to the school, enacting a strategy of personal exposure. Personal exposure to Oakwood is intended to dismantle stereotypes about individuals living in the Oakwood community, however, my data suggests that OS falls short in reaching this goal and continues to operate in the service of maintaining White supremacy.

First, while OS attempts to challenge stereotypes about Oakwood, these same stereotypes, or controlling images, influenced the founding of the school and shape how faculty understand student needs. OS was founded based on an understanding of the community which privileged imagery of crime and poverty. Additionally, OS students are generally framed within crisis and deficit narrative surrounding Black males and thought to need social and cultural development as a result of living in single parent homes. This framing of students allows us to see the intersection of race and gender in the iconic ghetto imagery and the impact it has on Black women.

Black women, the mothers of OS students, are framed in accordance with the controlling image of the "Bad Black mother." Bad Black mothers are abusive, neglectful, bitchy, single, living in poverty and depending on the state to support their families, and most importantly in this context, they pass on their bad values to their children. At OS this controlling image of the Bad Black mother is used to justify the boarding school 
model implemented at the school and encourages paternalism and the exclusion of parents from the school. If parents (or more specifically mothers) are seen the ones imbuing poor cultural values then logic follows that they must be excluded from the equation. Furthermore, this logic suggests that the optimal way to address the lagging achievement of Black boys is to remove them from the home and teach them morals and values.

The image of the iconic ghetto rendered student' and their families as unimaginable beyond the crisis and deficit narratives and the majority of OS are imagined coming from single parent homes. Anderson (2015) suggests that this obscuring of variation within the Black community is a function of the iconic ghetto image; "for many, their Black skin designates them as being from the ghetto" thus making the Black middle class as invisible (p.12). My data suggests that this was the case at OS. The way in which students were framed ignored the variation in the student population. The majority of the mothers interviewed challenged that they were single parents as framed in the popular imagination. These mothers and grandmother pointed out they were divorced, widowed, or currently married.

The variation in the student population was also obscured by the low-income admission criteria. In order to be an enrolled at OS the student must qualify for free or reduced lunch. This created an assumption that everyone in the school was low-income in accordance with the iconic ghetto, however administration acknowledge that some parents lied about their income and others gamed the system because they recognized the opportunities the school affords. Furthermore, such framing ignores how some lowincome individuals have assets and resources and may be upwardly mobile. Additionally, 
the racial framing ignores the intersection of race and class. The framing of OS students was decidedly Black, however, not all students attending OS were Black and faculty profess that OS was never intended to be a Black school. Similar to My Brother's Keeper (MBK) OS professes to be racially inclusive however the framing of the students and their issues is decidedly Black (Dumas 2016). Such framing ignores the nuances of race, marginalizes non-Black students attending OS, and misses an opportunity to engage with students based on the actual lived experiences.

It is important to note that even though OS is situated in a Black space it is a White institution, led by White actors, and teaching White values. Thus, by undertaking a strategy for educational inequality that removes students from their homes and denigrates their communities, OS positions itself, and thus "Whiteness" and a key intervention in ameliorating the educational deficits that Black boys face. This is the second way in which OS operates in maintenance of White supremacy. Harris (1993) argues that White property and White racial identity provide the basis for allocating social benefits and one property function of Whiteness is the right to transfer. In many ways OS attempts to extend or transfer the privileges of Whiteness to students attending the school. First, in simply being present and providing resources (i.e., providing social capital) and secondly, in teaching a character education curriculum (i.e., providing cultural capital). This attempt to transfer the property benefits of Whiteness falls short in large part because it adheres to neoliberal policy solutions in various facets of the school.

Neoliberalism as a policy paradigm interprets racial inequality through an individual lens emphasizing cultural deficits as demonstrated above. It also incentives private solutions to public issues. Neoliberal policy in education emphasizes efficiency, 
accountability, privatization, school choice (Hursh 2007). In urban communities that means disinvesting in public schools and opening charter schools (Lipman 2011). Baldridge (2014) asserts that along with increasing numbers of charter schools there is fierce competition for funds and the educational market incentives programs and policies that frame marginalized youth within a deficit narrative. Crenshaw (2104) argues that this type of framing hits a political sweet spot that speaks to both populations who love Black males and who hate them. Similar to other single-sex schools for Black males, after school programs, and MBK, OS relies on crisis and deficit framing in order to leverage funding (Baldridge 2014; Dumas 2016). In Chapter 5, I demonstrated that OS is centered around Whiteness and White racial framing. At OS White liberal guilt translates into a savior identity. Many volunteers and funders are drawn to the school because of the "mission" and their ability to "save" Black boys. It is important to note their ability to "save" boys is dependent on cultural failings on students and their families. At least one teacher understood the ways in which deficit framing of students was used in fundraising efforts. It caused him discomfort but he believed that this was a "necessary evil" in order to help students. However, such framing in the name of money further marginalizes students and White liberal guilt and the White savior complex ignores the structural factors of inequality.

In addition to a White savior complex, colorblind ideology is prominent in OS. In acknowledging the permanence of race and racism we must also acknowledge that these social constructs are mutable and subject to change. Alexander (2010) underscores that a racialized system of control has operated in the US since the advent of slavery (for more on racialized social systems also see Bonilla-Silva 1997, 2014 and Omi and Winant 
2015) and that ideas about racial superiority and inferiority have been used to maintain a racial caste system. The method for maintaining this system, however, has changed. Alexander (2010) argues that slavery, Jim Crow, and Mass incarceration all have operated in the service of White supremacy. Similarly, Collins (2005) argues that new racism presents hegemonic ideas that claim that racism is over and works to obscure that racism exists. She also notes that new racism relies more heavily on the manipulation of ideas within the mass media, thus the role of the iconic ghetto imagery.

Bonilla-Silva (2014) calls this colorblind racism, stating that it justifies racial inequality and explains racial inequality as products of market dynamics, naturally occurring phenomenon, and Blacks cultural limitations. Actors within OS engage in colorblind ideologies in many ways. Faculty at OS engage in variety of strategies which allow them to avoid discussions about race and trivialize the impact that race has on student's lives and the operating of the school. While OS prides itself on challenging stereotypes by encouraging personal contact with Oakwood, because of the centrality of White actors and Whiteness more generally, stereotypes assaulting the Oakwood community remain intact. The personal contact strategy does not require individuals to challenge the ways in which they think about Black people and Black communities, rather those affiliated with OS are understood as transcending their community. Some faculty engage in a discursive strategy of distancing racism. They understand that they may hold biases but work to place the blame elsewhere. Others superficially acknowledge race through the posters, food, and festivals strategy. A final group minimizes the importance of race in the quest for a colorblind society. Because there is no critical analysis of race the strategies engaged at OS do nothing to challenge the 
structure of inequality. And while OS may make a difference in the lives of some students this does not to challenge the structure of White supremacy. And thus, as Willis (1977) states, "A few can make. The class can never follow. It is through a good number trying however, that the class structure is legitimated" (p. 128), or in this case the racial structure is legitimated. Rather, the challenging the status quo, OS through offering benefits of Whiteness to students legitimates the structure of White supremacy.

A major component of the hidden curriculum is for students of color to reach the enlightenment of White faculty where race does not matter. Where it does not matter for their expectations for the futures nor their daily lived experience. The desire for a colorblind world and the circumscribed ways in which faculty address issues of race encourage students to adopt a raceless persona or for them to transcend race, so that their race will not matter once they enter spaces outside of the protective environment of OS, this is despite the fact that faculty know that outsiders continue to look down on the Oakwood community and even their students who have been socialized or molded into an "ideal" Black man. This approach can be understood within a neoliberal policy regime which emphasizes the Black male crisis narrative and private policy solutions. When the problem is situated within the Black male body (as argued by Dumas and Nelson 2016), the Black body becomes something that students should strive to overcome.

Fordham and Ogbu (1986) famously argued that a major reason Blacks have relatively low academic achievement because their culture is antithetical to mainstream US society and they are concerned about the accusation of acting White. Using this logic Fordham (1988) suggested that high achieving Black students minimize their relationship to the Black community and adopt a "raceless" identity in order pursue upward mobility. 
Similarly, Steele's stereotype threat theory proposed that a raceless identity aided Black students in circumventing stereotypes (Spence and Steele 1992; Steele 1988). Other research has found that a raceless strategy may be psychologically damaging (Tatum 1992) and that students with a positive racial/ethnic identity maintain a high self-esteem and are able to perform better because of their ability to navigate hostile and discriminatory environments (Miller 1999). The entire idea of transcending race supports of White supremacy. Perry (2001) argues that the claim that there is no unique White culture is an exercise of power. Compelling students of to transcend race is a manifestation of this power.

In adhering to colorblind ideology faculty consign race work to Black individuals and essentialize race and gender, which further supports White supremacy. By understanding race work as under the purview of people of color there is an implicit assumption that Whiteness is cultureless. Whites understand themselves as enlightened beyond issues of race and therefore they cannot imagine the plight of people of color and see no need to take action. Black people, or Black men more specifically, are well suited for the race work required for OS students. Because students are imagined living in single parent households Black men are deemed necessary to teach Black boys about their identities as Black males and to diminish the effects of living with Bad Black mothers.

Finally, character education is an expression of White supremacy. Emphasis on character education, respect and responsibility feeds into Black male crisis discourse. Character education, as carried out at OS, also reaffirms hierarchal relationships wherein Black men are expected to demonstrate respect and deference to Whiteness and power structures. In the process of engaging in character education OS denigrates students 
home lives in many subtle ways and this inhibits the ability of students to express their true selves.

\section{IMPLICATIONS}

The purpose of this research is not to demonize White teachers and administrators seeking to undertake efforts to address the lagging achievement of Black boys living in urban communities, nor is my goal to label them racist or suggest that they are ill intentioned. Rather, my goal is to show the importance of centering race and racism in education research and praxis work because we operate in a racialized social system. OS may very well help several boys, but schools such as this one do nothing to change the structure of inequality and in many ways reaffirms White supremacy. In order to make meaningful changes in the educational trajectories of Black boys we must enact strategies that challenge the power structure.

While OS would like to imagine itself as enlightened about the plight of boys living in Oakwood and untouched by stereotypes assaulting the community this research shows that that is far from the truth. While colorblindness may be the ideal to which the school strives, it has not reached it, and nor should it because of the ways it obscures the structural factors of racial inequality. Furthermore, character education, the selected avenue for addressing the lagging achievement of Black boys is dependent on deficit and crisis narratives which denigrate and marginalize students. Ultimately my work suggests that schools do not escape the structure of White supremacy and thus those wanting to engage in social justice work in education must seriously take into account an analysis of race and racism. 


\section{REFERENCES}

Alexander, Michelle. 2010. The New Jim Crow: Mass Incarceration in the Age of Colorblindness. New York: The New Press.

Allen, Quaylan. 2012. “They Think Minority Means Lesser Than’: Black Middle-Class Sons and Fathers Resisting Microaggressions in the School." Urban Education 48(2):171-97.

Anderson, Elijah. 2015. "The white space." Sociology of Race and Ethnicity 1(1):10-21.

Anderson, Elijah. 2011. The Cosmopolitan Canopy: Race and Civility in Everyday Life. New York: W.W. Norton.

Anderson, Elijah. 2012. “The Iconic Ghetto.” Annals of the American Academy of Political and Social Sciences 642:8-24.

Arieli, Mordecai, Jerome Beker, and Yitzhak Kashti. 2001. "Residential Group Care as a Socializing Environment: Toward a Broader Perspective." Child and Youth Care Forum 30:403-14.

Baldridge, Bianca J. 2014. "Relocating the Deficit: Reimagining Black Youth in Neoliberal Times." American Educational Research Journal 51(3):440-72.

Barton, Paul E., \& Richard J. Coley. 2009. Parsing the Achievement Gap II. Princeton, NJ: Policy Information Center, Educational Testing Services.

Bass, Lisa R. 2013. "Boarding Schools and Capital Benefits: Implications in Urban School Reform.” The Journal of Educational Research 107(1):16-35.

Bergin, David A. and Helen C. Cooks. 2002. "High School Students of Color Talk About Accusations of 'Acting White."' The Urban Review 34(2):113-34.

Bell, Derrick A. 1980. "Brown v. Board of Education and the Interest Convergence 
Dilemma." Harvard Law Review 93:518-533.

Bell, Derrick A. 1992. Faces at the Bottom of the Well: The Permanence of Racism. New York: Basic Books.

Bell, Derrick A. 1995. "Racial realism”. Pp. 302-312 in Critical Race Theory: The Key

Writings That Formed the Movement, edited by Kimberle Crenshaw, Neil

Gotanda, Gary Peller, and KendallThomas. New York: The New Press.

Bonilla-Silva, Eduardo. 2014. Racism Without Racists: Colorblind Racism and the

Persistence of Racial Inequality in America. Lanham,MD: Rowman \& Littlefield.

Bonilla-Silva, Eduardo. 1997. "Rethinking Racism: Toward a Structural Interpretation.” American Sociological Review 62(3):465-80.

Bourdieu, Pierre. 1973. "Cultural Reproduction and Social Reproduction.” Pp. 71-112 in Knowledge, Education and Cultural Change, edited by Richard Brown. London: Tavistock Publications.

Buch, Elana D. and Karen M. Stallar. 2014. "What is Feminist Ethnography?” Pp.107-44 in Feminist Research Practice: A Primer, edited by Sharlene Nagy Hesse-Biber. Los Angles: Sage.

Butler, Paul. 2013. "Black Male Exceptionalism? The Problems and Potential of Black Male-Focused Interventions.” Du Bois Review 511:485-511.

Bracey, Gerald. 2007. "The Success of Single-Sex Education is Still Unproven.” The Education Digest 72(6):22-26.

Brown, Anthony L. and Jamel K. Donnor. 2011. "Toward a New Narrative on Black Males, Education, and Public Policy.” Race Ethnicity and Education 14(1):17-32. 
Campbell, Marie L. 1998. "Institutional Ethnography and Experience as." Qualitative Sociology 21(1):55-73.

Campbell, Marie, and Frances Gregor. 2002. Mapping social relations: A primer in doing institutional ethnography. Toronto: University of Toronto Press.

Carter, Prudence L. 2005. Keepin' it Real: School Success Beyond Black and White. Oxford: Oxford University Press.

Charmaz, Kathy. 2006. Constructing grounded theory. Los Angeles: Sage.

Clark, Jelisa S. 2015. "To Be a Man is to Be Responsible: A Focus on Character at Urban City School. Department of Sociology: University of Louisville.

Crenshaw, Kimberle. 2014. “The girls Obama forgot.” New York Times, July 29. Retrieved, April 17 (https://www.nytimes.com/2014/07/30/opinion/KimberlWilliams-Crenshaw-My-Brothers-Keeper-Ignores-Young-Black-Women.html)

Crenshaw, Kimberle. W. 1988. "Race, Reform, and Retrenchment: Transformation and Legitimation in Anti-Discrimination Law." Harvard Law Review 101:1331-1387.

Crenshaw, Kimberle, Neil Gotanda, Gary Peller, and Kendall Thomas (Eds.). 1995. Critical Race Theory: The Key Writings That Formed the Movement. New York: The New Press.

Coleman, James S., Ernest Campbell, Carol Hobson, James McPartland, Alexander Mood, Frederick Weinfeld, and Robert York. 1966. "The Coleman Report." Equality of Educational Opportunity.

Collins, Patricia Hill. 2004. Black Sexual Politics: African Americans, Gender, and the New Racism. New York: Routledge.

Collins, Patricia Hill. 2000. Black Feminist Thought: Knowledge, Consciousness, and the 
Politics Of Empowerment. New York: Routledge.

Collins, Randall. 1971. "Functional and Conflict Theories of Educational

Stratification." American Sociological Review 36(6): 1002-1019.

Connell, Robert W. and James W. Messerschmidt. 2005. "Hegemonic Masculinity Rethinking the Concept." Gender \& Society 19(6):829-859.

Cook, Philip J., and Jens Ludwig. 1997. “Weighing the 'Burden of Acting White': Are There Race Differences in Attitudes toward Education?" Journal of Policy Analysis and Management 16:256-78.

. 1998. “The Burden of 'Acting White': Do Black Adolescents Disparage

Academic Achievement?" Pp. 375-400 in The Black-White Test Score Gap, edited

by C. Jencks and M. Phillips. Washington, DC: Brookings Institution.

Cookson, Peter W. and Caroline Hodges Persell. 1991. "Race and Class in America's Elite Preparatory Boarding Schools: African Americans as the 'Outsiders within."” The Journal of Negro Education 60(2):219-28.

Cornell, R. W. 1996. "Teaching the Boys: New Research on Masculinity, and Gender Strategies for Schools.” Teachers College Record 98(2):206-235.

Curto, Vilsa E. and Ronald G. Fryer Jr. 2014. "The Potential of Urban Schools for the Poor: Evidence from SEED.” Journal of Labor Economics 32 (1):65-93.

Davis, James Earl and Will J. Jordan. 1994. "Structure, the Effects of School Context, and Experiences on African American Males in Middle and High School." Journal of Negro Education 63(4):570-87.

Davis, James E. 2003. "Early Schooling and Academic Achievement of African American Males." Urban Education 38(5):515-37. 
DeCuir, Jessica T. and Adrienne D. Dixson. 2004. “'So When It Comes Out, They Aren’t That Surprised That It Is There': Using Critical Race Theory as a Tool of Analysis of Race and Racism in Education.” Educational Researcher 33(5):2631.

Delgado, Richard. 1989. "Storytelling for Oppositionists and Others: A Plea for Narrative." Michigan Law Review 87(8): 2411-2441.

Delgado, Richard and Jean Stefancic. 1993. "Critical Race Theory: An Annotated Bibliography." Virginia Law Review 79:461-516.

DeVito, Lee. 2016. "Detroit Teachers are Using Twitter to Document Poor School Conditions." Detroit Metro Times Jan 14. Retrieved March 30, 2016 (http://www.metrotimes.com/news-hits/archives/2016/01/14/detroit-teachers-areusing-twitter-to-document-poor-school-conditions)

Dick, R., S. Manson, and J. Beals. 1993. "Alcohol Use among Male and Female Native American Adolescents: Patterns and Correlates of Student Drinking in a Boarding School." Journal of Studies on Alcohol 54(2):172-77.

Dixson, Adrienne D. and Celia K. Rousseau. 2005. “And We Are Still Not Saved: Critical Race Theory in Education Ten Years Later." Race Ethnicity and Education $8(1): 7-27$.

Downey, Douglas B. 2008. Black/White differences in school performance: The oppositional culture explanation. Annual Review of Sociology 34: 107-126.

Downey, Douglas B. and Shana Pribesh. 2004. "When race matters: Teachers' evaluations of students' classroom behavior." Sociology of Education 77(4): 267282. 
Dumas, M. J. 2016. “My Brother as 'Problem': Neoliberal Governmentality and Interventions for Black Young Men and Boys.” Educational Policy 30(1):94-113.

Dumas, Michael J. and Joseph Derrick Nelson. 2016. “(Re)Imaging Black Boyhood: Toward and Critical Framework for Educational Research." Harvard Educational Review 86(1):27-48.

Dwarte, Marquis S. 2014. “The Impact of Single-Sex Education on African American Student Achievement: An Analysis of an Urban School's Reform Efforts." The Journal of Negro Education 83(2):168.

Elias, M. J. 2009. "Social-Emotional and Character Development and Academics as a Dual Focus of Educational Policy.” Educational Policy 23(6):831-46.

Emihovich, Catherine A. 1983. "The Color of Misbehaving: Two Case Studies of Deviant Boys.” Journal of Black Studies 13(3):259-74.

Farmer-Hinton, Raquel L. and Toshiba L. Adams. 2006. "Social capital and college preparation: Exploring the role of counselors in a college prep school for black students." Negro Educational Review 57(1/2: 101-116

Feagin, Joe R. 2013.The white racial frame: Centuries of racial framing and counterframing. New York: Routledge.

Fergus, Edward and Pedro Noguera. 2010. "Theories of Change Among Single-Sex Schools for Black and Latino Males: An Intervention in Search of Theory." Metropolitan Center for Urban Education. NYU Steinhardt School of Culture, Education, and Human Development.

Ferguson, Ann Arnett. 2001. Bad Boys: Public Schools in the Making of Black Masculinity. University of Michigan Press. 
Ford, Donna Y. and James L. Moore III. 2013. "Understanding and Reversing Underachievement, Low Achievement, and Achievement Gaps Among High-Ability African American Males in Urban School Contexts." Urban Review 45(4):399-415. Retrieved (http://link.springer.com/10.1007/s11256-013-0256-3).

Fordham, Signithia, and John U. Ogbu. 1986. "Black students' school success: Coping with the "burden of 'acting white"." The urban review 18(3): 176-206.

Fordham, Signithia. 1988. "Racelessness as a factor in Black students' school success: Pragmatic strategy or pyrrhic victory?" Harvard educational review 58(1): 54-85.

Frankenberg, Ruth. 1993. White women, race matters. Minneapolis: University of Minnesota Press.

Freeman, Alan D. 1977. "Legitimizing racial discrimination through antidiscrimination law: A critical review of supreme court doctrine." Minnesota Law Review 62: 1049.

Fultz, M. and a. Brown. 2008. "Historical Perspectives on African American Males as Subjects of Education Policy." American Behavioral Scientist 51(7):854-71. Retrieved (http://abs.sagepub.com/cgi/doi/10.1177/0002764207311994).

Glenn, William J. 2012. "School Resegregation: A Synthesis of the Evidence.” Pp. 28298 in The Educational Forum, vol. 76. Taylor \& Francis.

Goodkind, Sara. 2013. "Single-sex public education for low-income youth of color: A critical theoretical review." Sex Roles 69:393-402

Gotanda, Neil. 1991. "A Critique of" Our Constitution is Color-Blind"." Stanford Law Review 44(1): 1-68. 
Gouldner, Alvin W. 1970. The Coming Crisis of Western Sociology. New York: Basic Books.

Gregory, Anne, Russell J. Skiba, and Pedro A. Noguera. 2010. “The Achievement Gap and the Discipline Gap: Two Sides of the Same Coin?" Educational researcher 39(1):59-68. Retrieved (http://www.jstor.org/stable/27764554).

Hallinan, Maureen T. 1994. "Tracking: From theory to practice." Sociology of Education 67(2): 79-84.

Hannah-Jones, Nikole. 2014. "School Segregation, the Continuing Tragedy of Ferguson" ProPublica. Retrieved, https://www.propublica.org/article/ferguson-schoolsegregation

Harding, Sandra 2004. The Feminisist Standpoint Theory Reader: Intellectual and Political Controversies. New York: Routledge.

Harper, Shaun R. 2006. "Reconceptualizing Reactive Policy Responses to Black Male College Achievement: Implications from a National Study.” Focus: Magazine of the Joint Center for Political and Economic Studies 34(6):14-15. Retrieved (http://140.198.8.206/studentaffairs/minoritymales/Reconceptualizing_Reactive_Pol icy_Responses_to_Black_Male_College.pdf).

Harper, Shaun R. and Charles H. F. Davis. 2012. “They (Don’t) Care about Education: A Counternarrative on Black Male Students ' Responses to Inequitable Schooling.” Educational Foundations 103-20.

Harris, Angel L. 2006. “I (Don’t) Hate School: Revisiting Oppositional Culture Theory of Blacks’ Resistance to Schooling." Social Forces 85(2):797-834. Retrieved (http://sf.oxfordjournals.org/cgi/doi/10.1353/sof.2007.0006). 
Harris, Cheryl I. 1993. "Harvard Law Review Whiteness As Property." Harvard law review 106(8):1707-91.

Harvard Law Review. 1992. "Inner-City Single-Sex Schools: Educational Reform or Invidious Discrimination.” Harvard Law Review 105: 1741-60.

Hatt, Beth. 2011. "Still I rise: Youth caught between the worlds of schools and prisons." The Urban Review 43(4): 476.

Hirschfield, Paul J. 2008. "Preparing for prison? The criminalization of school discipline in the USA." Theoretical Criminology 12(1): 79-101.

Hoffman, Bobby H., Barbara A. Badgett, and Robert P. Parker. 2008. "The Effect of Single-Sex Instruction in a Large, Urban, At-Risk High School.” The Journal of Educational Research 102(1):15-35.

hook, bell. 2004. We Real Cool: Black Men and Masculinity. New York:Routledge.

Howard, Tyrone C. 2008. "Who Really Cares? The Disenfranchisement of African American Males in PreK-12 Schools: A Critical Race Theory Perspective.” Teachers College Record 110(5):954-85.

Howard, Tyrone C. 2014. Black Male(d):Peril and Promise in the Education of African American Males. Teachers College Press.

Howard, Tyrone C. 2003. "A tug of war for our minds": African American high school students' perceptions of their academic identities and college aspirations. High School Journal 87: 4-17.

Hudley, Cynthia. 1998. “Urban Minority Adolescents' Perceptions of Classroom Climate." Paper Presented at the Annual Meeting of the American Educational Research Association, San Diego, CA. 
Hursh, David. 2007. “Assessing No Child Left Behind and the Rise of Neoliberal Education Policies.” American Education Research Journal 44(3): 493-518.

Johnson, Latrise P. 2014. “The Writing on the Wall: Enacting Place Pedagogies in Order to Reimagine Schooling for Black Male Youth." Discourse: Studies in the Cultural Politics of Education 36(6):1-12.

Jones, Ashley. ND. "Millon Man March, 1995." Retrieved, April 10, 2016

(http://www.blackpast.org/aah/million-man-march-1995)

Jorgensen, Danny L. 1989. Participant Observation:A Methodology for Human Studies. Thousand Oaks: Sage.

Kozol, Jonathan. 2012. Savage inequalities: Children in America's schools. New York: Broadway Paperback.

Ladson-Billings, Gloria. 2006. "From the Achievement Gap to the Education Debt: Understanding Achievement in US Schools.” Educational researcher 35(7):3-12.

Ladson-Billings, Gloria. 1998. “Just What Is Critical Race Theory and What's It Doing in a Nice Field like Education?” International Journal of Qualitative Studies in Education 11(1):7-24.

Ladson-Bllings, Gloria and William F. Tate. 1995. "Toward a Critical Race Theory of Education.” Teachers College Record 97(1):47-68.

Lawrence, Charles. 1995. "The word and the river: pedagogy as scholarship as struggle" in K. Crenshaw, N. Gotanda, G. Peller \& K. Thomas (Eds) Critical race theory: the key writings that formed the movement. New York: The New Press 
Lewis, Amanda. 2003. Race in the schoolyard: Negotiating the color line in classrooms and communities. New Brunswick: Rutgers University Press

Lickona, Thomas. 1996. "Eleven Principles of Effective Character Education." Journal of Moral Education 25(1):93. Retrieved (http://search.ebscohost.com/login.aspx?direct=true \&db=pbh\&AN=9604291622\&si te=ehost-live).

Lipman, Pauline. 2012. "Neoliberal Urbanism, Race, and Equity in Mathematics Education." Journal of Urban Mathematics Education 5 (2):6-17.

Lipman, Pauline. 2011. The new political economy of urban education: Neoliberalism, race, and the right to the city. New York: Routledge.

Lofland, John, and Lyn H. Lofland. 2006. Analyzing social settings. Belmont, CA: Wadsworth Publishing Company.

López, Nancy. 2002 "Race-gender experiences and schooling: second-generation Dominican, West Indian, and Haitian youth in New York city." Race ethnicity and education 5 (1): 67-89.

Martin, Margary, Edward Fergus, and Pedro Noguera. 2010. "The Academic Characteristics of Black and Latino Boys that Matter in Achievement: An Exploratory Achievement Model of Boys in Single-Sex Schools." Metropolitan Center for Urban Education. NYU

Martino, Wayne, Martin Mills, and Bob Lingard. 2005. "Interrogating single-sex classes as a strategy for addressing boys' educational and social needs." Oxford Review of Education 31(2):237-54.

Matsuda, M. (1995). "Looking to the bottom: Critical legal studies and reparations." Pp. 
63-79 in Critical Race Theory: The Key Writings that Formed the Movement edited by K.Crenshaw, N. Gotanda, G. Peller, and K. Thomas. New York: The New Press.

Matsuda, Mari J, Charles R. Lawrence, Richard Delgado, and Kimberele Crenshaw (Eds.). 1993. Words that wound: Critical race theory, assaultive speech, and the first amendment. Boulder, CO: Westview Press.

Mayer, Susan, Boris Thomas, and William DeVane Logue. 2003. Close to Home: Community Boarding Schools and Disadvantaged Children and Youth. Chicago. Miller, David B. 1999. "Racial Socialization and Racial Identity: Can They Promote Resiliency for African American Adolescents?'” Adolescence 34:493-501.

Milner, H.Richard. 2007. "African American Males in Urban Schools: No Excuses: Teach and Empower.” Theory into Practice 46(3):239-46.

Nagengast, Benjamin, Herbert W. Marsh, and Kit-Tai Hau. 2013. "Effects of single-sex schooling in the final years of high school: A comparison of analysis of covariance and propensity score matching." Sex Roles 69: 349-55

Noguera, Pedro A. 2008. The Trouble with Black Boys:... And Other Reflections on Race, Equity, and the Future of Public Education. San Francisco: John Wiley \& Sons.

Noguera, Pedro A. 1997. Reconsidering the" crisis" of the Black male in America. Social Justice 24(2): 147-164.

Mullholland, Judith, Paul Hansen, and Eugene Kaminski. 2004. "Do single-gender classrooms in coeducational settings address boys' underachievement? An Australian study." Educational Studies 30(1):19-32. 
Oakes, Jeannie. 2005. Keeping track: How Schools Structure Inequality. New Haven: Yale University Press.

Omi, Michael, and Howard Winant. 2015. Racial formation in the United States.New York: Routledge.

Orfield, Gary, and Chungmei Lee. 2004. "Brown At 50: King’s Dream or Plessy’s Nightmare."The Civil Rights Project. Cambrigde: Harvard University

Pager, Devah. 2008. Marked: Race, crime, and finding work in an era of mass incarceration. Chicago: University of Chicago Press.

Parker, Lesley H. and Léonie J. Rennie. 2002. “Teachers’ Implementation of GenderInclusive Instructional Strategies in Single-Sex and Mixed-Sex Science Classrooms." International Journal of Science Education 24(9):881-97.

Parsons, Eileen Carlton. 2008. "Learning Contexts, Black Cultural Ethos, and the Science Achievement of African American Students in an Urban Middle School." Journal of Research in Science Teaching 45(6):665-83.

Perry, Pamela. 2001. "White means never having to say you're ethnic: White youth and the construction of "cultureless" identities." Journal of Contemporary Ethnography 30 (1):56-91.

Pitre, Paul E. 2006. "College choice: A study of African American and white student aspirations and perceptions related to college attendance." College Student Journal 40(3):562-574.

Pratt-Clarke, Menah. 2010. Critical Race, Feminism, and Education: A Social Justice Model. New York: Palgrave MacMillian. 
Raible, John and Jason G. Irizarry. 2010. "Redirecting the Teacher's Gaze: Teacher Education, Youth Surveillance and the School-to-Prison Pipeline." Teaching and Teacher Education 26(5):1196-1203.

Rios, Victor M. 2011. Punished: Policing the Lives of Black and Latino boys. New York: Teachers College Press.

Rist, Ray C. 1970. "Student Social Class and Teacher Expectations: The Self-Fulfilling Prophecy in Ghetto Education." Harvard Educational Review 40(3):411-51.

Riordan, Cornelius. 1990. Girls and Boys in School: Together or Separate? New York: Teachers College Press.

Robinson, W. P. and E. Gillibrand. 2004. "Single Sex Teaching and Achievement in Science." International Journal of Science Education 26(6):659-75.

Salamone, Rosemary. 2006. "Single-Sex Programs: Resolving the Research Conundrum."'Teachers College Record 108(4):778-802.

Sanders, Marvis G. 1998. "The Effects of School, Family, and Community Support on the Academic Achievement of African American Adolescents." Urban Education 33(3):385-409.

Scott, Lakia M., Ayana Allen, and Chance W. Lewis. 2014. "Dispelling Disparities for African American Male Students: A Review of Three Successful Charter School Models." Journal of African American Males in Education 5(1):1-22.

Schott Foundation for Public Education. 2015. Black Lives Matter: The Schott 50 State Report on Public Education and Black Males. 
Skiba, Russ and Reece Peterson. 2003. "Teaching the Social Curriculum: School Discipline as Instruction." Preventing School Failure: Alternative Education for Children and Youth 47(2):66-73.

Small, Mario L., 2009. "How Many Cases do I Need? On Science and the Logic of Case Selection in Field-Based Research.” Ethnography 10(1):5-38.

Smith, Dorothy E. 2005. Institutional ethnography: A sociology for people. Lanham: Altamira Press.

Solorzano, Daniel G. 1997. "Images and Words That Wound: Critical Race Theory, Racial Stereotyping, and Teacher Education.” Teacher Education Quarterly 24(3):5-19.

Solórzano, Daniel G. and Tara J. Yosso. 2002. "Critical Race Methodology: CounterStorytelling as an Analytical Framework for Education Research.” Qualitative Inquiry 8(1):23-44.

Solorzano, Daniel, Miguel Ceja, and Tara Yosso. 2000. "Critical race theory, racial microaggressions, and campus racial climate: The experiences of African American college students." Journal of Negro Education 69(1/2):60-73.

Sprague, Joey. 2005. Feminist methodologies for critical researchers. Lanham: Altamira Press.

Spencer, S. J. and Claude M. Steele. 1992. "The Effect of Stereotype Vulnerability on Women's Math Performance.” Paper presented at the 100th Annual Convention of the American Psychological Association. Washington, DC.

Steele, Claude. 1988. "The Psychology of Self-Affirmation.” Advances in Experimental Social Psychology 21:261-302. 
Tatum, Beverly Daniel. 1992. “African-American Identity Development, Academic Achievement, and Missing History." Social Education 56:331-33.

Toldson, Ivory A. 2008. Breaking Barriers: Plotting the Path to Academic Success for School-Age African American Males. Washington, D.C: Congressional Black Caucus Foundation, Inc.

Toldson, Ivory A., Ronald L. Braithwaite, and Rashika J. Rentie. 2009. "Promoting College Aspirations Among School-Age Black American Males.” Diversity in Higher Education 7(2009):117-37.

Tyson, Karolyn. 2002. "Weighing in: Elementary-Age Students and the Debate on Attitudes toward School among Black Students.” Social Forces 80:1157-89. . 2003. "Notes from the Back of the Room: Problems and Paradoxes in the Schooling of Young Black Students.” Sociology of Education 76:326-43.

Tyson, Karolyn, William Darity Jr., and Domini Castellino. 2005. "Black Adolescents and the Dilemmas of High Achievement.” American Sociological Review 70:582605

Vincent, Carol, Stephen Ball, Nicola Rollock, and David Gillborn. 2013. "Three Generations of Racism: Black Middle-Class Children and Schooling.” British Journal Of Sociology Of Education 34(5-6):929-946

Warner, Carol and Tracy X. Karner. 2010. Discovering Qualitative Methods. Oxford: Oxford University Press.

What Works Clearinghouse. 2014. WWC Evidence Review Protocol for Character Education Interventions: Character Education.Washinginton, DC: Institute of Education Science: 1-11. 
Williams, Patricia. 1991. The Alchemy of Race and Rights: Diary of a Law Professor. Cambridge: Harvard University Press.

Wilson, William Julius. 1987. The Truly Disadvantaged: The Inner City, the Underclass, and Social Policy. Chicago: University of Chicago.

Wilson, William. Julius. 2009. More Than Just Race: Being Black and Poor in the Inner City. New York: W.W. Norton \& Company, Inc.

Willis, Paul E. 1977. Learning to Labor: How Working Class Kids get Working Class Jobs. New York: Columbia University Press.

Wolfers, Justin, David Leonhardt, and Kevin Quealy. 2015. “1.5 Million Missing Black Men." New York Times. http://www.nytimes.com/interactive/2015/04/20/upshot/missing-Blackmen.html?_r=0

Yan, Wenfan. 1999. "Successful African American Students: The Role of Parental Involvement." Journal of Negro Education 68(1):5-22.

Yosso, Tara J., Laurence Parker, Daniel G. Solórzano, and Marvin Lynn. 2004. “ From Jim Crow to Affirmative Action and Back Again: A Critical Race Discussion of Racialized Rationales and Access to Higher Education." Review of Research in Education 28(1):1-25.

Zamudio, Margaret M., Caskey Russell, Francisco A. Rios, and Jacquelyn L. Bridgeman. 2011. Critical Race Theory Matters: Education and Ideology. New York: Routledge. 
Student Interview Guide

APPENDIX A

Pseudonym:

Grade:

Race:

\section{Background Questions}

1. Tell me about yourself.

2. What things do you like to do in your free time?

a. Tell me about any extracurricular activities you participate in.

3. Tell me about the schools you attended before OS.

a. Describe your relationships with other students.

b. Describe your relationships with teachers/ administrators/ other staff.

Experiences and Relationships at OS

4. Tell me about your experiences at OS.

a. How long have you been a student at OS?

b. How did you and your family make the decision to apply here?

c. What is your favorite thing about being a student here?

d. What is your least favorite thing about being a student here?

e. Tell me about your relationships with other students at OS.

i. Tell me about which students you consider to be your friends.

ii. What is it that makes you all friends?

f. Tell me about your relationships with the faculty and staff here? (What kind of relationship do you have with the teachers?)

i. Tell me about your favorite teachers.

ii. What is your relationship like with those teachers?

iii. What is your relationship with other faculty and staff like?

g. How does OS compare to other schools you've attended?

Discipline

5. What do faculty here expect in terms of behavior? (How do they want you to behave?)

a. How do you know that this is what they expect?

b. How do you feel/what do you think about those expectations? 
6. What things have you gotten in trouble for?

7. What was that experience like?

8. What have you gotten rewarded for? How did that make you feel?

9. What happens when you do not behave as expected?

10. What happens when you do behave as expected or better than expected?

Race and Gender at OS

11. What is it like to go to an all boys school?

12. How do your teachers/coaches/advisors talk about issues of race/ethnic groups?

a. How do they talk about issues affecting your community?

b. What do you think about these discussions?

13. Majority of the kids in this school are Black, what impact does the racial make-up have on you?

a. How does it impact the way that you interact with others here at school?

14. In what ways does OS pay attention to your race?

15. What have you learned about yourself as a Black male by attending OS?

a. How did you learn these things?

Academics

16. Tell me about your goals (educational, occupational and life).

a. What role has OS played in helping you develop these goals?

17. Which classes do you excel in?

18. Tell me about what you expect after leaving OS?

Closing

19. Is there any thing else you would like to share?

20. Do you have any questions or concerns for me at this time? 
Teacher/Staff Interview Guide

\section{APPENDIX B}

Pseudonym:

Years Experience:

30

Gender:

Subject/Grade:

Race:

1. Tell me what drew you to the field of education?

2. Tell me what drew you to the OS?

3. Describe your teaching philosophy.

4. Tell me about working at OS.

a. How long have you been working here?

b. Talk to me about the pillars of the school?

c. Describe your relationship with the other teachers and staff here.

d. What does OS do best? Which things could use improvement?

5. Tell me about your students.

a. Talk to me about the students' strengths.

b. What are their needs and challenges?

c. What is your relationship like with OS students?

d. Which characteristics of OS stick out to you as being most beneficial to students?

Race and Gender

6. In what ways do you think the school focuses on their racial and gender identity?

a. What do you think about the school motto, being a man means being responsible?

b. What role do you believe that race and/or gender plays in your students' life chances?

c. What do you teach your students about the discrimination they may face outside of the schools?

d. In what ways do you affirm the student's cultural backgrounds?

7. How do you talk with students about issues of race/ethnic groups?

8. How do you talk with students about different communities?

9. Being that majority of the student body is African American, how do you balance the needs of those students who don't fit neatly into that racial category? (How do the students who are not Black fit into the school?)_

a. What efforts are made to affirm their racial identities? 
10. What types of discussions have you had students regarding their feelings about the racial dynamics of the school, particularly those students who don't exactly fit in?

11. How often do you think about your racial identity? Has that changed since you've been working here?

Discipline

12. What is your personal philosophy about discipline?

13. How do you feel about the manner in which students behave?

14. What kinds of changes have you noticed in terms of behavior as students spend more time at OS?

15. What role does your recognition of students background impact how you handle discipline?

16. Tell me about your past experiences with disciplining students?

a. What types of behaviors do you deal with regularly?

b. How do both the behaviors and the ways that you deal with them compare to other schools you've worked at?

17. Have you had to discipline any student here? What did that look like?

18. Talk to me about suspensions?

Academics

19. Tell me about your goals for each grade level?

a. How did you decide on these goals?

20. How do you respond to a student who is struggling with the material in your class?

Closing

21. Is there any thing else you would like to share?

22. Do you have any questions or concerns for me at this time? 


\section{APPENDIX C}

Parent Interview Guide

Age

Race

Gender
High Level of Education

Income

1. Tell me about your son.

a. What has his childhood been like?

b. How is he as a student?

c. What is he like around the house and family?

d. What activities is he in to?)

2. Describe your goals and aspirations for your son?

a. How does OS fit into that?

\section{Choosing OS School}

3. How did you learn of OS?

a. How did you decide to enroll your son here?

b. Why did you choose this school for your son?

4. How would you describe OS school to someone that's never heard of it?

5. What do your family/friends think about the decision you made to enroll your son(s) here?

6. How do you feel about your decision?

a. In what ways has OS met your expectations?

b. In what ways has OS not met your expectations?

Experiences and Relationships at OS

7. How would you describe your son's school experiences so far?

a. Describe some of his successes and failures in this school?

b. How confident are you about the quality of education your child is receiving at this school?

c. How does OS compare to other schools your son has attended?

8. Describe you relationship with the administration here?

9. Describe your relationship with the teachers and other faculty/volunteers?

d. Tell me about your contact with the school this year (who do you talk to, who initiated, nature of contact, level of satisfaction with it?)

10. Describe your relationship with other parents and/or students at this school?

11. What do you think about the character education aspect of the school? 
a. What do you think about the pillars of the school?

b. What do you think about the notion of, "to be a man is to be responsible")?

Race and Gender

12. What things do you want your son to know about being a Black male?

a. How does OS support this?

13. What do you think are the issues that Black men face in society today?

b. What role do you believe that race and/or gender plays in your son's life chances?

c. In what ways do you think that race is an issue in your son's schooling experiences?

d. What do you teach your son about the discrimination they may face outside of school? Inside school?

14. In what ways does OS pay attention to your son's race/gender?

e. What has OS taught your son about being a Black male?

\section{Closing}

15. Would you recommend this school to friends/family members? Why or Why not?

16. Is there any thing else you would like to share?

17. Do you have any questions or concerns for me at this time? 


\section{CURRICULUM VITA}

\section{JELISA CLARK}

115 Lutz Hall * University of Louisville * Louis ville, KY 40292 *

jelisa.clark@louisville.com

\section{EDUCATION}

University of Louisville, Louisville, KY

Ph.D. in Applied Sociology, Expected May 2017

Areas of Specialization: Race, Education, and Qualitative Methods

Dissertation: This is a Black and White Conversation: Navigating Race, Class, and Gender at an Urban Boarding School

Chair: Derrick Brooms

M.A. in Sociology, 2013

Thesis: Hope for Cities or Hope for People? HOPE VI at Liberty Green

Chair: Cynthia Negrey

University of Kentucky, Lexington, KY

Bachelors of Business Administration, 2010

Major: Marketing; Minor: Sociology

Summa Cum Laude

\section{SCHOLARSHIP}

\section{Publications}

Clark, J. S. and Negrey, C. "Hope for Cities or Hope for People: Neighborhood Development and Demographic Change." (Forthcoming, City and Community)

Brooms, D.R., and Clark, J.S. "Being and Becoming Men of Character: Exploring Latino

and Black Males' Brotherhood and Masculinity through Leadership in College." (Forthcoming, Journal of Hispanic Higher Education)

Brooms, D. R., Goodman, J. M., and Clark, J.S. 2016 "“We Need More of This": Engaging

Black Men on College Campuses" College Student Affairs Journal 33(1): 105123.

\section{Reports}

Brooms, D. R. and Clark, J.S. 2016. "Engaging Men of Color in their Educational Journeys."

Clark, J.S. 2015. "To Be a Man is to Be Responsible: A Focus on Character at Urban City School." 


\section{Under Review}

Brooms, D.R., Clark, J.S., and Smith, M. Building Community on Campus:

Empowering and Engendering Success for Men of Color in Higher Education. (Under Contract, Rutgers University Press).

Clark, J.S. and Brooms, D. R. "Examining Black Male Persistence in College: Engagement, Sense of Belonging and Bonding on Campus." (Revise and Resubmit, Journal of Negro Education)

Brooms, D. R., and Clark, J. S. "Reasonable Racism and the Killing of Black Men" (Under

\section{In Progress}

Review, Sociological Focus)

Clark, J. S. "Bring Our Girls Back: Race, Gender, and School Discipline."

\section{Conferences and Presentations}

Women Faculty of Color. Panel Sponsored by University of Louisville's School of Interdisciplinary and Graduate Studies, University of Louisville, 2017.

Examining Black Men's Persistence: Engagement, Bonding, and Self-Authorship on Campus. Presented at the 2017 annual meeting of the Midwest Sociological Society Conference (Milwaukee, WI).

Colorblind Character Education: School Culture and Racial Ideology at an Urban Boarding School. Presented at the 2016 annual meeting of Midwest Sociology of Education Conference (Bloomington, IN).

Respect and Responsibility: Building Character for Urban Black Males. Presented at the 2016 annual meeting of the Association of Black Sociologist (Memphis, TN).

Race, Gender, and the School to Prison Pipeline. Invited lecture. University of Louisville, 2016.

Bring Our Girls Back: The Missing Discourse on Girls in the School to Prison Pipeline. Presented at the 2016 annual meeting of the Southern Sociological Society (Atlanta, GA).

Racial Discourse on the School to Prison Pipeline: A Lesson in Color-Blind ideology. Presented at the 2015 annual meeting of the Association of Black Sociologist (Chicago, IL).

Closing the School to Prison Pipeline: Litigation and Civil Rights Appeals. Presented at the January 2015 Council on Postsecondary Education: Committee on Equal Opportunities Meeting (Frankfort, KY).

Entering the Spotlight: National News Coverage of the School to Prison Pipeline. Presented at the 2014 annual meeting of the Association of Black Sociologists (Charlotte, NC).

The Cycle of Demolition: Public Housing in the US. Invited lecture, University of Louisville, 2014. 
From Slum Clearance to HOPE VI: Brief History of Public Housing. Invited lecture, University of Louisville 2013.

Hope for Cities or Hope for People? Hope VI at Liberty Green. Presented at the 2013 Mid South Sociological Association conference (Atlanta, GA).

Push Her Against the Wall: Rap, Misogyny, and Young Listeners. Presented at the 2013 Anthropologist and Sociologists of Kentucky conference (Louis ville, KY).

Session Organizer: Race, Ethnicity, and Identity

\section{Research Experience}

Investigating Alternative Forms of Education: School Culture at an Urban Boarding School

University of Louisville Sociology Department, 2015-2016

Ethnographic research at an urban boarding school, investigating how the policies and

practices impact school culture and student success.

Engaging Men of Color in Their Educational Journey

University of Louisville, Sociology Department, 2015-2016

Co-Investigator of a mixed method program evaluation of a Black and Latino Male

college success program.

Perceptions of Race, Stereotyping and Profiling

University of Louisville Sociology Department, 2013-present

Conducted in-depth interviews as a member of a three-person team.

Graduate Research Assistant

University of Louisville Sociology Department, 2012-2013

Worked alongside faculty member to develop a literature review and analyzed

qualitative interview data.

Undergraduate Research Assistant

University of Kentucky, 2008

Conducted phone surveys for a large-scale study on posthumous reproduction.

\section{TEACHING}

Instructor

Simmons College of Kentucky, Sociology, Fall 2015

Undergraduate course on Race, Ethnicity, and Gender.

Undergraduate course on Sociological Theory.

Graduate Teaching Assistant

University of Louisville Sociology Department, 2012-2013

Served as instructor for recitation sections of Race in the US. Main duties included facilitating discussion, developing active learning activities, and assessing student assignments.

Neighborhood Mentor

New Directions Housing Corp, 2008

Developed daily lesson plans and organized daily activities including meals, games, and educational activities for day campers. 


\section{AWARDS AND HONORS}

Outstanding Research Award, University of Louisville Sociology Department, 2014-2015 Academic Year

Doctoral Scholars Fellowship, Southern Regional Educational Board, 2013-present

Graduate Teaching Assistant Academy, University of Louisville, 2012

Sigma Alpha Lambda National Leadership and Honors Organization, 2009

Phi Sigma Theta National Honor Society, 2009

Delta Epsilon Iota National Honor Society, 2008

William C. Parker Scholarship, Diversity scholarship, Full tuition, 2006-2010

Governor's Scholar Scholarship, Academic scholarship, 2006-2010

Provost's Enhancement Scholarship, Academic scholarship, 2006-2010

\section{GRANTS RECEIVED}

Commission of Diversity and Racial Equity Graduate Student Research Grant, University of Louisville, Summer 2016

Graduate Student Council Research Funding Grant Recipient, University of Louisville, Fall 2015

Graduate Student Council Travel Funding Grant Recipient, University of Louisville, Fall 2014

Graduate Student Council Travel Funding Grant Recipient, University of Louisville, Fall 2013

Graduate Student Union Travel Funding Grant Recipient, University of Louisville, Fall 2013

\section{SERVICE}

Vice President, Minority Association of Graduate Students, 2016-present

Treasurer, Minority Association of Graduate Students, 2014-2016

Graduate Student Ambassador, School of Interdisciplinary and Graduate Studies, 2014-2016

Editorial Assistant, The Griot: The Newsletter of the Association of Black Sociologists, 2014-

present

Sociology Representative, Graduate Student Union, 2012

Member, Sociology Graduate Student Association, 2011-present 